\title{
A Review of the Fund's External Communications Strategy
}




\section{INTERNATIONAL MONETARY FUND}

\section{A Review of the Fund's External Communications Strategy}

Prepared by the External Relations Department

Approved by Thomas C. Dawson

February 13, 2003

Contents

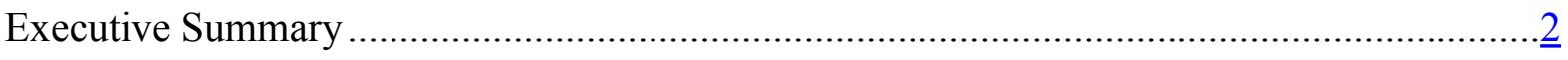

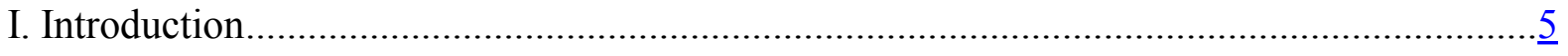

II. A Forward-Looking External Communications Strategy ……..........................................

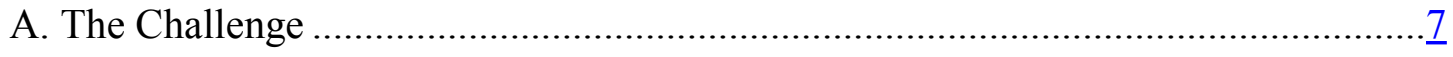

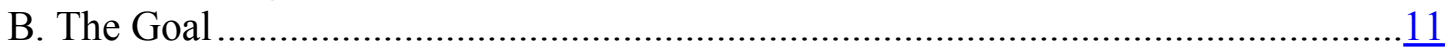

III. Increasing the Effectiveness of the Fund's External Communications Strategy..................12

A. Focusing and Coordinating the Fund's Communications ......................................12

B. Improving the Availability and Accessibility of Fund Information and Messages $\underline{15}$

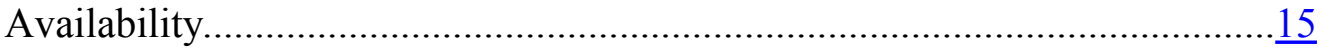

Accessibility—Making Fund Material More Available and User-Friendly ..... 17

C. Engaging Proactively in Outreach and Dialogue ..................................................21

Communicating with Legislatures, the Private Sector,

and Civil Society Organizations ...................................................................

Responding Rapidly to News and Views.....................................................

D. Broadening the Reach of the Fund's Communications............................................29

Expanding material on the Fund's external website and in print.......................

Increasing In-Country and Regional Communications ....................................

Educating the General Public about the Fund.................................................

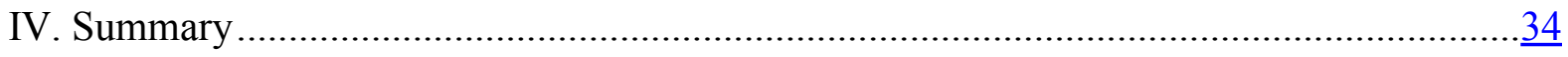

Annexes

I. Report of the Publications Policy Task Force .................................................................

II. Survey of Country Outreach by Area Departments ......................................................

III. The Fund and Civil Society Organizations (CSOs) ………..........................................

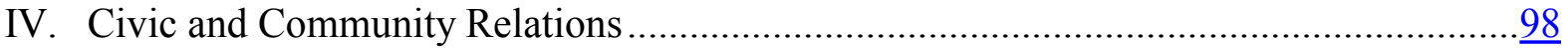

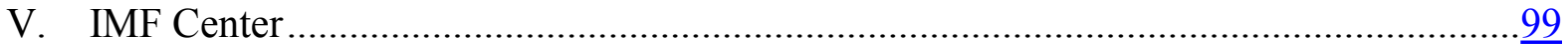

VI. EXR: Authorized Regular Staffing and Outturns ……………………………….... 


\section{EXECUTIVE SUMMARY}

I. Introduction (paragraphs 1-5). This paper reviews implementation of the Fund's external communications strategy and suggests issues that the Board may wish to discuss at its third meeting since 1998 on the subject. The strategy has been shaped by the previous Board discussions and more recent decisions and discussions on transparency, conditionality (national ownership of programs), PRSP/PRGF, the Independent Evaluation Office, and other issues. This paper represents more of a stocktaking than a fundamental reconsideration of the Fund's approach to external communications. It examines the progress made in recent years and steps that might be taken with current resources to increase the effectiveness of the strategy.

\section{Setting Goals for a Forward-Looking External Communications Strategy}

A. The Challenge (paragraphs 6-10) the Fund faces is long-standing and deep-rooted. Although the Fund is now seen as less secretive, its public image continues to be slightly less favorable than the World Bank's, and both trail the United Nations in polls of elites and of the general public. The Fund's media visibility varies but is near peak levels, especially in non-English language media. The Fund should seize this opportunity to build on its greater transparency through a continuous, well-coordinated communications effort aimed at improving understanding of and support for the Fund and its activities.

B. The Goal (paragraph 11) is increasing understanding of and support for the Fund's work, especially in its core functions. Two-way communication with nonofficials is increasingly important, as the Fund continues to engage in self-assessment and reform, and seeks to learn from its interlocutors.

\section{Increasing the Effectiveness of the Fund's External Communications Strategy}

A. Focusing and Coordinating the Fund's Communications (paragraphs 13-19). The Fund should focus upon a few key issues and messages at a time, using internal communications to help staff keep up-to-date on the themes. Training for staff who interact with the media is also important. Op-eds and public speeches should be coordinated through the External Relations Department (EXR) to support the main themes.

\section{B. Improving the Availability and Accessibility of Fund Information and Messages}

1. Availability (paragraphs 20-24). Major advances have been made in publishing policy and country papers and summaries of Board papers under the transparency policy, and also in publishing data on the Fund's finances, its staff's research, and economic statistics. Two areas where more could be done are: (a) coordinating the release of country-related material to the media; and (b) increasing posting by authorities of translations of their policy intention documents on their official websites (to which the Fund could then link).

2. Accessibility-Making Fund Material More Available and User-Friendly (paragraphs 25-32). Clear summaries and supplementary explanatory material should 
be provided for Fund documents and papers destined for publication, and briefings, interviews, and public speeches should be used more systematically to emphasize main messages. Distribution of pamphlets and other explanatory material on key issues, which are already available in several languages, should be increased, especially in developing countries.

\section{Engaging Proactively in Outreach and Dialogue}

\section{Communicating with Legislatures, the Private Sector, and Civil Society} Organizations (paragraphs 33-50). The Fund engages in outreach and dialogue to listen and learn as well as to inform and persuade. The Fund takes into account the views of its critics as well as supporters in revising and improving Fund policies, practices, and advice. Given limited resources, outreach and dialogue with nonofficials must be selective. The Fund has increased contacts with legislators but more sustained and systematic interaction could be beneficial. Fund staff often meet with the private sector at the country level and maintain informal contacts with market participants globally. The Fund's outreach and dialogue with civil society organizations (CSOs) has also increased and is wide-ranging: a current priority is to compile best practices and guidelines for Fund staff outreach to CSOs. Fund missions have fairly frequent and useful contact with national labor unions, and the Fund has a constructive dialogue with the international labor movement. Dialogue with NGOs has been rather frequent at the international level and at Fund headquarters but more could be done on outreach to NGOs in developing countries that play important roles in the PRSP process and in contributing to consensus on economic policies.

2. Responding Rapidly to News and Views (paragraphs 51-52). The Fund now responds quickly and forcefully to unbalanced or inaccurate stories and to its critics through letters to the editor, op-ed articles, media interviews, and public speeches. Sustained effort to correct false or misleading information is often required, as in the case of recent charges against the Fund on Malawi (Box 1).

\section{Broadening the Reach of the Fund's Communications}

1. Expanding Material on the Fund's External Website and in Print (paragraphs 53-57). The Fund's external website is deliberately designed for easy access by users in developing countries and elsewhere who have relatively slow connections. The costs of adding more webcasts, online discussion sessions, and other features need to be weighed against benefits and demand, which has been limited compared with the interest in expanding textual information. Extranets offer opportunities for selective (password-protected) communication, and an extranet for journalists is planned for 2003. The distribution of print publications could be increased, including through expansion of the Fund's depository library program, which aims to include 400 locations by 2005 .

2. Increasing In-Country and Regional Communications (paragraphs 58-61). Area departments and EXR have been collaborating on regional external communications strategies and activities, especially in conjunction with missions, regional offices, and 
resident representatives. During 2003 three regions warrant particular focus within the Fund's external communications strategy: (a) Africa, owing to the large number of PRGF/HIPC countries; (b) Latin America, where special economic challenges face several economies; and (c) the Middle East, with the Annual Meetings in Dubai in September.

3. Educating the General Public About the Fund (paragraphs 62-63). The Fund is responding in cost-effective ways to growing demand from the general public, students, and educators for basic information and material, especially for classroom use. The IMF Center has developed and posted educational material in several languages on its website.

IV. Summary (paragraph 64). The Fund's external communications work has evolved rapidly and made progress in a number of areas, but there is still much room for improvement.

Annex I. Report of the Publications Policy Task Force. The report reviews the Fund's current publications policies and practices and provides comparisons with those of other international organizations, especially with respect to publications in languages other than English. The Fund, like the World Bank but in contrast to many international organizations, does not have a formal mandate to publish in languages other than English. Publishing decisions in most international organizations (and in the Fund), where they have discretion and are not mandated to publish, are made on the basis of judgments by management and staff of perceived utility, demand, and cost factors. Most international organizations have found costs and low demand to be serious barriers to increasing their translations and publications in languages other than their official or working languages. Although there has been some increase in requests by Executive Directors and staff for non-English publications, both sales and requests for complimentary copies of the Fund's existing non-English publications remain very low. Any significant expansion of the translation and publication in non-English languages of material by the Fund, on the website and/or in print, would entail large costs that could only be included within the Fund's administrative budget targets by making corresponding cuts in expenditures in other areas. 


\section{INTRODUCTION}

1. This paper updates information on the Fund's external communications strategy and suggests issues for the Board's third discussion of external relations in five years. ${ }^{1}$ The first Board discussion, in July 1998, called for a more proactive external communications approach to help preserve and enhance the credibility of the Fund. Directors noted that a strengthened communications effort "would entail providing more information to diverse target audiences, extending the reach of our communications, and engaging critics more effectively." Directors also observed that "external relations must be a genuine dialogue, and the Fund should be open to suggestions and criticisms by informed parties outside the Fund, and take into account such feedback in our policy discussions" (Buff 98/65, July 16, 1998; see also: "The Fund's Approach to External Communications-Next Steps," SM/98/153, June 22, 1998).

2. A second Board discussion, in February 2000, considered plans to strengthen the Fund's external communications and the implications for staff resource requirements in the medium-term (see "Strengthening the Fund's External Communications: Plans and Resource Implications" SM/00/14, January 27, 2000, and Buff/00/20, the Acting Chairman's Concluding Remarks on the Executive Board meeting held February 4, 2002). The staff paper prepared for the discussion included summaries of findings and recommendations by outside consultants submitted to EXR during 1999. ${ }^{2}$ The principal report, by Edelman Public Relations, drew upon a global survey conducted by Wirthlin Worldwide and recommended that the Fund develop a communications strategy comprising a clearer message, sharper focus and improved coordination of the Fund's public output, and more proactive external communications, including efforts to draw attention to the successes of the Fund's work and to respond more effectively to critics. The consultants' reports recommended, in particular, that the Fund increase its outreach to and dialogue with national legislatures and influential civil society organizations (CSOs), including the private financial sector, labor unions, nongovernmental organizations (NGOs), and the media.

3. Directors "generally agreed with the consultants' findings that the Fund's external communications problems can be addressed through broader, deeper, and more proactive efforts." They welcomed many of the initiatives proposed in the staff report: "In particular, there was agreement on the immense public communications value of the Fund's external website, and on the need to increase the output of material for the print media and the public explaining and defending the Fund's work, and to sharpen 'the voice of the Fund." Directors "referred to the need for greater outreach to civil society in conjunction with the national authorities concerned, a strengthening of the Fund's publications program,

\footnotetext{
${ }^{1}$ The term "external communications" as used in the Fund does not include the Fund's extensive communications with the authorities and officials of member countries.

2 The main report was "Moving the IMF Forward: A Plan for Improving the Fund's Communications with Critical Audiences Around the Globe" by Edelman Public Relations Worldwide, June 1999. All of the consultants' reports are listed in footnote 2 to SM/00/14.
} 
engagement of member countries' legislatures in coordination with the Executive Board, and improvement of relations with the private financial sector." Directors also "underscored that the Fund's efforts should have as broad-based and wide-ranging an outreach as possible, especially in view of its near universal membership." Directors agreed to an increase in staff positions for EXR in FY 2001 in order to "strengthen Fund communications, and in particular the various measures proposed by EXR."3

4. Other Board discussions and decisions have also significantly affected the direction and scope of the Fund's external communications strategy and related activities.

- Transparency policy. External web posting and print distribution of staff country reports and many other Board documents under the transparency policy decision of January 2001 have greatly increased public information about the Fund and its activities. ${ }^{4}$ They have also naturally gone a long way to repair the Fund's former reputation of being an inordinately secretive organization. While the transparency policy has made a crucial contribution to improving the Fund's external communications, it has also increased work in many Fund departments, not only to implement the transparency policy itself but also to explain Fund decisions and policies and respond to related inquiries from the press and public. The material being released under the transparency policy has become so voluminous that the Fund's core messages may not be conveyed clearly unless they are deliberately highlighted, and unless the material is effectively summarized and explained.

- Poverty Reduction Strategy Papers (PRSPs)/Poverty Reduction and Growth Facility (PRGF). In the latest PRSP review, Directors noted that the PRSP participatory process, which is designed and implemented country-by-country by the authorities concerned, needs to be strengthened by encouraging and broadening the systematic participation of stakeholders and partners in developing and monitoring PRSPs: specifically_-besides government leaders and officials - parliaments, the business community, trade unions, and groups representing the poor. ${ }^{5}$ Directors observed that there is also scope for more openness and transparency in decisionmaking and in the dialogue among government, stakeholders, and their partners. The policy of encouraging and facilitating wide consultation in PRGF countries as part of the PRSP process, together with the Fund's increased emphasis on national ownership of Fund-supported programs, has stimulated requests for in-

\footnotetext{
${ }^{3}$ See Annex VI for EXR staffing levels over the past decade.

4 "The Fund's Transparency Policy_Review of the Experience and Next Steps," May 24, 2002, at http://www.imf.org/external/np/pdr/trans/2002/eng/052402.htm, and Public Information Notice (PIN) No. 02/111, September 27, 2002, at http://www.imf.org/external/np/sec/pn/2002/pn02111.htm.
}

${ }^{5}$ See IMF Annual Report 2002, pp. 47-49, and "Poverty Reduction Strategy PapersProgress in Implementation" (SM/02/250 Revision 1, 9/11/02). 
country briefings by Fund staff and for translation and publication of Fund materials in local languages and in formats accessible to a wide range of users. ${ }^{6}$

- Other recent decisions and discussions that have involved and affected the Fund's external communications include: (1) the review of Fund conditionality and adoption of new conditionality guidelines, which involved numerous outreach efforts and external consultations; (2) the establishment and operations of the Independent Evaluation Office (IEO); (3) the Fund's work on standards and codes, especially the effort to disseminate related material widely throughout the Fund's membership; (4) the 2002 biennial review of surveillance; and (5) the ongoing work on reform of the international financial system, notably the wide-ranging dialogue on a Sovereign Debt Restructuring Mechanism (SDRM) and on collective action clauses (CACs).

5. This paper represents a stocktaking rather than a fundamental reconsideration of the Fund's approach to external communications. It examines the progress made in recent years and steps that might be taken, essentially with current resources, to increase the effectiveness of the strategy.

\section{A ForWARD-Looking EXTERnal COMMUnications STRATEgy}

\section{A. The Challenge}

\section{The Fund continues to face a long-standing external communications challenge} despite the increase in the Fund's openness in recent years and its greater responsiveness to concerns and criticism. Perhaps less because of the wide dissemination of the views of critics than because of the particular mandate of the IMF to safeguard the macroeconomic and monetary foundations of economic growth - which may appear to many to have less beneficial impact than the work of some other international organizations - the Fund's public image appears to remain similar to what it was in 1998 relative to those of the World Bank, United Nations (UN), and Red Cross/Crescent. A recent survey indicates that the Fund's image with the general public remains slightly less favorable than the World Bank's, and both institutions received significantly less favorable ratings than did the UN, which is consistent with earlier surveys.

- 1998 - a survey of 500 opinion leaders commissioned by the Fund in 1998 found higher levels of "confidence" in the World Bank than in the Fund and that the "job favorability" of the UN and World Bank were both higher than that of the Fund (4.4 versus 4.1 on a 7-point scale). The Red Cross/Crescent came out ahead in the poll of "job favorability" by a wide margin.

- 2000 - an Ipsos-Reid poll of 20,000 people in 39 countries rated the UN higher than the World Bank, the Fund, World Trade Organization (WTO), and multinational companies in terms of respondents" "confidence" that the institution could help to

\footnotetext{
${ }^{6}$ Questions regarding language versions of Fund publications are addressed in the attached report of the Publications Policy Task Force (Annex I)
} 
ameliorate economic problems - the UN held the confidence of 45 percent of respondents; the World Bank and the Fund trailed considerably, at 35 and 32 percent respectively.

- 2002 - a Gallup International/Environics International poll of 36,000 people for the World Economic Forum found that respondents to a question about "trust in institutions to operate in society's best interests" rated the UN higher than either the World Bank or the Fund. The Bank and Fund each had 41 percent of respondents expressing "little or no trust" although 43 percent expressed "a lot or some trust" in the Bank versus 39 percent for the Fund. The UN received 34 percent negative and 55 percent positive on the same question.

7. The Fund's visibility in the media has been highly variable, depending partly on global economic circumstances, although in recent months - late 2002 - the Fund appears to have received as much media attention as at the height of the Asian crisis, following a dip in media attention in 2000-01 (See Figure 1). There are important national and regional differences, however. Coverage of the Fund in U.S. and other English-language publications has remained well below the peaks of 1997-99, which means that the recent rise in coverage has been almost entirely in non-U.S. publications and in languages other than English. During periods of low media interest in the Fund, as in the U.S. media recently, the need for defensive communication may be less but the challenge of communicating positively about the Fund's work remains. Indeed it may become greater as high visibility generally makes it easier for the Fund to deliver its messages and deepen its external communications work. The current period may offer an opportunity to intensify implementation of the Fund's external communications strategy, especially through non-English media in developing countries. 
Figure 1. References to the IMF in the Press (Publications), 1992-2002

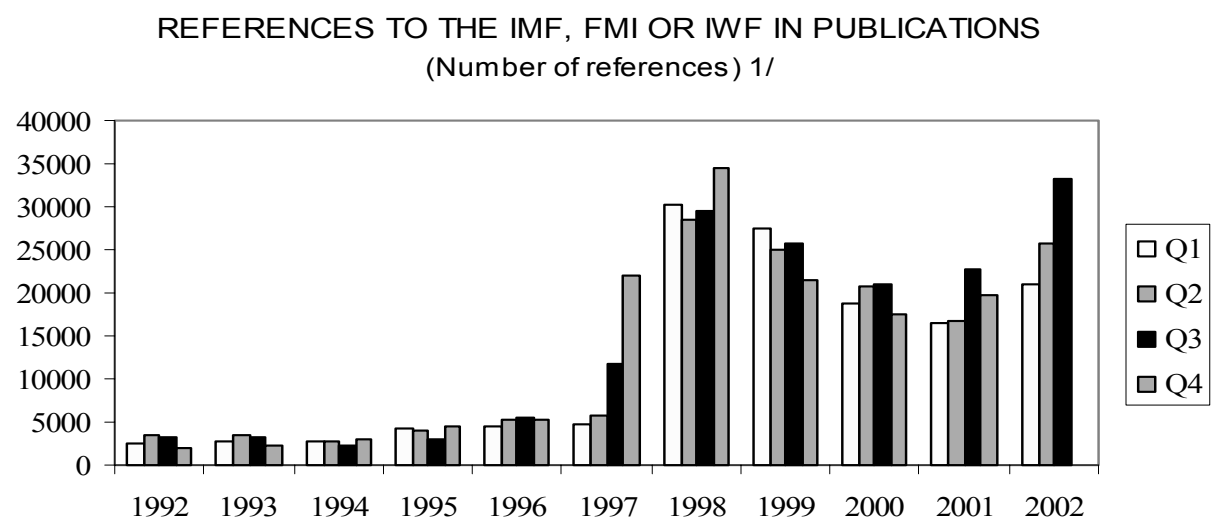

REFERENCES TO THE IMF IN U.S. PUBLICATIONS

(Number of references) 1/ $2 /$

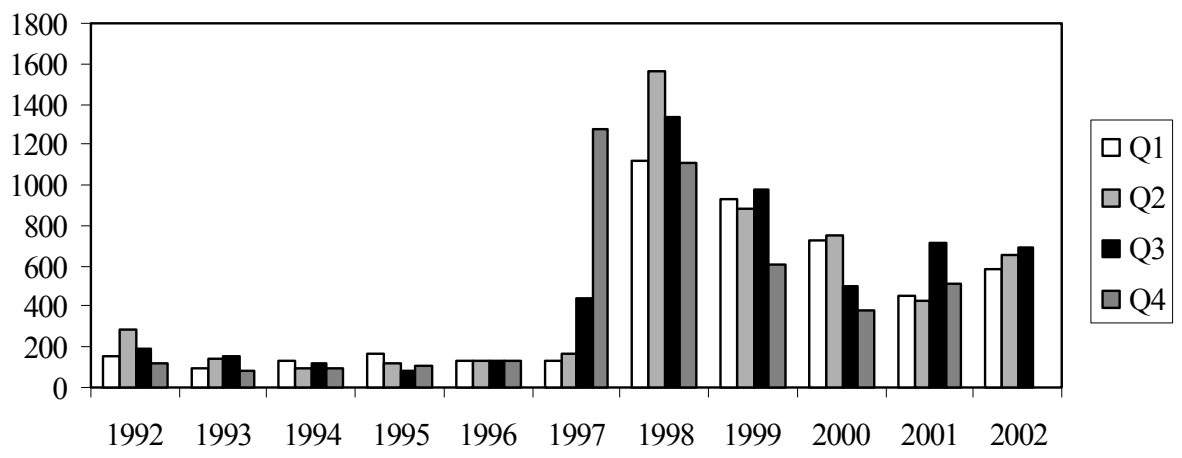

REFERENCES TO THE IMF IN ENGLISH LANGUAGE PUBLICATIONS

(Number of references) $1 / 3 /$

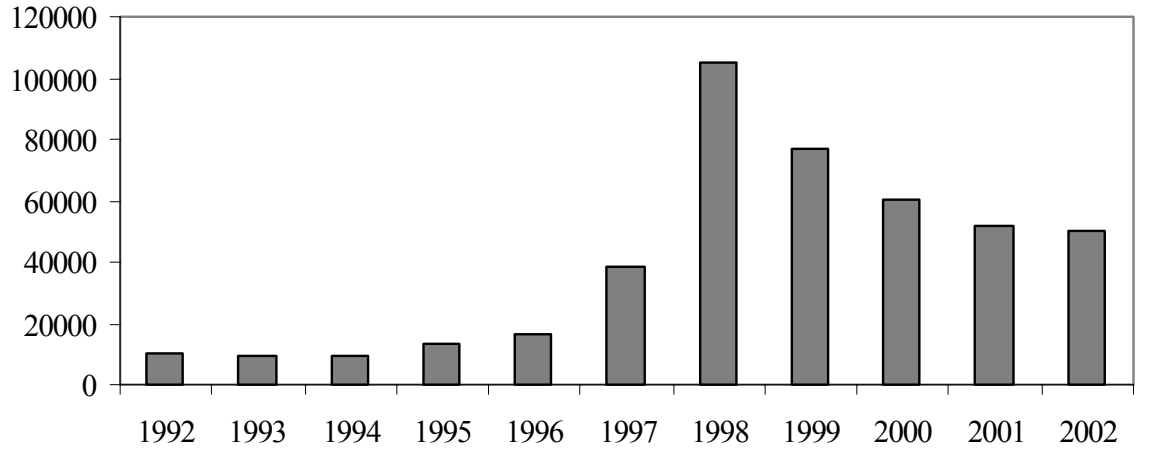

Source: Factiva.com database.

1/Excludes republished news, market data, and calendars.

2/ Search conducted in AP, The Washington Post, The Wall Street Journal, and The New York Times. The New York Times was available in the database since 1996.

3/ The Financial Times and The New York Times were available in the database since 1995 and 1996 respectively. 
8. The Fund's transparency policy has largely overcome past perceptions that the Fund was "secretive" about its surveillance and policy advice, including in the context of Fund-supported programs. The Fund is now much less often referred to in the media as secretive than it was just a few years ago (See Figure 2). The transparency policy, together with other elements of increased openness, has also benefited the Fund by making it more receptive and accountable to outside views and analysis. Although further advances in Fund openness may well occur-for example, given the potential for increases in the number of countries agreeing to the release of their respective staff reports - there are limits to how fully the Fund can satisfy calls for additional transparency. Some information must be kept confidential for a period because it is market-sensitive or to allow the authorities time to prepare appropriate responses. Moreover, greater transparency should not come at the expense of candor in the Fund's dialogue with members.

Figure 2. References to the IMF and the Word "Secretive" in English-Language Publications

1992-2002

(proximity of five words)

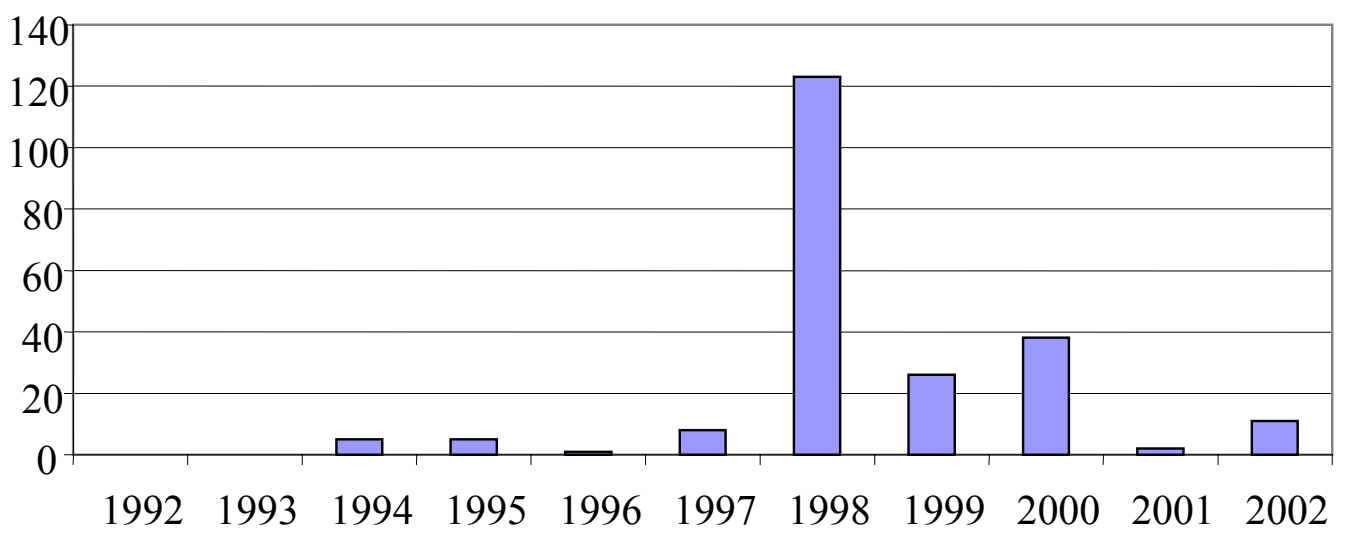

Source: Factiva database

9. Building on transparency to achieve effective-well understood and persuasive-communication is a major part of the current challenge for the Fund. The large volume and technical complexity of the material now made publicly available under the transparency policy risks obscuring key messages. Transparency increases the importance to the Fund of implementing a communications strategy that ensures that the material the Fund publishes presents, among other things, prominent, clear, coherent, and persuasive messages that promote understanding of, and support for, the Fund, its work, and its policies.

10. Finally, while the Fund's public image is important because it affects how receptive people are to the Fund's messages and information, and because the credibility of the Fund's policies helps to determine their success, expectations should be realistic regarding the extent to which the Fund's image can be improved relative to other international organizations. As Directors have often pointed out, much of the 
Fund's work is inherently controversial, not least because of the conditional nature of its financial support to countries with balance of payments problems and, in most cases, deteriorating economic and social conditions. Indeed, the Fund tends to be most visible during the negotiation of programs, which often occur in difficult circumstances. Countries must adopt credible economic policies aimed at the achievement of external viability as a condition for borrowing from the Fund, and those policies are sometimes perceived as an arbitrary imposition rather than a necessary adjustment made easier by the Fund's support. And there continue to be cases in which governments unwilling to take responsibility for pursuing the necessary policies use the Fund as a scapegoat. Directors at the Board's meeting in 2000 on external communications "recognized that the Fund's mandate inevitably places limits on its popularity." The fact that the Fund's external communications challenge is deep-rooted in this way implies (1) that only a continuous, concentrated effort to improve understanding of and support for the Fund can succeed; (2) that improving understanding of the Fund's work, respect for its competence, and the credibility of its policies may be more realistic and important objectives than increasing the Fund's popularity; and (3) that success may well be incremental and modest, especially relative to international organizations providing humanitarian aid and financial assistance with little or no conditionality.

\section{B. The Goal}

11. As a center of competence for the stability of the international financial system, the Fund has an obligation to disseminate its data, research, and analysis. But the goal of the Fund's external communications strategy is, of course, broader: it is to increase understanding of and support for the Fund's work in each of its core functions: (1) conducting surveillance of member countries' economic policies at the country, regional, and global levels, as well as of the international monetary system; (2) providing financial resources to support members' efforts to resolve balance of payments problems through adjustment and reform; (3) delivering capacity-building services (training and technical assistance) to member countries; (4) setting standards and providing standardized information; and (5) research and policy development. To be effective the Fund's external communications must: (1) go beyond transparency to establish effective two-way communication with its interlocutors; (2) adjust its outreach to the peaks and valleys of public attention; and (3) use the limited resources it can afford for external communications efficiently in order to increase awareness and understanding throughout the membership of the Fund's mission, functions, policies, and performance. Two-way communication is especially important as the Fund continues to engage in self-assessment and reform; the Fund in recent years has been giving more attention to listening and learning by eliciting, considering, and responding to public comments and views on its policies and practices. This paper summarizes the Fund's current external communications activities and output and suggests for discussion steps that might be taken by Fund management, Executive Directors, Governors, the External Relations Department (EXR), and other Fund staff to raise further the effectiveness of the external communications strategy. This paper assumes that nearly all the steps mentioned can be accomplished through departments and offices reprioritizing their activities within existing staffing levels and budgets. If there are any steps that cannot be accommodated in this way, 
departments and offices would need to raise them for consideration in the administrative budget process.

\section{InCREASING THE EFFECTIVENESS OF THE FUND's EXTERNAL COMMUNICATIONS STRATEGY}

12. Many of the ingredients of a more effective external communications strategy directed toward the above goal were already identified in earlier Board discussions as the need to (1) coordinate more effectively the Fund's external communications and focus on a few main messages; (2) improve message delivery through the prompt dissemination of information while remaining consistent with the Fund's mandate, and explain more clearly and simply what the Fund is doing and why; (3) engage proactively in dialogue with legislatures, the private financial sector, CSOs, and prominent critics; and (4) broaden the reach of the Fund's communications to better encompass, directly or indirectly, in costeffective ways, not only key organizations and groups but the general public in all member countries. This section considers these ingredients in turn.

\section{A. Focusing and Coordinating the Fund's Communications}

\section{One of the central recommendations of the 1999 Edelman report was that the} Fund needed sharper focus and better coordination of its messages to achieve more positive results in the media and with other groups. The consultants recommended that the Fund's external communications be more carefully planned and coordinated with priority to developing and delivering the right messages at the right time, in the right way, and to targeted audiences.

\section{The first requirement is to select, and maintain focus on, one or a few key} messages at a time instead of trying to address too many issues at the same time. The process of deciding on the near-term focus of the external communications strategy includes periodic discussions with management by the Director of the External Relations Department and other department heads, drawing upon the guidance provided by Governors through the International Monetary and Financial Committee (IMFC) and the priorities agreed by the Executive Board in the context of the work program. It is a task of Management to take the lead in highlighting the chosen messages through coordinated preparation and delivery of public speeches and media interviews, but Executive Directors might also do more in this regard, especially on points that they have supported strongly within the Board or that have been agreed at IMFC meetings. EXR's role has been to advise management on appropriate messages and communications opportunities and to assist in planning and drafting management speeches and talking points. EXR is also charged by management to (1) ensure that the staff at large knows what the central messages and focus currently are; (2) provide staff with advice, training, and supportive material, which may include draft speeches, op-ed articles, Issues Briefs, pamphlets, and other items; and (3) arrange suitable opportunities for message delivery by senior staff as well as management, and in some cases by Executive Directors. 
15. Effective internal communication about the Fund's key policy issues and messages is needed to foster effective external communication. ${ }^{7}$ In addition to drafting material for publication or public use, EXR is responsible for reviewing draft speeches and articles prepared by staff in other departments, and often makes suggestions for modifications to put forward the Fund's main messages more effectively. A more proactive approach, however, has been developed in recent years to convey continuously to staff the information they need in order to speak and write effectively about the Fund's main themes. This is done by posting items on the Fund's Intranet where staff, including staff overseas who give public presentations or speak with journalists, can readily turn when they need such information. (The Intranet is also accessible by Executive Directors and their offices.) EXR began posting in June 2001 Current Account, an electronic newsletter for staff covering key Fund policy developments; this now usually appears on a weekly basis. One of Current Account's purposes is to help staff prepare to be ambassadors for the Fund, and to this end EXR hopes in 2003 to increase the newsletter's coverage of Fund events and management activities. Also relevant for Fund staff who have contact with journalists is Headline Issues, which, also via the Intranet, presents questions about IMF policies and country operations raised by journalists and others, together with edited excerpts of the public responses and statements of IMF officials. The Intranet also carries the most recent media "briefing books" prepared for the Managing Director as well as background material used for other public appearances. For more general presentations, EXR can provide generic texts and slide presentations for staff, although they will generally need to be tailored for presentations to particular audiences.

16. Management, staff, and Executive Directors need to be well prepared for media interviews and press conferences. EXR staff is available to advise staff and Executive Directors on their interactions with the media; and there is a set of "Media Guidelines" prepared for staff that includes a special section for resident representatives. EXR has also worked with other departments and external consultants to develop a training course for staff on how to communicate effectively with journalists. This training, which has been positively received, is now mandatory for new mission chiefs and resident representatives. (According to a recent survey, a majority of resident representatives and mission chiefs have been quoted in the press in the past year: see Annex II). Executive Directors, and their alternates and advisors, might consider taking the course, or a version thereof.

17. “Op-eds" (articles that appears opposite a newspaper's editorials) form a key vehicle for proactive and focused message delivery and for the explanation of Fund policies, to wide audiences, and have been used with increasing frequency. EXR proposes, drafts or edits, and helps to place op-eds on core Fund issues as well as more

\footnotetext{
${ }^{7}$ As reported in the Board paper in 2000, "Edelman/Wirthlin emphasized that strengthening external communication would require a Fund-wide effort and improvements in internal communications, especially EXR's communications with other departments, but also its communications with resident representatives and regional offices."(p. 5 of SM/00/14).
} 
specialized topics. Op-eds signed by management, staff, and, on a few occasions, Executive Directors have appeared in newspapers worldwide in many languages (See Table 1). Op-eds are most frequently published around the Spring and Annual Meetings, but experience shows that there is considerable interest year-round in Fund-authored articles in newspapers and other periodicals, as long as they are clearly and engagingly written and focus on topics of interest to the relevant readership.

Table 1. Published Op-Eds and Letters to Editor, 2001-2002

\begin{tabular}{lcc}
\hline & 2001 & 2002 \\
\hline Op-Eds ${ }^{1 /}$ & 26 & 34 \\
Letters to the Editor & 34 & 45 \\
Total & 60 & 79 \\
\hline
\end{tabular}

Source: Estimates generated by or in consultation with EXR's Policy Communication Division. Resident Representatives and other staff have placed additional material directly with press in their country of assignment, though inconsistent reporting practices prevent a full tabulation.

${ }^{1 /}$ Because the practices of major newspaper syndicates do not permit the systematic tracking of secondary publication of op-eds and letters, these estimates are probably on the low side.

18. Looking forward, the challenge will be to identify and take advantage of more opportunities for publication of op-eds, which will require more authorship from area and functional departments, in particular, as well as management. Particular attention might be paid to the considerable untapped potential for communicating policy messages related to Fund advice and operations in individual countries. More mission chiefs and resident representatives might actively seek opportunities to place op-eds at important junctures - for instance, after the conclusion of an Article IV consultation or approval of a Fund arrangement. A number of country teams have already been quite successful in this regardfor example in Bulgaria and Korea, where Fund staff in collaboration with EXR have frequently contributed pieces to the media, which have responded in turn by inviting additional submissions. Fund staff has also contributed regularly to the media in Japan via press seminars, interviews, and articles. Executive Directors could also author more op-eds, especially to explain the Fund's role and policies in countries within their constituencies.

\section{Matching Fund speakers with appropriate speaking opportunities also}

contributes to well-coordinated external communications. The demand for the Managing Director and other senior officials to speak at unofficial events far exceeds their availability (38 speeches by Management were published in 2002). EXR provides advice on speaking invitations and matches opportunities with suitable speakers from the senior staff and, when appropriate, Executive Directors' offices. EXR, in cooperation with other departments, maintains a list of public speakers on the senior staff of the Fund (a "Speakers' Bureau") who can address specialized or general topics when needed. EXR organized 123 briefings in 2002 for audiences totaling more than 4,000 people. About one-half of these briefings were done by staff from other departments. Additionally, EXR reviewed 140 drafts of presentations for delivery outside the Fund by non-EXR staff. 


\section{B. Improving the Availability and Accessibility of Fund Information and Messages}

\section{Availability}

20. The Fund's transparency policy has led to the release of a vastly increased volume of policy and country papers and summaries of Board discussions, with the Fund's external website (www.imf.org) being the primary vehicle for dissemination. (This is apart from historical material provided by the Archives and Records Section of the Technology and General Services Department (TGS).) As reported to the Board and the IMFC in September 2002, over 60 percent of staff reports for Article IV consultations and over half of stand-alone reports on the use of Fund resources have recently been published. ${ }^{8}$ Nearly three-fourths of all completed Reports on the Observance of Standards and Codes (ROSCs) modules have been published. Nearly all members have been giving consent to the publication of their policy intentions documents (letters of intent and memoranda of economic policies) when requesting Fund financial assistance, and Public Information Notices (PINs) have recently been published following over 80 percent of Article IV Board discussions. Most papers on general policy issues discussed by the Executive Board are published, and the Board recently adopted the principle of "presumed publication" of policy papers and the associated PINs. All Board documents authorized to be released are posted on the Fund's external website, and print copies of country papers can also be ordered from EXR's Publication Services Section for a nominal charge (intended to cover printing and shipping costs). Most other Board documents become accessible under the Fund's archives policy after five, ten, or twenty years, depending upon the type and classification of the document.

21. Comprehensive information on the Fund's finances is now published on the external website. The "IMF Finances" section includes extensive data on members' financial positions with the Fund, quarterly Fund financial statements, monthly data on financial resources and liquidity, and weekly data on financial transactions, all of which are kept up to date by the Treasurer's Department. In addition, the public can access important policy papers on financial matters, such as the quota reviews and safeguards assessments, as well as background papers on the Fund's financial structure and operations, written in accessible language. Outside observers have acknowledged that the IMF is now the leader among international institutions in financial transparency.

22. Fund research is being published in growing quantities not only by the Fund itself, but also by academic journals and commercial publishers. ${ }^{9}$ The World Economic Outlook (WEO), the Global Financial Stability Report (GFSR), and IMF Staff Papers $(I M F S P)$ are among the main Fund publications based on staff research. The Working Paper

${ }^{8} \mathrm{SM} / 02 / 302,9 / 23 / 02$.

${ }^{9}$ See "Research at the IMF" at http://www.imf.org/research and the annual reports of the Working Group on Fund Research. 
series (WPs) provides a ready outlet for quick dissemination of the latest staff research via the external website and in print (copies may be ordered for a charge intended to cover average printing and postage costs). Policy Discussion Papers (PDPs), reviewed by the Fund's Working Group on Research, do the same for short papers on policy issues. ${ }^{10}$ The quarterly IMF Research Bulletin, authored in the Research Department (RES) and made available in print and on the external website, highlights selected Fund analytical output. Finance \& Development and the IMF Survey (both available on www.imf.org) showcase Fund research, and the Economic Counsellor and Director of the Research Department now contributes a column ("Straight Talk") to Finance \& Development. Manuscripts addressing particular topics may be published by the Fund as books or in the Occasional Papers series.

23. Publication by the Fund of statistical data in various formats, and providing links to data posted by authorities on their websites, is another important dimension of transparency. The Dissemination Standards Bulletin Board maintained by the Statistics Department (STA) is key to the sharing of statistical standards and data globally. ${ }^{11}$ The Fund's main statistical data series (Balance of Payments Statistics (BOPS), Direction of Trade Statistics (DOTS), Government Finance Statistics (GFS), and International Financial Statistics (IFS)), currently available by subscription in print versions and on CD-ROM, will also be made available on the Internet, as information technology (IT) projects are completed that are either already underway or planned in the Fund's IT budget. $^{12}$ International Financial Statistics (IFS) has recently been made available online for subscription at www.imfstatistics.org with a differentiated price structure designed to facilitate access by users in developing countries and academic institutions while, at the high end, market-based rates are charged to commercial users in industrial countries. (The practice of charging fees for access to major online databases is followed by most international organizations, including the World Bank, UN, and the Organization for Economic Cooperation and Development (OECD).

${ }^{10}$ Work is also underway to prepare WPs and PDPs as non-scanned PDF (portable document format) files for web posting instead of the current practice of scanning hard copies to create PDFs. This will result in much smaller, more legible files which will facilitate downloading, printing, and searching by users, especially those who have to rely on low bandwidth and less advanced computers and printers.

${ }^{11}$ A new annual Coordinated Portfolio Investment Survey (CPIS) database, which will produce estimates of cross-border holdings of portfolio investment assets and contribute to better data on international capital flows, is forthcoming.

${ }^{12}$ Survey results indicate that print versions of Fund statistical publications continue to be valued highly by many users, especially in developing countries where access to computers and the Internet is limited, costly, or less reliable. STA, TGS, and EXR have collaborated to develop technical solutions to reduce the production cost and improve the readability of the print version of IFS. The new system will go into full operation early in 2003. 
24. The Fund's increased transparency has been widely appreciated by the public, winning praise even from frequent critics. More could be done to increase the reach of the Fund's current transparency, however. ${ }^{13}$ Two areas in which some Executive Directors have contributed are (1) arranging activities in their countries coordinated with the Fund's release of country-related material so as to encourage greater media attention; and (2) encouraging their authorities to post on their official websites policy intention documents related to Fund-supported programs in domestic non-English languages, to which the Fund's external website can provide links. More could be done in both cases. Coordinating and supporting the release of country material to promote media coverage requires early discussion in each case between EXR and the office of the Executive Director concerned. The Media Relations Division could provide journalists with advance access to the material under embargo for a short period; indeed, EXR is planning to establish an "extranet" for journalists that would facilitate such embargoed releases. The Executive Director or national authorities could arrange a media statement, interview, or press conference in conjunction with the release of the material by the Fund. The opportunity to facilitate public access to local language versions by establishing links from www.imf.org to non-English country policy intention documents on authorities' websites was announced by the Director of EXR in a memorandum to Executive Directors on March 19, 2002. Each link will include a standard disclaimer to indicate that the Fund has not verified the accuracy of the non-English language texts. ${ }^{14}$

\section{Accessibility-Making Fund Material More Available and User-Friendly}

25. Merely releasing documents and data will not necessarily help to improve the public's understanding of the Fund's work, which is the key to the communications strategy. Most of the Fund's output is prepared for the officials of member countries or for internal deliberation, often in specialist language, and the scale of the output adds to the difficulty that outsiders can face in trying to absorb it or draw the essence from it. Much of it needs to be summarized and explained for outside audiences. As the Fund's transparency policy has prompted the release of more documents and data, this need for explanation has become larger and more urgent. Even journalists who specialize in monitoring the Fund say that the Fund's policy advice and program conditions are often difficult to understand and, consequently, not reported as accurately or as widely as they might be. Users of Fund documents on the external website often ask the Fund to provide

\footnotetext{
${ }^{13}$ One possibility proposed by some, which is not considered here in depth because of its budgetary implications, would be the provision, free of charge, of more publications, particularly on the website. This would have an uncertain, but possibly significant negative, impact on publications revenue, and hence on the publications budget and administrative budget.

${ }^{14}$ A disclaimer is required because providing or verifying translations of large numbers of documents would be quite costly for the Fund. Language translation and publication issues are discussed in the report of the Publications Policy Task Force, attached as Annex I.
} 
explanatory material in more accessible language, using less jargon, and giving background and context. Users of statistical data are requesting more "help desk" support than in the past, especially when using CD-ROMs and on-line versions.

26. The problem with documents could be addressed by employing more writers and editors to 'translate' official papers into publications in accessible language. But it is less costly and more practical to address the problem largely at the source, by recognizing that many documents are not as well-organized or well-written as they should be. EXR and other departments (principally the Human Resources Department (HRD) and the Secretary's Department (SEC)) have been working with the main authoring departments to help staff write more clearly and develop self-editing skills. Staff have appreciated "The Guide to Clear Writing" produced by EXR and distributed Fund-wide in hard copy and placed on the Intranet. EXR and other departments are also considering adoption of a software package that will help Fund authors review and edit their own work and avoid some of the more common pitfalls in writing. The Fund's online Redbook, spell check, and grammar check, as well as formal training offered through HRD in writing and editing skills, are all also intended to help to improve writing in the Fund.

27. Editing documents before presentation to the Board is a critical second step in rendering them suitable for later public distribution. Authoring departments are responsible for editing papers to be submitted to the Board. EXR does not have sufficient staff resources to edit such papers during the interdepartmental review process, with a few notable exceptions. The WEO and the GFSR, for example, are edited prior to the Board discussions in order for them to be printed and placed on the external website promptly afterward.

28. EXR has begun to work more closely with authoring departments to strengthen intradepartmental editing of material destined for publication. EXR and STA have collaborated on a common format and editing guidelines for STA manuals and guides. EXR and RES have together revised the guidelines for authors of IMFSP articles and streamlined the editing and production process. EXR and other departments have also made use of the Temporary Assignment Program (TAPs) to strengthen departmental editing.

29. The third stage_preparing clear summaries and other supplementary explanatory material for released documents - is also challenging, especially where Board decisions are concerned. Many decisions, Summings Up, and consequently sections of PINs, are complex, and written in legal language, with intricacies that can be difficult to explain to outside audiences seeking to understand what the Board is saying. Legal and technical expressions should be reduced to a minimum in statements intended for publication, and consideration might be given to the routine "translation" of legal language in decisions, etc., into language that could be more readily understood, without having to read between the lines. A degree or two of precision might be sacrificed in the interest of clarity, brevity, and the more effective delivery of messages to the press and general audiences. Fund management, staff, and Executive Directors should all be diligent in 
working to clarify and simplify documents - here executive summaries tailored more for public audiences would be helpful-Summings Up, and PINs. ${ }^{15}$ EXR will continue its efforts to make language clearer in the Fund's press releases. (To eliminate confusion among journalists and the public arising from the variety of types of news releases published by the Fund, EXR at the beginning of 2003 discontinued the "News Briefs" series and special news releases, and consolidated all media releases into a single series, "Press Releases," a name previously reserved for releases referring to Board decisions.)

30. The fourth stage_presenting and explaining Board actions and policy deliberations to the public through the media and the Fund's external websiteinvolves Fund management, and senior staff in EXR and other departments, as well as Executive Directors and, in some cases, Fund Governors. ${ }^{16}$ The Managing Director speaks for the Fund in his dual capacity as Chairman of the Executive Board and head of Fund staff but the time he can devote to speaking to the press and public is limited. The Deputy Managing Directors also use public speeches, press briefings, and interviews, plus occasional op-ed articles, to help deliver the Fund's messages. The Director of EXR, as the chief media spokesperson, holds regular, usually biweekly, press briefings to help guide media coverage and interpretation of Fund actions and policies. The Director of EXR and other senior Fund staff, including those stationed in regional offices, also provide ad hoc media briefings and interviews, in line with a media strategy approved by management, when direct comment by management is not considered appropriate or necessary. Staff brief media at the conclusion of some Article IV consultations or missions, and this practice could be expanded. Executive Directors have also participated in press briefings and interviews, and authored op-ed articles and letters to the editor on various issues. There is scope for Executive Directors to take a more active role in explaining the work of the Board, and EXR is prepared to help them do so.

\section{The fifth stage is preparing and disseminating information that explains and} defends persuasively the work done by the Fund. EXR and other departments have increased their output of information products providing user-friendly explanations, but more is needed. The increased emphasis on such products responds, in part, to Directors' comments supporting a recommendation in the Edelman report that the Fund shift its publishing efforts somewhat toward educational material from technical publications. EXR and other departments have prepared a large quantity of expository material in recent years

\footnotetext{
${ }^{15}$ The Fund is far from alone among institutions struggling to make writing clearer. Many national governments have "plain language" guidelines offering strikingly similar advicewrite shorter sentences, avoid embedded subordinate clauses, avoid the "noun disease" (nominalization), passive voice, and obscure terms. In 1998 the European Commission started a "Fight the FOG" campaign to stem "Eurojargon, Euro-waffle, and plain bad English" in EU documents.

${ }^{16}$ A salient example is the press conferences held by the IMFC Chairman following IMFC meetings.
} 
for the print and electronic publications program, the video program, and as handouts for seminars and briefings including:

- Pamphlets, such as "Fiscal Dimensions of Sustainable Development" prepared by the Fiscal Affairs Department (FAD) for the Johannesburg Summit, "A New Approach to Sovereign Debt Restructuring" by Ms. Krueger, and "Governance of the IMF" by the Fund's former Secretary (a pamphlet on Fund conditionality, prepared by the Policy Development and Review Department (PDR) is in process);

- the Economic Issues series - summaries of WPs and other Fund research on topical issues:

- Issues Briefs - short discussions of key policy issues of interest for the Fund and its critics;

- Factsheets - one-or two-page summaries of specific Fund policies and activities on which EXR receives frequent inquiries.

- Videos on selected Fund issues have been prepared and distributed through educational and commercial television networks in a host of countries and through sales to educational institutions.

- $\quad$ The IMF Survey and Finance \& Development make a special effort to include articles and interviews that discuss key economic issues in layman's language. Finance \& Development introduced a new feature ("Picture This") in 2002 that summarizes a key development message through charts and an artistic layout.

- The IMF Center has developed and distributed on the Fund's external website and in hard copy basic educational modules about the Fund in several languages. The material is designed for use in primary and secondary schools.

32. Accessibility also depends on effective distribution of communications products. Unfortunately, distribution not only through the Internet, but also of the print versions of explanatory material, including non-English versions, has been limited, especially in developing countries. Fund resident representatives, regional offices, and Executive Directors could assist EXR by identifying ways and opportunities to distribute such material. Resident representatives should also consider having short explanatory material prepared in local languages (languages that are not among those for which the Fund normally provides translations) and printed locally in low-cost formats in order to deliver information more widely and efficiently to priority audiences in their countries. ${ }^{17}$ To

${ }^{17}$ Resident representatives and area departments would need to consider case by case whether such efforts deserve priority and could be accomodated through reallocation within existing budget ceilings. Material in non-English languages that has not been translated or 
increase electronic distribution, resident representatives who have not so far used the Fund's external website to distribute information are being encouraged to take up EXR's offer to help create Resident Representative website segments on the Fund's external website.

\section{Engaging Proactively in Outreach and Dialogue}

\section{Communicating with Legislatures, the Private Sector, and Civil Society Organizations}

33. The purposes of the Fund's engagement in outreach and dialogue beyond official circles include listening and learning as well as informing and persuading interlocutors on Fund-related matters. Inviting comments from the public on Fund policy proposals via the external website and in specially-convened meetings and conferences has become routine - some major recent examples include the PRSP and PRGF reviews, the development of the HIPC (debt reduction) policy, the review of Fund conditionality, the establishment and work program of the IEO, and the proposal for an SDRM. The Fund now, more actively than in the past, seeks to take into account the views of its critics as well as supporters in revising and improving Fund policies, practices and advice, especially in low-income countries through the PRSP process. ${ }^{18}$

34. Given its limited resources, the Fund, like other international organizations, has to be selective in expanding its outreach and dialogue with nonofficials, and may also need to strike a balance between outreach and improving its communications with the authorities of member countries. The Executive Board's discussion of external communications in 1998 and 2000 indicated that Directors generally agreed that the Fund's strengthened external communications effort should include more proactive engagement with national legislatures and important groups and organizations in the private sector and civil society. At the same time, however, Directors recognized the impossibility of the Fund's carrying out face-to-face or even indirect communications and dialogue with more than a small fraction of groups and prominent persons who might welcome such interaction. Accordingly, Directors advised the Fund's management and staff to be proactive but selective in initiating dialogue as well as in responding publicly to its critics. In fact, in some cases, enhancing the dialogue with governments beyond the Fund's main counterparts (ministries of finance and central banks) to ministries responsible for social and sectoral policies and the judicial system, for example, may have higher

reviewed by TGS Language Services (TGSLS) will need to include a disclaimer to indicate that the Fund has not verified the accuracy of the non-English language.

${ }^{18}$ On outreach in conjunction with the PRSP, and regional PRSP learning events in particular, see Annex 2 of Poverty Reduction Strategy Papers-Progress in Implementation (SM/02/250 Revision 1, 9/11/02). A recent academic study that attempts to identify how the Fund's policies have been changed through such interaction is Jan Aart Scholte's monograph entitled "Civil Society Voices and the International Monetary Fund," published by The North-South Institute, Ottawa, Canada, in May 2002. 
priority than increasing the Fund's interaction with the private sector and civil society. Moreover, the Fund might encourage some authorities to increase their own outreach and dialogue activities, and not only in PRSP countries where the authorities' consultation mechanisms with all stakeholders are an important element of the process.

\section{Legislatures}

35. A common theme emerging from the $\mathbf{2 0 0 2}$ biennial surveillance review and conditionality review was the need for the Fund to develop a dialogue with legislative bodies in member countries to promote better understanding of the Fund and the policies it supports. In PRSP countries, in particular, as legislative input in monitoring and implementing poverty reduction strategies has become more critical, the need for communication between the Fund and legislatures has grown.

36. The Fund has begun to increase its outreach to parliamentarians. In April 2000, Fund staff, working with the Zambian authorities, organized a seminar for parliamentarians, alongside one with civil society organizations, in Lusaka. In April 2002, Fund staff, together with the Kenyan authorities, organized a workshop for Kenyan parliamentarians. At both events, economic policy issues were actively debated and discussed. The Fund is also working jointly with the Parliamentary Network on the World Bank (an informal group of parliamentarians from both industrial and developing countries who are interested in development issues), including participating in visits by parliamentarians to PRSP countries. The Fund also provides training opportunities for legislators through its regional institutes; for example, over the past two years, six seminars on macroeconomic policy and structural reform issues were offered at the Joint Vienna Institute for parliamentarians from transition countries. In addition, management and staff have often met at Fund headquarters with visiting groups of legislators. The Managing Director has also spoken in capitals to members of national parliaments - for example, in 2001, the Deutsche Bundestag, and in 2002, the Treasury Select Committee of the UK House of Commons, ${ }^{19}$ members of the Dutch parliament, and the Chilean Senate. He also met with EU parliamentary committees of the European Union (EU) in Brussels in 2000. The Fund, in consideration of the role of the United States as host country and largest shareholder, has been highly responsive in communications with the U.S. Congress, in collaboration with the U.S. Executive Director.

37. Looking ahead, more sustained and systematic interaction with legislators could, over time, bring important benefits by improving understanding of the Fund among members of society who are not only important because they represent public opinion, but who are also influential in the policymaking process and in the formation of public opinion. Such interactions must, of course, always be arranged with the concurrence of the relevant authorities and tailored to the circumstances of the individual country. Outreach to legislators who are closely involved in policymaking in areas such as budgets, civil service reform, and financial sector reform is likely to be particularly productive. Regional seminars

${ }^{19}$ http://www.imf.org/external/np/speeches/2002/070402.htm 
and individual country seminars for parliamentarians could be organized in collaboration with country authorities, resources permitting. In addition, it would be desirable for country teams/resident representatives to maintain contacts with key legislators and parliamentary committees. In a recent survey, about one-half of country teams and a quarter of resident representatives report having no recent contact with legislators. Of the rest, an overwhelming majority of the cases where staff meet legislators more than once per year (one-half of resident representatives and a quarter of country teams) are transition countries (see Annex II). Executive Directors can also play an important role by briefing legislators within their constituencies, especially in program countries. In some countries, the executive branch provides a periodic report to the legislature on relations between the Fund and the country-a practice that could be replicated in other countries. ${ }^{20}$

\section{Private Sector}

38. The Fund's interactions with the private business and financial sector at the country level often include meetings by its mission teams and resident representatives with employer associations, private companies, banks, and other financial institutions. Data have not been collected on such meetings, but a recent survey of country outreach (Annex II) indicates that country teams meet with business and trade associations (some of which might qualify as civil society organizations rather than strictly private sector entities - see next section) an average of twice per year, while resident representatives, on average, meet with such groups once every two months. As might be expected, there is a great deal of variation across the membership, as some resident representatives speak to such groups almost weekly, while some have little or no such contact. Globally, the International Capital Markets Department (ICM) maintains an extensive informal network of communications with private financial market participants. At the management level, the semiannual meetings of the Capital Market Consultative Group (CMCG) provide opportunities for informal discussion of key topics of mutual interest. Other Fund departments maintain contacts with the private financial sector to exchange information. A systematic communication effort by the Fund with the private financial sector on the SDRM proposal is underway.

\section{Civil Society Organizations}

39. The definition of civil society organizations (CSOs) used in the Fund focuses on voluntary, not-for-profit organizations, including labor organizations, business associations, nongovernmental organizations (NGOs), faith-based organizations (FBOs), and academic

20 See, for example, the annual report to the House of Commons by H.M. Treasury http://www.hmtreasury.gov.uk./Documents/International_Issues/International_Institutions/int ii ukimf.cfm 2 and the report of the government of France to the National Assembly on "Les activités du Fonds monétaire international et de la Banque mondiale" (see reference at http://www.assemblee-nationale.fr/12/cr-cfiab/02-03/co203033.asp. 
and policy research institutions ("think tanks"). Officialdom, legislatures, the media, and private enterprises are not included under this definition of civil society. ${ }^{21}$

40. The IMF has significantly increased outreach and dialogue with CSOs in recent years. IMF staff and management now meet often with CSOs both at headquarters and in member countries. In low-income countries, the PRSP process has firmly established CSOs as participants in formulating and implementing better policies to fight poverty. In many Article IV consultation missions, efforts are made to consult with broad elements of civil society on the economic situation. The terms of reference for IMF offices abroad and resident representatives often include maintaining contact and dialogue with CSOs. In practice the extent and forms of in-country communication vary greatly from country to country. This diversity was documented in a survey of the outreach activities toward CSOs of mission teams and resident representatives (see Annex II). ${ }^{22}$ Many resident representatives and even some country teams reported dozens of contacts with media and CSOs. In general, the Fund's dialogue with CSOs appears well-established in PRSP countries and in the transition countries of eastern Europe and central Asia. In other regions, however, contacts and dialogue are less extensive.

41. The Fund's dialogue with CSOs covers a wide range of issues, including macroeconomic policy and other related policies, structural adjustment and the poor; debt relief and poverty reduction; trade and capital account liberalization; globalization and the governance of the global economy (including discussions on new rules for the global financial system); promoting good governance; and fighting corruption. CSOs have been especially effective in shaping public opinion in many countries in support of more debt relief for low-income countries and in promoting discussion of how to achieve better globalization. It is becoming increasingly apparent that interaction with CSOs is taking on a country focus, reflecting, among other things, the participatory process associated with PRSPs, and the increased emphasis on national ownership of policies. A planned priority in the period ahead is to compile a set of best practices and guidelines for Fund staff outreach to CSOs that pays particular attention to the issues arising in interaction with civil society that influence the Fund's operational work. Some of the considerations that will arise in this context are reviewed in Annex III.

42. Staff contact with national labor unions in the context of Article IV or program discussions has become much more common in recent years, although not a universal practice. According to a recent survey conducted by the Policy Development and Review Department (PDR), 69 percent of Fund missions had contacts with labor unions or other labor representatives at least once in the previous two years, for the purposes of hearing the

${ }^{21}$ The definition is similar to that used by Scholte, op.cit.

${ }^{22}$ The survey was limited to area departments and excluded significant outreach by other Fund departments and offices. 
views of labor unions and explaining and discussing the Fund's policy advice. Nearly all Fund missions considered the discussions useful.

43. The Fund maintains a constructive dialogue with the international labor movement, represented mainly by the International Confederation of Free Trade Unions (ICFTU) and the World Confederation of Labor (WCL), through workshops, regional seminars, and leadership meetings held in Washington, D.C. jointly with the World Bank. The Fund and Bank have agreed with the ICFTU and WCL to hold such leadership meetings at intervals of 18 to 24 months (the most recent leadership meeting was held in October, 2002, and included 90 trade union representatives from 40 countries), with stafflevel meetings on particular issues to be interspersed between general leadership meetings. Fund staff preparations for such meetings have been led by EXR and PDR. This enhanced dialogue with the international trade union organizations is constructive without being excessively formalized.

44. Although the Fund does not have an NGO consultative group or grant permanent accreditation to NGOs as some international organizations do, it has increased its efforts at dialogue with NGOs engaged in research and policy advocacy on development, debt, environmental, and other related economic issues. The Fund's practice is to respond positively, resources permitting, to all requests from NGOs interested in engaging in constructive dialogue but to concentrate upon communications with NGOs having a leadership role within the NGO community on issues directly related to the Fund's work. During the Annual Meetings, for instance, NGOs are provided space and opportunities to discuss issues on the Meetings agenda with IMF and other officials, as well as to participate in the Program of Seminars. More than 160 NGO representatives were accredited at the September 2002 Annual Meetings.

45. At the international level, a number of major advocacy NGOs are in regular touch with Fund staff to discuss policies and programs. Numerous meetings on a variety of issues ranging from debt relief and PRSPs to transparency, governance, and the environment take place regularly in Washington and in Europe (about 310 meetings with NGOs and other civil society organizations were held at Fund headquarters in 2002). NGOs are also invited to participate actively in reviews of IMF policies - recent examples include their involvement in the conditionality, transparency, trade, and PRSP reviews - and are often invited to conferences organized around these reviews (EXR arranged NGO participation in the January 2002 PRSP conference, for example, and PDR arranged two roundtables on trade with NGOs/CSOs in Washington, two in Europe, and numerous individual meetings with NGO delegations at which the NGOs provided their views on Fund trade policy advice ahead of an internal review of this area). NGOs also always have the option of submitting views and comments via the Fund's external website or through direct contact with NGO liaison staff in EXR.

\section{The Fund is making a greater effort to increase its outreach to NGOs in} developing countries ("Southern NGOs") because of the important role they can play in the PRSP process and in contributing to consensus on economic policies, but also because even well-established Southern NGOs tend not to have good access to information about the 
Fund and economic policy analysis, and fewer resources for research than their Northern counterparts. To the extent that resources and other priorities allow, EXR organizes workshops and seminars for NGOs (especially in the South), often in collaboration with resident representatives and regional offices, to explain the Fund and the role it plays in the formulation of policies in program countries. Given their limited opportunities for face-toface contact with Southern NGOs, EXR staff responsible for liaison with NGOs are in frequent contact with them by e-mail and telephone (the email address is "ngoliaison@imf.org”). EXR also prepares a quarterly newsletter to NGOs and other CSOs that is distributed by mail and e-mail to some 700-800 recipients around the world in English, French, Spanish, and Russian and published in all these languages except Russian on the Fund's external website at http://www.imf.org/external/np/exr/cs/eng/index.asp. The newsletter aims to keep CSOs up-to-date with developments at the Fund and to refer them to resources offered to them by the Fund. Resident Representatives are encouraged to distribute the letter to their CSO contacts, and those who have done so have received positive feedback.

47. The extent to which different faith-based organizations (FBOs), and religious leaders more generally, take an active part in advocacy of social and economic policies varies greatly. Some faiths take less interest in secular matters and do not seek dialogue with the Fund, but the Fund is at pains to avoid giving any appearance of favoring contact with one faith over another. The Christian organizations, both Catholic and Protestant, have been the most activist, and many Catholic and Protestant church leaders and lay persons have petitioned the Fund on various issues, but especially on debt relief and poverty reduction. The Jubilee 2000 movement was in large part a church-based movement, with clergy and congregations working together to build support for deeper debt reductions for low-income countries.

48. The Fund has had limited, sporadic communications and meetings with FBOs in the past, primarily with Christian organizations at their request at events held in Washington, D.C. and in Western Europe. These discussions have generally been cordial and constructive. There may be opportunities to expand the dialogue with FBOs somewhat. The World Council of Churches has shown renewed interest in dialogue with the Fund, and management has responded positively with suggestions for a combination of workshops and seminars designed to allow the two institutions to exchange information and views. Meetings and activities of the World Faiths Development Dialogue (WFDD) led by the Archbishop of Canterbury and the President of the World Bank may also provide future opportunities to participate in dialogue with leaders of a range of faiths. ${ }^{23}$ Generally, there would seem to be considerable potential for FBOs to increase their support for good governance, increased aid and trade liberalization, as well as poverty reduction — all important parts of the Fund's agenda as well.

\footnotetext{
${ }^{23}$ The proposed work program of WFDD includes among its components efforts to promote the Millennium Development Goals and to engage faith groups in Poverty Reduction Strategy consultations.
} 
49. Communication with academic researchers and policy research institutes ("think tanks") around the world is mainly the responsibility of RES and the IMF Institute (INS) but supplemented significantly by the work of Fund offices and missions. European I Department, for example, reports that almost all missions maintain contacts with national academic and policy research communities, and the Offices in Europe and Asia have been active in communications with universities and research institutes, as well as in outreach to NGOs. Because of the prominence in recent years of public statements by some academics and policy researchers critical of the Fund, EXR has increased its collaboration with other Fund departments to initiate more Fund staff participation in policy seminars and discussions over the past two years, especially within the Washington, D.C. area but also elsewhere when resources permit. The purpose is to broaden and deepen the understanding among influential policy analysts of the Fund's policies, as well as bringing outside views and expertise into the Fund. EXR initiated a series of pre-Spring/Annual Meetings briefings for university audiences in 2001 and a "Think Tank Briefing" at Fund headquarters in September 2002. Both feature presentations by senior staff on some of the key issues to be addressed at the Meetings. Greater participation by Fund management, senior staff, and Executive Directors would strengthen this outreach effort.

50. The Economic Forum series also serves to expand policy dialogue. EXR organizes 10 to 12 Economic Forums at IMF headquarters each year to promote informed discussion on issues confronting the Fund and the international community. These events, which have occasionally been covered by the local press and reported in the IMF Survey, bring together Fund senior staff, and occasionally Fund management and Executive Directors, with counterparts in the academic, think tank, and policymaking communities. Topics of recent Economic Forums have included the euro, IMF governance, direct foreign investment in China, social safety nets, capacity building, crisis early warning systems, and transparency. Transcripts and video replays of Economic Forums are made available on the external website.

\section{Responding Rapidly to News and Views}

51. In line with the Edelman Report's recommendations, EXR has developed over the past few years a rapid-response approach to major news developments. Unbalanced or inaccurate stories can be damaging and are more difficult to counteract after they have been reported. Devising ways to ensure that the Fund's side of the story is told, particularly when reporters do not initially approach Fund officials for comment, is a key element of EXR's media relations work. This means responding quickly to the demands of reportersand initiating contact in some cases before news reports appear-in order to ensure balanced coverage of Fund-related issues. After reports appear, misrepresentation of the Fund's role or position often demands immediate response through direct feedback to reporters and/or letters to the editor. Because private sector and civil society organizations frequently serve as sources for journalists, rapid and direct responses to these are often needed as well.

52. The Fund has also been responding to its critics more promptly and forcefully, especially to incorrect statements, but selectively not reflexively. Letters to the editor, op-ed articles, media interviews, and public speeches have all been employed to set the 
record straight and debate influential critics. Responses to criticism appearing in the media must always be prompt, brief, and focused. Delayed and detailed rejoinders are less likely to be accepted by publishers and broadcasters, and less likely to be effective even if they are accepted. When false charges are aired about the Fund's work in a member country, Executive Directors and Governors could be especially effective respondents, particularly in their national media. See Box 1 on the Fund's rapid response to charges regarding its alleged role in the Malawian food shortage. 


\section{Box 1. Rapid Reaction: The Case of Malawi}

Reports appearing in May-June 2002 accused the IMF of having contributed to food shortages in Malawi. Government officials and others were quoted as saying that the Fund had "forced" or "pressured" Malawi to sell off its grain reserves - in some cases supposedly to repay debts. The charges were reported by some mainstream news outlets in the U.S. and the UK, and in many cases these organizations did not seek the Fund's side of the story before publishing. Fortunately, some news organizations did seek the full story, and where the Fund was able to provide the facts, the accusations about the Fund's alleged role received little or no mention. However, the recirculation of the initial reports has required rapid response on a continuing basis, even following publication of a Malawi government enquiry into the sale of the grain reserves, which fully exonerated the Fund.

Negative press coverage, although recurrent, has been contained due in large part to EXR/AFR staff's persistence in responding to each occurrence with letters to the editor, which have been published in newspapers from Ireland to India. In addition, EXR has communicated directly with the main propagators of misinformation - especially UK-based NGOs - through letters and meetings in an attempt to explain the true sequence of events and to reduce the repetition of the unsupported allegations. This effort has caused some groups to moderate their criticism on this issue and has also served to open new lines of communication with groups that devote considerable attention to Fundrelated issues.

The Malawi case also highlights, however, the handicaps that the Fund sometimes faces in responding rapidly and fully to false charges. Some senior Malawian officials were unwilling to confirm that the accusations were false, despite the findings of the enquiry, and one or two may even have repeated the charges after the enquiry. The Fund also felt constrained in what it could say about the role of other international organizations that had more direct responsibility for food policies in Malawi. To a large extent these organizations stayed silent initially, although they could have brought information to light that would have helped to refocus the spotlight on the true causes of the Malawian food shortages. Finally, some Northern NGOs and media commentators who are critical of almost all "structural adjustment policies," including the elimination of agricultural subsidies, have sought to use false allegations about the Fund's role in Malawi to discredit the Fund's work throughout Africa. This has drawn the Fund into debate on general economic policy affecting agriculture - the proper domain of other international organizations. The World Food Program and the U.K. Secretary of State for International Development have recently made helpful statements correcting press reports in this regard. Executive Directors and Governors of the Fund might also consider stepping forward in such cases to help clarify roles and responsibilities.

\section{Broadening the Reach of the Fund's Communications}

53. In previous Board discussions Directors have emphasized that the Fund's external communications should serve all members and regions and reach the general public, at least indirectly, but do so cost-effectively. EXR and other Fund departments have been working to achieve this objective by (1) expanding material on the Fund's external website and in print intended to reach audiences remote from Fund headquarters, and considering opportunities and costs of increasing the availability of both electronic and print material in non-English languages (see Annex I, the report of the Task Force on Publication Policy); (2) increasing in-country and regional external communications 
work by missions, Fund offices abroad, and Fund resident representatives, including through the creation and expansion of resident representatives' websites; ${ }^{24}$ and (3) developing general educational material on the Fund and economic and financial issues for global distribution.

\section{Expanding material on the Fund's external website and in print}

54. The Fund has consciously developed and designed its external website so that English-speaking audiences in developing countries have easy access. The focus of the website is content, not graphics or special effects, which would slow down access. In the past two years the website's search feature has been improved, and links between related material have been substantially increased. Entry pages in French, German, and Spanish have been posted. In addition, more basic information has been added for non-specialist users. Features that require special software or may be difficult to open or download from slower Internet connections and older computers have been kept to a minimum. Improving access to and increasing the amount of material in non-English languages on the Fund's website (or links to such material) is possible; however, a number of policy and budget considerations would need to be addressed (discussed in Annex I).

55. Further development of the external website might include further increases in the use of webcasts (of press briefings, the Economic Forum series, and other seminarstyle events, for example), and more Fund participation in online discussion forums on IMF policy issues. The Office in Europe, for example, could be used for real-time participation by European journalists in press conferences and briefings at Fund headquarters. Expanding the reach of the Fund's website by offering live and taped audio and video webcasts in more than one format would have resource implications. Given that the demand from outside the Fund for such features still seems to be very limited compared with the interest in textual information, the cost of expanding the Fund's webcasting capacity should be considered carefully and tradeoffs with other initiatives weighed.

56. A narrower application of technology would involve extranets (an extranet is a private network that uses the Internet protocol and the public telecommunication system to securely share part of an organization's information or operations with others) for participation by selected groups through password-protected access. This is being done to a limited extent at present via an extranet for Executive Directors and authorities. EXR has proposed that an extranet be instituted in $\mathbf{2 0 0 3}$ for journalists that would expand current ad hoc arrangements through which they can obtain advance copies of certain Fund publications under embargo. ${ }^{25}$ The goal is to establish a reliable system for

24 Seventeen resident representative/offices abroad websites have been established and are listed in Table III-2 in Annex I.

${ }^{25}$ It has become standard practice among public organizations to provide accredited journalists with access for a short period to important material before it is released to the 
selectively highlighting and disseminating accurate, timely information of special interest to media globally or in individual countries. By enabling the Fund to target the placement of important information in the media, the new extranet will indirectly enhance the Fund's communications with the public and civil society organizations that rely on the media for information about the Fund and related issues. Fund staff and Executive Directors will be able to reach out to specific media audiences via real time webcasts, and additional costeffective technology features can be introduced in future years to better serve media in all member countries. The extranet for journalists will also allow EXR to monitor consumption of press releases and other publications efficiently, and this enhanced feedback on media uptake will be taken into consideration in adapting the Fund's external communications more closely to meet specific media goals.

57. Recognizing that many individuals and organizations, especially in low-income countries, will not have for many more years the reliable access and high-grade equipment needed to take advantage of material published on the Fund's external website, the Fund should continue its print publication program and seek to improve the distribution of both complimentary and priced publications. One step underway has been the initiation of a depository library program (launched with the help of the Joint Library) to place copies of all Fund print publications in libraries where they will receive wide readership. Each library will be sent an initial inventory of IMF research and data, and receive copies of virtually everything the IMF publishes, including CD-ROM databases. Invitations to apply to this new program have already been sent to more than 150 libraries, research institutes, and information centers throughout the developing world. Formal agreements have been established in 58 locations. The goal is to expand the program over the next two years to 400 locations. Executive Directors are invited to nominate institutions to participate in this program.

\section{Increasing In-Country and Regional Communications}

58. EXR has established arrangements with each area department to increase the coordination of external communications done in-country. EXR media relations officers and other staff have been designated to advise each area department on media contacts and public outreach, and to monitor and follow up on external communications activities. The bilateral discussions between EXR and area departments include reaching understandings about the roles of mission chiefs and resident representatives in external communications in-country, especially in conjunction with missions. Mission teams have been asked by Fund management to consider in advance of each mission whether they should meet with legislators, labor representatives, NGOs, and others, and whether a press conference should be held or press interviews given, or other actions taken with the agreement of the authorities to increase public awareness and understanding of the Fund's analysis and policy

public. The purpose is to reduce the risk of erroneous reporting by enabling journalists to digest and distill material covering complex issues and subjects before the embargo expires and the race is on to be first out with the "news." 
recommendations. EXR can often provide specific recommendations on what media and public outreach activities are most likely to be successful, drawing upon the experience of its staff, many of whom have extensive media and other contacts in the region. In addition, it should be noted that PDR and other departments will continue to organize regional PRSP learning events that combine outreach, capacity building, and opportunities for Fund input into the PRSP process.

59. The Edelman report recommended that the Fund make greater use of its field offices as outreach platforms. EXR responds to requests received regularly from resident representatives for advice and support in organizing outreach events in their countries. EXR also supports occasional travel by headquarters staff to participate in outreach events organized by resident representatives, with priority in recent years given to PRGF countries. Executive Directors could help national authorities to understand better the benefits of increased outreach in conjunction with Fund missions, especially in PRGF and other program countries where "national ownership" implies making policy choices more transparent and raising public understanding of the respective roles played by the Fund, the national authorities, and other institutions.

60. Particular regional issues need to be addressed consistently in communications throughout a region. Also, what works best in terms of in-country external communications tends to vary across regions. Accordingly, EXR and area departments have begun to develop regional external communications strategies that can be reviewed and updated as warranted but provide a framework for coordinating external communications work of the area department, EXR, resident representatives, and other staff who may visit the region. Suggestions from Executive Directors on regional external communications priorities and opportunities would be welcome, and Executive Directors might wish to meet informally with EXR and area department senior staff regularly to discuss external communications approaches for their region.

\section{Although external communications are important in all regions and member} countries, three regions would seem to warrant particular focus in 2003: Africa, because of the large number of PRGF and HIPC countries; Latin America, because of the special economic challenges facing several economies in the region; and the Middle East, because of the Annual Meetings to be held in Dubai in September.

- The strategy for Africa is likely to focus on building basic knowledge of Fund policies through seminars and workshops, and on media and publications to support PRGF/HIPC and new initiatives in Africa; including investor councils and technical assistance centers and monitoring progress under NEPAD.

- The strategy for communications in Latin America will necessarily focus on media relations related to the countries in the region having Fund programs. Contacts with journalists who report for Spanish and Portuguese language media in the region are likely to continue at the current high level of frequency and intensity. Publications and outreach will also have an important role to play. A report prepared by an 
internal task force tentatively entitled "Managing Financial Crises: Recent Experience and Lessons for Latin America" will be published in spring 2003.

- The strategy for communications in the Middle East will be geared to preparations for the 2003 Annual Meetings and will include seminars and press briefings by staff from the Middle Eastern Department, EXR, and other departments in several locations in the region prior to the Meetings. The Program of Seminars at the Annual Meetings will focus partly on regional themes and seek keynote speakers from the region. EXR and MED will collaborate on efforts to disseminate Fund publications, especially material in Arabic describing the work of the Fund, and to increase publicity throughout the region in advance of the Meetings on the positive contributions of Fund work in the region.

\section{Educating the General Public about the Fund}

62. The prominence of the Fund in the media together with controversy over globalization and related economic issues has brought growing demand from the general public for basic information about the Fund. Much of the explanatory material published by the Fund, including pamphlets, Issues Briefs, Finance \& Development, the IMF Survey, and videos, are widely used by students at the university level, including ones not majoring in economics. Teachers and students at the middle school and high school levels have also requested educational material that could be used in their classrooms. EXR has begun a very modest and low-cost effort to respond to these needs through special web postings of educational material in several languages (the material has been developed and tested by the IMF Center with the help of local educators). ${ }^{26}$ A book on the Fund for high school students (ages 14 to 17) is being developed for release in 2003. It will explain the work of the Fund in an engaging and thought-provoking way intended to make macroeconomics and globalization relevant for the students. EXR would be pleased to provide Executive Directors with sample folios or online demonstrations of this educational material. Looking ahead, the costs and benefits of developing short distance-learning courses on the website and CD-ROM on the work of the Fund for educational purposes for CSOs as well as students, customized for regions and produced in different languages, will be assessed.

\section{The Fund also receives e-mail requests and comments from the public on} specific issues - a very large number of messages was received in 2002 from Argentina, for example - although in many cases the communications reflect a lack of basic

26 EXR has also designed and is testing an interactive game intended to be both educational and entertaining for young adults (secondary school and university). The game posits an imaginary country with balance of payments difficulties. The challenge for players--who will be presented with a series of policy choices--is to develop a financial program that will stabilize the economy and encourage growth. The game will be distributed via $C D-R O M$ and on the Internet. 
information about the Fund and how it works. In many cases, EXR responds through template-based e-mail messages that can be adapted to individual questions or to e-mail "campaigns" or "petitions." (Hard-copy responses to letter and postcard campaigns are normally too costly to be considered.) EXR will continue to explore new software developments that may improve the efficiency of sorting and responding to incoming e-mail from the general public. Increasingly, however, EXR will need the assistance of other departments in crafting effective and timely responses that provide substantive answers to the growing volume of more technical and nuanced questions received from the public.

\section{SUMMARY}

64. The Fund's external communications work has evolved rapidly over the past few years, and progress has been made in a number of areas, but there is still much room for improvement. External communications is now generally understood to be not just EXR's job but to require a continuous, well-coordinated Fund-wide effort. Coordination of Fund message delivery has increased, primarily through better internal communication of policy developments, but achieving fully effective coordination remains a challenge. The Fund does a better job than it did five years ago of delivering focused messages to and through the media, in part because management and staff are better prepared for external communications, but senior staff in area and functional departments could be more actively involved in conveying messages publicly. Overall, the Fund has become a much more open institution over the past five years, not simply through the increasingly prompt and comprehensive release of documents and information but through reaching out to engage in dialogue - listening and responding to key groups and organizations including its criticsand providing explanatory material geared to specialized audiences and the general public. 


\section{Issues for Discussion}

1. Are Directors satisfied with the general direction and scope of the Fund's current external communications strategy, or would they wish to see significant modifications of the strategy or changes in priorities for implementing the strategy? For example:

- Are there ways to increase internal coordination beyond those identified?

- What more might be done, or done differently, with existing resources to improve the delivery of the Fund's messages through the media?

- Would Directors have suggestions for improving the accessibility ("user friendliness") of the Fund's documents and publications?

- Do Directors agree with the finding of the Publications Policy Task Force that the costs of translating and publishing additional non-English language material would be substantial and that the benefits, while potentially significant, are of uncertain magnitude and would depend upon many variables, including effective dissemination of the material. Accordingly, do Directors agree that the scope for translating and publishing additional material in languages other than English should be determined within approved departmental administrative budgets.

- Do Directors agree with the priorities and modalities for outreach to legislatures, the private sector, and civil society — in particular, the increased emphasis on incountry outreach by Fund missions and resident representatives?

2. With respect to roles and responsibilities, do Directors agree with the suggestions for enhanced participation in implementing the external communications strategy by:

- Senior staff of area and functional departments;

- Mission chiefs and resident representatives; and

- Executive Directors, Governors, and Ministers? 


\section{Report of the Publications Policy Task Force}

February 13, 2003

Contents

Page

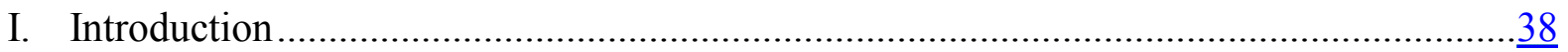

II. Fund Publications: Current Policies and Practices ...................................................... $\frac{39}{39}$

A. Publications Mandate and Policies .............................................................. $\frac{39}{39}$

Articles of Agreement .......................................................................... $\frac{39}{40}$

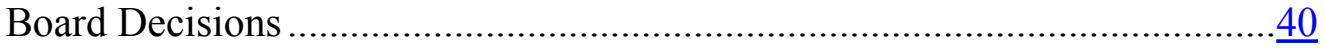

Languages of Publications .................................................................. $\underline{43}$

Formats of Publications .................................................................... 44

B. Current Practices on Languages and Formats .............................................. 44

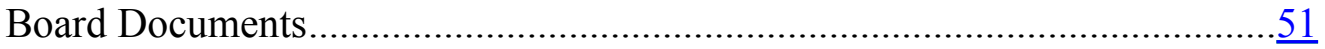

Professionally Produced Publications ..................................................

Other Publications...........................................................................

C. Comparing Recent Practice at the Fund and Other International

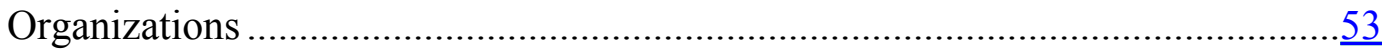

III. Options and Costs for Languages and Formats of Publications .....................................58

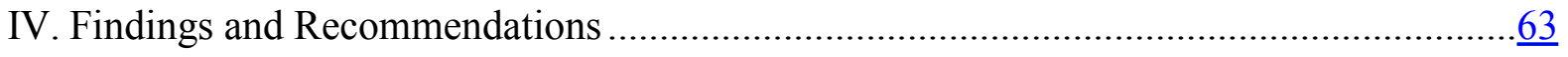

Boxes

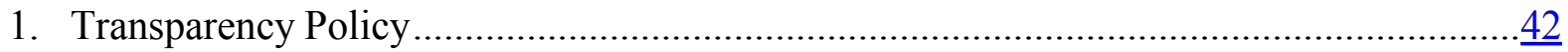

2. Legal Basis for Publication of Language Editions ................................................ 43

3. The Fund's Publications Program.................................................................... $\frac{56}{57}$

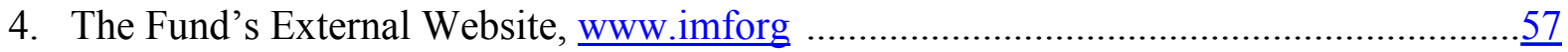

Text Tables

1. Current Practice on Formats and Languages of Fund Publications ............................... 46

2. Statistics on Translated Publications in FY 2002 .................................................. $\frac{50}{61}$

3. Estimates for Translating and Posting Selected Material on the Web .............................61

Appendices

I. Terms of Reference for Publications Policy Task Force .............................................67

II. Executive Summary: 1994 OIA Review of Non-English Publications ............................69

III. Translation of Board Documents .......................................................................

IV. Languages and Formats of Publications: Practices of Other International

Organizations 
Appendix Tables

III-1. Board Documents in Languages Other than English ..............................................

III-2. Web Pages of Resident Representatives and Overseas Offices ................................... $\frac{76}{.6}$

IV-1. Languages on Homepages of 42 Websites..............................................................

IV-2. Languages on the Main Websites of the United Nations and Its Affiliated Bodies ...........................................................................................

IV-3. Languages on Websites of the Specialized Agencies, and the IAEA, EU,

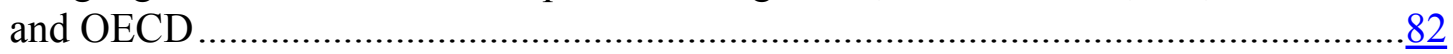

IV-4. Official and Working Languages of the United Nations and Affiliated Bodies ........... 16

IV-5. Official and Working Languages of the Governing Bodies of the Specialized Agencies, and the IAEA, BIS, EU, OECD, and WTO ………………......87 


\section{Report of the Publications Policy Task Force}

\section{INTRODUCTION}

1. This report responds to requests by the Executive Board in 2000-2001 for options and proposals on the publication of Board documents and other material in languages other than English, taking into account resource costs and modalities, including web-based alternatives to printed publications. The report also refers to options for facilitating access to documents on the Fund's external website by establishing links between relevant documents. (See Appendix I for the terms of reference for this report and their provenance.)

2. Even though the Fund's revenues from its publications are significant, the Fund's publishing activities are not profit making. Its ability to publish material in English and other languages, in print format or on its website, is therefore constrained by the administrative budget. At the same time, reflecting the growth in output of English-language publications - chiefly Board documents released under transparency policies adopted in recent years - there has been an increase in requests for additional documents and other material to be translated and published in other languages, especially from some Executive Directors and from some staff working in countries where English is not the primary language. In general, these requests have not been met, pending the Board's review of current policy and practice and consideration of options and their budgetary implications. ${ }^{27}$ There has not been any suggestion from Executive Directors or the staff that Rule C-13which establishes English as the Fund's only working language-be changed.

3. Apart from, but connected to, the issue of languages, there is the issue of publication delivery mechanisms, or what this report refers to as formats - whether to publish on the external website and/or in hard copy (print/CD-ROM/other) and whether print publications should be "professionally produced"- that is produced with such enhancements as editing, graphic design, typesetting, color illustration, and commercial-quality cover and bindingor produced in low-cost format, essentially reproduced from the original document, possibly with a soft cover. The Fund's external website, www.imf.org, created in 1996, has become the Fund's primary means of publication for a large proportion of material, including certain Board documents that are released only on the website under transparency policies. Despite the continuing expansion of the worldwide web, however, connectivity (especially highspeed connectivity) remains limited, notably in low-income countries, and some users have to pay per-minute access charges. Questions therefore arise about the extent to which the Fund's print publication program should be expanded commensurately with its electronic publications (website, CD-ROM, and on-line subscription services). The limited, concentrated, and costly distribution of print publications in low-income countries suggests that expanding print production would not by itself ensure that persons without access to the Internet would have greater access to print versions. This problem may be alleviated

\footnotetext{
${ }^{27}$ The External Relations Department (EXR) has, however, meanwhile offered to establish links on the Fund's website to versions of countries ' policy intention documents posted on authorities' websites in languages other than English. (See Section II.B below.)
} 
somewhat, however, by a stronger distribution effort, and it is generally less difficult to reach the Fund's highest-priority target audiences, including the media.

4. Expanding print and/or web publication in languages other than English would carry costs, which would depend on such factors as the number of languages; the required standard of reliability of translations; the formats of publication, including the level of professional graphic design (unless already done for the English version) and production of printed publications; the quantities to be produced; the time allowed for the preparation and release of the non-English versions following release of the English version; and the modes of distribution. The choice among options will necessarily be a matter of containing any increase in costs as well as satisfying more demand. In preparing this report, the Task Force has held to the commitment, embodied in the Executive Board's medium-term budget discussions, to limit the expansion of expenditures. Indeed, the Task Force spent most of its time developing costs estimates-work that took more time than expected owing in part to difficulties in developing estimates for the costs of cross-departmental activities. The estimates indicate that any significant expansion of Fund translation and publication of additional language versions would exceed the budgetary envelope. Staying within the budget targets would therefore necessarily involve either (a) strictly maintaining current practice, or (b) reducing other costs in order to accommodate a significant increase in translation and publication of additional language versions, or (c) adjusting current practice at the margin in order to allow for high-priority translation and publication to be accommodated to the extent that resources and efficiency gains allow. ${ }^{28}$

5. It is in the context of these issues that the Task Force has assessed current policies and practices on the formats and languages of publications and is presenting options for discussion by the Board.

\section{Fund Publications: Current Policies and Practices}

\section{A. Publications Mandate and Policies}

\section{Articles of Agreement}

6. The Fund currently publishes - in web-only, hard-copy-only, or a combination of these formats - numerous documents, reports, studies, statistical compilations, periodicals, books, and pamphlets; and the volume has increased markedly in recent years, owing mainly to transparency policies providing for the publication of Board documents and related material. The Fund's authority to publish certain material derives from several sources. First, the Fund is required to publish (i) "an annual report containing an audited statement of its accounts;",29 and (ii) "at intervals of three months or less, a summary statement of its operations and transactions and its holdings of special drawing rights, gold, and currencies

\footnotetext{
${ }^{28}$ Some options, including the role of resident representative offices, are described in Section IV.

${ }^{29}$ Article XII, Section 7(a).
} 
of members." ${ }^{30}$ Second, "the Fund may publish such other reports as it deems desirable for carrying out its purposes." 31 Third, "if requested, the Fund may decide to perform ...

technical services ... that are consistent with the purposes of the Fund." "32 Fourth, the Fund is vested with "full juridical personality," 33 and may exercise implied powers (as recognized under international law) to fulfill its functions.

\section{Board Decisions}

7. Before the development and implementation, mainly since 1999, of the Fund's current transparency policies, the Board approved publication of its documents on an ad hoc basis (as in the cases of the Occasional Papers series, the World Economic Outlook, and other titles in the World Economic and Financial Surveys series), generally without reference to publication in languages other than English and often without specifying the format of publication. Also before the development of current transparency policies, Board decisions on publication were partly concerned with establishing requirements for the publication of information about members' financial positions at the Fund and their exchange practices. Thus, in separate 1985 decisions, the Board specified that certain information relating to overdue financial obligations, or a member's ineligibility to use the Fund's general resources, must be reported in the Fund's Annual Report, in the quarterly financial statements of the General Department and the SDR Department, in Balance of Payments Statistics, and in International Financial Statistics. In a 1993 decision, the Board specified that information on the suspension of the voting rights of a member must be included regularly in the Annual Report. Other decisions relating to the publication of Board

${ }^{30}$ Article XII, Section 7 (a).

${ }^{31}$ Article XII, Section 7(b). Under its authority to publish reports under this provision, the Fund may publish "a report setting forth the causes of the scarcity [of a particular currency] and containing recommendations to bring it to an end" (referred to in Article VII, Section 2) and "annual reports on restrictions in force" (referred to in Article XIV, Section 3). In addition, under Article XII, Section 8, the Fund "may, by a seventy percent majority of the total voting power, decide to publish a report made to a member regarding its monetary or economic conditions and developments which directly tend to produce a serious disequilibrium in the international balance of payments of members," a power that has not been exercised so far. The same provision proscribes the Fund from publishing "a report involving changes in the fundamental structure of the economic organization of members."

${ }^{32}$ Article V, Section 2(b).

${ }^{33}$ Article IX, Section 2. 
documents have been superseded by the January 4, 2001, transparency decision as amended on November 11, 2002 (see Box 1 on Transparency Policy). ${ }^{34}$

34 The pre-2001 decisions are "Release of Information-Reports on Recent Economic Developments and Statistical Appendices and Annexes," Decision No. A-10138-(94/61), adopted July 11, 1994; "Use of Fund Resources - Release of Chairman's Statement," Decision No. 11971-(99/58), adopted June 3, 1999; "Public Information Notices for Policy Matters," Decision No. 11972-(99/58), adopted June 3, 1999; "Publication of Letters of Intent, Memoranda of Economic and Financial Policies and Policy Framework Papers," Decision No. 11974-(99/58), adopted June 3, 1999. The January 4, 2001 Decision, No. 12405- (01/02), "Publication Policies of the Fund," was amended on November 11, 2002. 


\section{Box 1. Transparency Policy}

Since 1999 transparency decisions by the Executive Board have authorized the publication of a wide range of Executive Board documents and related material.

A pilot project, initiated in June 1999, allowed the publication of Article IV staff reports, including those that also related to the use of Fund resources, when the country concerned agreed. At the same time, the Executive Board agreed that in the case of documents produced by a member country setting out its intentions for policies to be supported by IMF lending-including Letters of Intent (LOIs) and Memoranda of Economic and Financial Policies (MEFPs) - the presumption would be that they would be published by the Fund.

In August 2000, following a review of the pilot project, the Board agreed on the following main elements of the January 2001 Decision on Publication Policies of the Fund:

- voluntary publication (that is, publication with the agreement of the country concerned) of country staff reports and related documents. These would include Article IV staff reports, staff reports on the use of Fund resources (UFRs), combined Article IV/use of Fund resources staff reports, and staff reports on staff-monitored programs; background documentation such as Recent Economic Developments papers (REDs), Selected Issues papers, and Statistical Appendices; and Reports on the Observance of Standards and Codes (ROSCs);

- a continuing presumption in favor of releasing documents stating national authorities' policy intentions in IMF-supported programs. This would apply to LOIs, MEFPs, and Technical Memoranda of Understanding (TMUs) with policy content;

- $\quad$ mandatory publication by the countries concerned of Interim Poverty Reduction Strategy Papers (IPRSPs) and Poverty Reduction Strategy Papers (PRSPs), given that their formulation involves the participation of civil society;

- a continuing expectation that documents relating to the Initiative for Heavily Indebted Poor Countries (HIPCs), and Joint Staff Assessments of PRSPs, would be published;

- $\quad$ voluntary publication of Public Information Notices (PINs) (which had been introduced in 1997) following Article IV consultations and Executive Board discussions of regional surveillance papers, and of concluding statements of IMF missions;

- that the Board would facilitate the release of PINs following Board discussions of general policy issues, and the more systematic publication of policy papers in order to encourage a more informed public debate on IMF policies.

Following a review in June 2002, the Board agreed in November to amend this decision by introducing a presumption of publication of papers on general policy issues and related PINs. 


\section{Box 2. Legal Basis for Publication of Language Editions}

The basic legal source is Rule C-13 (adopted September 25, 1946, amended April 1, 1978 and published in By-Laws, Rules and Regulations (IMF, $58^{\text {th }}$ Issue, May 2001)): "The working language of the Fund shall be English. The discussion, documents, and reports of meetings shall ordinarily be in English. Speeches or papers presented in other languages shall be translated into English." This provision clearly requires that Fund publications be in English, but permits their publication in other languages. As noted in the 1994 OIA Report, "Review of Non-English Publications," operational practice has varied. Depending on the publication, available resources, and the perceived need to publish in one or more languages other than English, the Fund has published various documents in Arabic, Chinese, French, Russian, Spanish, and other languages.

There is no Rule or Regulation, Executive Board decision, or requirement established by the Managing Director for publication of Fund reports, material, or other documents in languages other than English, the Fund's "working language" under Rule C-13. For example, there is no relevant reference to the language of publication of Fund documents in GAO No. 26, Rev. 2 (1990), Records; or in GAO No. 35, Rev. 1 (2002), Information Security. Again, in Executive Board Decision No. 12405-(01/02) (Jan. 4, 2001), Publication Policies of the Fund, there is no reference to publication in any language other than English. Also, in instances of disputes over the contents of a document in a language other than English, the dispute must be settled using the English version. Any requirement to publish a Fund document in additional languages might be questioned as contrary to the intent of the "working language" provision of Rule C-13, given the operational difficulty of requiring timely translation of technical and policy-sensitive documents, although such an inference would not necessarily be justified.

As the 1994 OIA Report stated: "In summary, there is no approved general Fund policy statement —or rule, regulation or other legal requirement--applicable to language editions of publications" or "regarding the translation of documents in the Fund." (See p. 6 of the full report and the Executive Summary reprinted as Appendix II to this report) According to the Legal Department of the World Bank, the same is the case at the Bank, notwithstanding its stated preference, quoted in the 1994 OIA Report, "to make its publications - particularly those of general interest and those that provide public information about the institution-available in languages other than English whenever possible."

See Appendix II for the Executive Summary of this study. The purpose of the study was to reconcile the increasing demand for non-English publications-stemming from both the growth in Fund membership and widening interest in the Fund-with the prospect of a tightly constrained publications budget.

\section{Languages of Publications}

8. The Fund's Rules (Rule C-13, adopted in 1946) establish English as its working language. There is no Executive Board decision or other binding requirement that Fund documents of any kind be published in languages other than English (see Box 2 on Legal Basis for Publication of Language Editions). Publication in non-English languages is permitted, but there has never been a language policy in the Fund establishing which documents should be translated or published in which languages. Similarly, the Fund has never had a guiding policy on decisions to produce non-English-language publications. Languages of publication have therefore been subject to a variety of ad hoc practices. 


\section{Formats of Publications}

9. There is also no clear policy on the formats of publications in most cases. In Board discussions on transparency between 1994 and 2000, decisions and concluding remarks have not specified the format of publications, with the following exceptions:

- The Executive Board's January 4, 2001 transparency decision — relating to a broad range of country documents, including staff reports - states that "publication by the Fund under this decision shall mean normally publication on its website but may include publication through other media." (Board documents have been issued in print format if the Board has explicitly so indicated, or where the authoring departments and EXR have agreed to publish a print version.)

- Executive Board Decision 11725-(98/54) specifies that collections of PINs will be released three times a year. But publication of this series-IMF Economic Reviews - was, in fact, discontinued with the last issue of 1999, because of the lack of demand, reflecting the public's established familiarity with PINs and their accessibility on the web.

10. The formats of publication have evolved case by case, therefore, taking into account the intended use and distribution of the publications concerned, the available technology, and cost considerations.

\section{B. Current Practices on Languages and Formats}

11. For the purposes of clarifying current practices and identifying options, this report distinguishes three broad categories of Fund publications, shown in Table 1:

(1) Board documents (Table 1, Section 1) are produced in print initially and primarily for the Board and other internal uses. When authorized for publication, most are posted on the Fund's external website and, in many cases, print copies are made for public distribution, but without professional production; ${ }^{35}$

(2) Professionally produced publications (Table 1, Section 2) are published in print and in some cases also on the web or in compact disk (CD) format, with the guidance of editors in EXR or (in the case of statistical publications) the Statistics Department (STA), and with advanced-stage production processing in the Multimedia Services Division of the Technology and General Services Department (TGS); and

\footnotetext{
35 The term "professional production," like the term "professionally produced," is used in this report to refer to a set of enhancements - including professional editing, graphic design, typesetting, color illustration in some cases, and commercial-quality cover and bindingused for many Fund publications. Most Board documents that are published by the Fund, however, appear in the Country Report series and are printed in black and whiteessentially reproduced from the original-with a stapled soft cover, and are not professionally produced in this sense (but only in this sense).
} 
(3) Other publications (Table 1, Section 3) neither originate as Board documents prior to publication nor are professionally produced. These include Working Papers and Policy Discussion Papers, Press Releases, Factsheets and Issues Briefs, and mission concluding statements.

12. Current publication practices are summarized in Table 1 and the following paragraphs. Board documents, professionally produced publications, and other publications are listed in the first column of Table 1, alphabetically by type or title within the three categories. Policies, including any relevant Board decisions, are noted in the second column. Current practices regarding formats and languages are indicated in the last two columns. Entries in the third column also show for each type or series of publication whether lowercost (H-1) or higher-cost (H-2, H-3) formats are used for print versions, and indicate if there is web and/or CD publication.

13. Requests from the Fund membership and staff for translation of documents into an increasing number of languages have grown with the increase in Fund membership, with the growth in volume of English-language publications, and, especially recently, with the need for the Fund to communicate with wider and more diverse audiences. Table 2 provides statistics on translated publications in FY 2002. At the same time, market demand for priced Fund publications in languages other than English has remained limited and, surprisingly, so has demand for language versions of publications made available without charge. And while resources have been added to support the Fund's transparency and communications work programs, budget constraints have led in some cases to the elimination of some nonEnglish-language publications for which there was little demand and switches to lower-cost formats for others. 
Table 1. Current Practice on Formats and Languages of Fund Publications

\begin{tabular}{|c|c|c|c|}
\hline Document/Publication/Series & $\begin{array}{l}\text { Release Policy } \\
\text { with Board } \\
\text { Decision If Any }\end{array}$ & $\begin{array}{c}\text { Formats* } \\
\text { (for full text) } \\
\mathrm{H}=\text { hard copy } \\
\mathrm{W}=\text { web } \\
\mathrm{CD}=\mathrm{CD}-\mathrm{ROM}\end{array}$ & $\begin{array}{c}\text { Languages** } \\
\text { (Other than } \\
\text { English) } \\
\text { Currently } \\
\text { Published }\end{array}$ \\
\hline \multicolumn{4}{|c|}{ 1. Board Documents, Not Professionally Produced } \\
\hline $\begin{array}{l}\text { Staff Country Reports } \\
\text { Article IV Staff Reports; Combined Article IV/ Use of Fund } \\
\text { Resources (UFR) Staff Reports;UFR Staff Reports; Stand- } \\
\text { Alone Staff Reports } \\
\text { Post Program Monitoring (PPM) Staff Reports: Recent } \\
\text { Economic Developments (REDs); Selected Issues Papers; } \\
\text { Statistical Appendices; } \\
\text { Mission Team Assessments on SMPs; Financial System } \\
\text { Stability Assessments (FSSAs); } \\
\text { Reports on Observance of Standards and Codes (ROSCs) }\end{array}$ & $\begin{array}{l}\text { Voluntary } \\
\text { (i.e., when } \\
\text { agreed } \\
\text { by country } \\
\text { concerned) }\end{array}$ & $\begin{array}{c}\mathrm{H}-1 \\
\mathrm{~W}\end{array}$ & \\
\hline $\begin{array}{l}\text { Chairman's Statements } \\
\text { Summings Up }\end{array}$ & $\begin{array}{l}\text { Presumed } \\
\text { Depends upon } \\
\text { what is covered }\end{array}$ & $\begin{array}{l}\mathrm{W} \\
\mathrm{W}\end{array}$ & \\
\hline $\begin{array}{l}\text { Decision on waivers of non-observance or applicability of } \\
\text { performance criteria }\end{array}$ & $\begin{array}{l}\text { Presumed- } \\
\text { Referenced in } \\
\text { Chairman's } \\
\text { Statement }\end{array}$ & W & \\
\hline Financial Transaction Plan, Quarterly & & $\mathrm{W}$ & \\
\hline Financial Statements, Quarterly & & $\begin{array}{c}\mathrm{H}-1 \\
\mathrm{~W}\end{array}$ & \\
\hline HIPC Summings Up & $\begin{array}{l}\text { Presumed- } \\
\text { Combined into } \\
\text { Chairman's } \\
\text { Statement } \\
\end{array}$ & $\mathrm{W}$ & \\
\hline HIPC Initiative Papers & Presumed & $\mathrm{W}$ & \\
\hline $\begin{array}{l}\text { Letters of Intent/Memoranda of Economic and Financial } \\
\text { Policies, Technical Memoranda of Understanding (with } \\
\text { policy content) }\end{array}$ & Presumed & $\mathrm{H}-1^{2}$ & \\
\hline $\begin{array}{l}\text { Staff-Monitored Program LOIs, MEFPs, TMUs (with } \\
\text { policy content) }\end{array}$ & Voluntary & $\mathrm{W}$ & \\
\hline
\end{tabular}

\begin{tabular}{|c|l|}
\hline \multicolumn{2}{|c|}{ *Formats Key } \\
\hline H-1 & $\begin{array}{l}\text { No editing, no color, printed in- } \\
\text { house }\end{array}$ \\
\hline H-2 & $\begin{array}{l}\text { Edited, no color, printed in- } \\
\text { house }\end{array}$ \\
\hline H-3 & $\begin{array}{l}\text { Edited, color (some cases), } \\
\text { printed outside }\end{array}$ \\
\hline W & Web publication \\
\hline CD & CD-ROM \\
\hline
\end{tabular}

\begin{tabular}{|c|l|c|l|}
\hline \multicolumn{5}{|c|}{$* *$ Languages Key } \\
\hline A & Arabic & P & Portuguese \\
\hline C & Chinese & R & Russian \\
\hline F & French & S & Spanish \\
\hline G & German & Z & Czech \\
\hline J & Japanese & \multicolumn{3}{|c|}{} \\
\hline
\end{tabular}

1/ Hard copy publication of ROSCs began in July 2001.

2 / Some are available in hard copy if published with a staff report. 


\begin{tabular}{|c|c|c|c|}
\hline Policy Papers (about 25 per year) & Presumed & W & \\
\hline $\begin{array}{l}\text { Poverty Reduction Strategy Papers (PRSPs), Interim- } \\
\text { PRSPs (I-PRSPs), and Progress Reports of PRSPs }\end{array}$ & Presumed & $\mathrm{W}$ & \\
\hline $\begin{array}{l}\text { Joint Staff Assessments (JSAs) of PRSPs and Progress } \\
\text { Reports of PRSPs }\end{array}$ & Presumed & $\mathrm{W}$ & \\
\hline $\begin{array}{l}\text { Public Information Notices (PINs) following Article IV } \\
\text { Consultations }\end{array}$ & Voluntary & & \\
\hline $\begin{array}{l}\text { PINs following Board discussions on regional } \\
\text { surveillance }\end{array}$ & & $\mathrm{W}$ & \\
\hline PINs following Board discussions on policy issues & Presumed & & \\
\hline \multicolumn{4}{|c|}{ 2. Publications, Professionally Produced } \\
\hline \multirow[t]{2}{*}{ Annual Report } & \multirow{2}{*}{$\begin{array}{l}\text { Article XII, Section } 7 \text { of the } \\
\text { Articles of Agreement }\end{array}$} & $\mathrm{H}-3$ & $\mathrm{FC} \mathrm{G}^{3} \mathrm{~S}$ \\
\hline & & $\mathrm{W}$ & F G S \\
\hline $\begin{array}{l}\text { Annual Report on Exchange Arrangements and } \\
\text { Exchange Restrictions }\end{array}$ & & $\mathrm{H}-3$ & \\
\hline \multirow[t]{2}{*}{ Articles of Agreement } & & $\mathrm{H}-2$ & A F R S \\
\hline & & $\mathrm{W}$ & A F R S \\
\hline Books (various topics; approx. 8 a year) ${ }^{4}$ & & $\mathrm{H}-3$ & \\
\hline \multirow[t]{2}{*}{ By-laws, Rules and Regulations } & & $\mathrm{H}-2$ & A F R S \\
\hline & & $\mathrm{W}$ & F S \\
\hline \multirow[t]{2}{*}{ Economic Issues (approx. 5 a year) } & & $\mathrm{H}-3$ & $\begin{array}{l}\text { A C F R S } \\
Z^{5}\end{array}$ \\
\hline & & W & $\begin{array}{c}\text { A C F R S } \\
Z^{5}\end{array}$ \\
\hline \multirow[t]{2}{*}{ EXR pamphlets (approx. 1 a year) } & & $\mathrm{H}-3$ & F S \\
\hline & & $\mathrm{W}$ & F S \\
\hline \multirow[t]{2}{*}{ Finance and Development (quarterly) } & & $\mathrm{H}-3$ & A C F R S \\
\hline & & W & F S \\
\hline
\end{tabular}

3/ Appendices in English only.

4/ Some books are translated into languages other than English as part of copublishing arrangements with nonU.S. publishers - for example, Banking Soundness and Monetary Policy was published in Chinese through an arrangement with the China Financial Publishing House.

5/ Selected titles for the 2000 Annual Meetings in Prague. 
ANNEX I

\begin{tabular}{|c|c|c|}
\hline IMF Pamphlet Series (1 a year) & $\begin{array}{c}\mathrm{H}-3 \\
\mathrm{~W}\end{array}$ & F R S \\
\hline IMF Research Bulletin (quarterly) & $\begin{array}{c}\mathrm{H}-3 \\
\mathrm{~W}\end{array}$ & \\
\hline IMF Staff Papers (3 a year, plus a special issue) & $\begin{array}{c}\mathrm{H}-3 \\
\mathrm{~W}\end{array}$ & \\
\hline IMF Survey (23 issues a year) & $\begin{array}{c}\mathrm{H}-3 \\
\mathrm{~W}\end{array}$ & $\begin{array}{l}\text { F S } \\
\text { F S }\end{array}$ \\
\hline IMF Survey Supplement (annual) & $\begin{array}{c}\mathrm{H}-3 \\
\mathrm{~W}\end{array}$ & $\begin{array}{l}\text { A C F G R S } \\
\text { F S }\end{array}$ \\
\hline Independent Evaluation Office reports (3 a year) & $\begin{array}{c}\mathrm{H}-3 \\
\mathrm{~W}\end{array}$ & \\
\hline $\begin{array}{l}\text { Independent Evaluation Office reports (abridged versions) } \\
\text { ( } 3 \text { a year) }\end{array}$ & $\begin{array}{c}\mathrm{H}-3 \\
\mathrm{~W}\end{array}$ & \\
\hline Independent Evaluation Office Annual Report & $\begin{array}{c}\mathrm{H}-3 \\
\mathrm{~W}\end{array}$ & \\
\hline Occasional Papers (approx. 8 or more a year) & $\mathrm{H}-3$ & \\
\hline Selected Decisions & $\begin{array}{c}\mathrm{H}-2 \\
\mathrm{~W}\end{array}$ & \\
\hline $\begin{array}{l}\text { Study Guide to "the Fabric of Reform" } \\
\text { An IMF Video on Exploring Economic Change } \\
\text { in Western Africa }\end{array}$ & $\begin{array}{c}\mathrm{H}-3 \\
\mathrm{~W}\end{array}$ & $\begin{array}{l}\mathrm{F} \\
\mathrm{F}\end{array}$ \\
\hline Summary Proceedings & $\begin{array}{c}\mathrm{H}-3 \\
\mathrm{~W}\end{array}$ & \\
\hline \multicolumn{3}{|l|}{ World Economic and Financial Surveys (WEFS) } \\
\hline World Economic Outlook (normally 2 a year) & $\begin{array}{c}\mathrm{H}-3 \\
\mathrm{~W}\end{array}$ & A C F S \\
\hline Global Financial Stability Report (quarterly) & $\begin{array}{c}\mathrm{H}-3 \\
\mathrm{~W}\end{array}$ & \\
\hline Official Financing for Developing Countries & $\mathrm{H}-3$ & \\
\hline Biennial Report on Exchange Arrangements & $\mathrm{H}-3$ & \\
\hline \multicolumn{3}{|l|}{ Statistical } \\
\hline $\begin{array}{l}\text { Annual Report of the IMF Committee on } \\
\text { Balance of Payments Statistics }\end{array}$ & $\begin{array}{c}\mathrm{H}-3 \\
\mathrm{~W}\end{array}$ & \\
\hline Balance of Payments Statistics Newsletter & $\begin{array}{c}\mathrm{H}-2 \\
\mathrm{~W}\end{array}$ & F S R \\
\hline Balance of Payments Statistics Yearbook & $\mathrm{H}-2$ & \\
\hline Direction of Trade Statistics (Quarterly) & $\mathrm{H}-2$ & \\
\hline Direction of Trade Statistics Yearbook & $\mathrm{H}-2$ & \\
\hline Government Finance Statistics Yearbook & $\mathrm{H}-2$ & \\
\hline International Financial Statistics $^{6}$ (monthly) & $\begin{array}{c}\text { H-3 } \\
\text { C D } \\
\text { W }\end{array}$ & \\
\hline SNA News and Notes & $\mathrm{W}$ & $\mathrm{R}$ \\
\hline
\end{tabular}

6/ STA, with the participation of TGS and EXR, is re-engineering the IFS production process, so much of it, including the preparation of files for an external commercial printer, will be automated. 


\begin{tabular}{|c|c|c|}
\hline Manuals \& Guides & & \\
\hline $\begin{array}{l}\text { Balance of Payments Codes for Standard } \\
\text { Components and Additional Items, A Guide to }\end{array}$ & $\mathrm{W}$ & \\
\hline Balance of Payments Compilation Guide & $\begin{array}{c}\mathrm{H}-2 \\
\mathrm{~W}\end{array}$ & A C F S R \\
\hline Balance of Payments Manual & $\begin{array}{c}\mathrm{H}-2 \\
\mathrm{~W}\end{array}$ & A C F S R \\
\hline $\begin{array}{l}\text { Balance of Payments Statistics-International } \\
\text { Standards and Guidelines }\end{array}$ & $\mathrm{CD}$ & \\
\hline Balance of Payments Textbook & $\begin{array}{c}\mathrm{H}-2 \\
\mathrm{~W}\end{array}$ & C F R S \\
\hline $\begin{array}{l}\text { Coordinated Portfolio Investment Survey } \\
\text { Guide }\end{array}$ & $\begin{array}{c}\mathrm{H}-2 \\
\mathrm{~W}\end{array}$ & $\begin{array}{c}\text { F S R } \\
\text { F S }\end{array}$ \\
\hline Direction of Trade Statistics, A Guide to & $\mathrm{H}-2$ & F S \\
\hline $\begin{array}{l}\text { Equity and Efficiency in the Reform of Price } \\
\text { Subsidies, A Guide for Policymakers }\end{array}$ & $\begin{array}{c}\mathrm{H}-3 \\
\mathrm{~W}\end{array}$ & \\
\hline $\begin{array}{l}\text { External Debt Statistics: Guide for Compilers } \\
\text { and Users }\end{array}$ & $\begin{array}{c}\mathrm{H}-3 \\
\mathrm{~W}\end{array}$ & \\
\hline $\begin{array}{l}\text { Financial Derivatives: A Supplement to the Fifth Edition } \\
\text { of the Balance of Payments Manual }\end{array}$ & $\begin{array}{c}\text { H - } 2 \\
\text { C D } \\
\text { W }\end{array}$ & $\begin{array}{c}\text { A C R S } \\
\text { C R }\end{array}$ \\
\hline $\begin{array}{l}\text { Foreign Exchange Reserve Management, Draft } \\
\text { Guidelines }\end{array}$ & $\mathrm{W}$ & A F R S \\
\hline Government Finance Statistics Manual & $\begin{array}{c}\mathrm{H}-2 \\
\mathrm{~W}\end{array}$ & C R S \\
\hline Guide to SDDS: Revised Edition & $\mathrm{H}-3$ & A C F S R \\
\hline Guideline for Public Debt Management & $\mathrm{W}$ & A F R S \\
\hline International Reserves and Foreign Currency Liquidity & $\begin{array}{c}\mathrm{H}-3 \\
\mathrm{~W}\end{array}$ & F R S \\
\hline Manual on Fiscal Transparency & $\begin{array}{c}\mathrm{H}-3 \\
\mathrm{~W}\end{array}$ & A C F P S R \\
\hline Monetary and Financial Statistics Manual & $\begin{array}{c}\mathrm{H}-3 \\
\mathrm{~W}\end{array}$ & $\begin{array}{c}\mathrm{F} \\
\mathrm{ACFS}\end{array}$ \\
\hline $\begin{array}{l}\text { New International Standards for the Statistical } \\
\text { Measurement of Financial Derivative Changes } \\
\text { to the Text of the } 1993 \text { SNA }\end{array}$ & W & \\
\hline Producer Price Index Manual & $\mathrm{W}$ & \\
\hline Public Expenditure Management Guidelines & $\begin{array}{c}\mathrm{H}-3 \\
\mathrm{~W}\end{array}$ & \\
\hline Quarterly National Accounts Manual & $\begin{array}{c}\mathrm{H}-2 \\
\mathrm{~W}\end{array}$ & \\
\hline Tax Policy Handbook & $\mathrm{H}-3$ & $\mathrm{R}$ \\
\hline
\end{tabular}




\begin{tabular}{|c|c|c|c|}
\hline \multicolumn{4}{|c|}{ 3. Other Publications } \\
\hline Commodity Prices & & $\mathrm{W}$ & \\
\hline $\begin{array}{l}\text { External Debt, Joint BIS-IMF-OECD-World Bank, A } \\
\text { Quarterly }\end{array}$ & & $\mathrm{W}$ & \\
\hline Factsheets & & $\begin{array}{c}\mathrm{H}-2 \\
\mathrm{~W}\end{array}$ & $\begin{array}{c}\text { F S } \\
\text { F J S }\end{array}$ \\
\hline Financial Data for IMF Members & & $\mathrm{W}$ & \\
\hline Mission Concluding Statements & Voluntary & $\mathrm{W}$ & \\
\hline Offshore Financial Center Assessments & Voluntary & $\mathrm{W}$ & \\
\hline Policy Discussion Papers (approx. 8 a year) & & $\begin{array}{c}\mathrm{H}-1 \\
\mathrm{~W}\end{array}$ & \\
\hline SDR Exchange Rates & & $\mathrm{W}$ & \\
\hline SDR Interest Rates & & $\mathrm{W}$ & \\
\hline Staff Statements at Donor Meetings & & W & $\mathrm{F}$ \\
\hline Terminology, A Multilingual Directory & & $\mathrm{W}$ & F G S P \\
\hline WEO Database & & $\mathrm{W}$ & \\
\hline Working Papers (approx. 220 a year) & & $\begin{array}{c}\mathrm{H}-1 \\
\mathrm{~W}\end{array}$ & \\
\hline
\end{tabular}

Table 2. Statistics on Translated Publications in FY 2002

\begin{tabular}{|c|c|c|}
\hline Languages & $\begin{array}{c}\text { Number of Translated } \\
\text { Publications }\end{array}$ & Pages \\
\hline Arabic & 16 & 941 \\
\hline Chinese & 6 & 395 \\
\hline French & 49 & 2,517 \\
\hline German & 2 & 297 \\
\hline Russian & 32 & 991 \\
\hline Spanish & 41 & 3,018 \\
\hline TOTAL & $\mathbf{1 4 6}$ & $\mathbf{8 , 1 5 9}$ \\
\hline
\end{tabular}

Source: TGS Language Services. 


\section{Board Documents}

\section{Translation}

14. Very few Board documents that are not professionally produced for publication are translated. Over a recent two-year period, only a small number ${ }^{36}$ of Board documents were translated by the TGS Language Services (TGSLS); this was shown by the Task Force's analysis of FundWise records ${ }^{37}$ on all Board documents and its survey of area and functional departments on translation of country documents (see Appendix III and Appendix Tables III1 and III-2). Departments also report that a slightly higher percentage of country documents are translated for internal operational purposes, although only one-half of those translations are done by TGSLS (with three-fifths of the rest being done by country authorities).

15. Policy intentions documents (LOIs/MEFPs/TMUs and PRSPs) are more likely to be translated because they are prepared (or negotiated with) and owned by countries. Of the 129 country document translations identified by departments for the period between June 2000 and June 2001, 51 were LOIs/MEFPs/TMUs and 23 were PRSPs/I-PRSPs/PRSP Progress Reports. Departments also believe that non-English versions of PRSP documents exist in nearly all PRSP countries in which English is not the primary language, and in most of these countries the original versions are prepared in a language other than English.

\section{Publication of translations}

16. The responsibility of the Fund is to publish documents in its one working language, and the Fund does not publish translated Board documents (apart from the Annual Report, WEO, GFSR, and a few others that are professionally produced for publication). ${ }^{38}$ Country authorities have sometimes published translated versions of Board documents. The full extent of such publication is not known, but less than one-fifth of the 129 non-Englishlanguage country documents identified in the departmental survey had been published by country authorities. These comprised 11 LOIs/MEFPs, 7 PRSPs/I-PRSPs, and 5 staff reports. Newspapers and NGOs have also published non-English versions of some country documents, although only two such cases were identified in the survey. In March 2002, the Director of EXR invited Executive Directors to inform EXR of non-English versions of policy intentions documents posted on member countries' official websites, so that links to them could be established on the IMF's website. Such information has been provided for only one document thus far.

${ }^{36} 194$ of 3666 Board documents, based on an analysis of Fundwise records.

${ }^{37}$ FundWise is a computer application system that allows staff to search for and retrieve bibliographic information about all Executive Board documents in numbered series issued since 1983, as well as to view the full text for certain series.

${ }^{38}$ The only exceptions the Task Force found are three non-English ROSC modules that have been posted on the website. 


\section{Professionally Produced Publications}

\section{Nonstatistical publications}

17. The Fund publishes most nonstatistical publications only in English; the exceptions are selected titles that are published in one or more of the other seven languages for which TGSLS has translators on staff (Arabic, Chinese, French, German, Portuguese, Russian, and Spanish). ${ }^{39}$ These comprise primarily such major titles as the World Economic Outlook and the Annual Report, the IMF Survey and Finance \& Development, and Economic Issues and some other pamphlets aimed at broad audiences. As a general rule, the decision to translate, publish, and distribute in languages other than English is taken by EXR in consultation with the authoring department, TGSLS, and other affected departments, taking into account the nature of the publication and its relationship to the external communications strategy. A decision to translate, publish, and distribute is taken only after it is clear that there is a significant benefit to be achieved and that the cost can be managed within the budget. These decisions are reviewed from time to time, to ensure that the benefits remain high and the costs affordable.

18. As for web publication, the Annual Report (in French, German, and Spanish, as well as English), WEO (and the WEO database), Global Financial Stability Report, IMF Staff Papers, and manuals and guides (in all languages in which print copies are produced) are posted (in English) in full text, along with all free or nominally priced publications (the latter including Working Papers and Policy Discussion Papers). For other priced publications — including books and all but a few Occasional Papers —only the list of contents and, in most cases, an introductory chapter appear on the Fund website, in the interest of maintaining sales revenues.

\section{Statistical publications}

19. Statistical publications are produced by STA, in cooperation with EXR and TGS. The Fund distributes them free of charge to official users in member countries and on a paid basis to others. Titles include International Financial Statistics (IFS) and IFS Yearbook, Balance of Payments Statistics Yearbook (BOPSY), Direction of Trade Statistics (DOTS), and Government Finance Statistics Yearbook (GFSY). Statistical publications appear in print and on CD, with the International Financial Statistics database also available to subscribers on the Internet. ${ }^{40}$ Statistical titles, other than manuals and guides, are produced only in English, the French and Spanish versions of IFS having been discontinued in 2001 because of low demand and resulting high costs, which had risen above $\$ 700$ per copy.

${ }^{39}$ In special circumstances, selected works may be translated into another language, such as for the Prague Annual Meetings in 2000, for which selected titles were published in Czech.

${ }^{40}$ IFS online is available free of charge to individual subscribers in developing countries affiliated with academic or nonprofit institutions. Other categories of subscribers receive partial discounts. Commercial users in industrial countries pay full price. A table of rates and discounts for IFS is available from Publication Services Section EXR. 


\section{Manuals and Guides}

20. Manuals and guides are published in hard copy and posted in full text on the Fund website. Many of the recent editions have been posted in multiple languages (Arabic, Chinese, French, Russian, and Spanish).

\section{Other Publications}

21. This category of publications - which neither originate as Board documents nor are professionally produced - includes Working Papers and Policy Discussion Papers, Press Releases, Factsheets and Issues Briefs, EXR's quarterly NGO Newsletter, and mission concluding statements.

22. Working Papers and Policy Discussion Papers are written by staff, reviewed for sensitivity in EXR, and published in low-cost print format and on the Fund website. The Fund has in recent years published about 220 Working Papers and 8 Policy Discussion Papers annually. These are usually published only in English, but may be translated into one or more of the seven other languages handled in TGSLS upon request. Non-English-language versions have not been distributed by EXR's Publication Services Section, nor posted on the website.

\section{News Releases, Factsheets, and Issues Briefs}

23. EXR prepares Press Releases, Factsheets, and Issues Briefs in consultation with relevant departments. EXR published 55 Press Releases and 133 News Briefs in 2002; the two series were merged into a single series of Press Releases in 2003, as explained in the main paper, "A Review of the Fund's External Communications Strategy." EXR also drafts Factsheets and Issues Briefs, in consultation with other departments. Press Releases are published in hard copy and on the Fund website, in English only. Typically, Factsheets and Issues Briefs are published in print format and on the website in English, French, and Spanish; other language versions have occasionally been prepared and posted on an ad hoc basis.

\section{Mission concluding statements}

24. Mission concluding statements describe the preliminary findings of IMF staff at the conclusion of certain missions; they are released at the option of member countries. These are posted in full text in English only on the Fund website; they are not published in print by the Fund, except sometimes as handouts to the local media.

\section{Comparing Recent Practice at the Fund and Other International Organizations}

25. The Task Force sought information from a number of other international organizations on their policies and practices regarding languages, translated documents/publications, and formats (see Appendix IV). Six international organizations - the Bank for International Settlements (BIS), the Food and Agriculture Organization (FAO), the Organization for Economic Cooperation and Development (OECD), the United Nations (UN), the World Bank, and the World Trade Organization (WTO)_provided responses on their translation and publication practices. The UN also provided a report on "Implementation 
of Multilingualism in the United Nations System," prepared by the United Nations Joint Inspection Unit (JIU) in 2002. ${ }^{41}$

26. Policies and practices on publishing in languages are diverse and largely discretionary at these organizations. Policies seem to be partly determined by the designation of one or more "official" and/or "working" languages by the respective organizations - the Fund and World Bank have one "working" language, English, and no other language has any official status. The terms "official language" and "working language" are not defined consistently by international organizations, however, nor is there a clear pattern of translation and publication based upon such designations. Language and publication practices seem to a considerable extent to be determined by the availability and cost of translation services and publishing resources within the respective organizations.

27. BIS. Although the working language of the BIS is English, it publishes its Annual Report, Quarterly Review, some Committee Papers, the BIS Profile, and the BIS Statutes (both hardcopies and web) in its four official languages (English, French, German, and Italian). Its Annual Report and the BIS Profile are also published in Spanish. Some items are published only electronically, on the BIS website.

28. FAO. The FAO regularly publishes official documents in its five official languages (English, French, Spanish, Arabic, and Chinese) "where relevant." Some items are published only electronically, on the FAO website.

29. OECD. The OECD publishes a wide range of documents (Reports, Surveys, Proceedings, Working Papers, Outlooks, and others) on the web and in print in its two official languages (English and French). The OECD publishes irregularly in nonofficial languages (German, Japanese, and Spanish), depending upon the "interest of the publication for specific countries/constituencies." Some publications appear only electronically, on the OECD website.

30. United Nations. The UN has six official and working languages (Arabic, Chinese, English, French, Russian, and Spanish) and is required by its rules of procedure concerning languages (adopted in 1946) to make available "all resolutions and other important documents" in all official languages. The UN General Assembly specified in 1981 (Resolution 36/117 B) that all official documents submitted to any of the principal organs "shall be given effective simultaneous distribution in the official and working languages." UN publications are not considered official documents and are not produced in all six languages. Press releases, for example, are produced only in English and French. The UN Department of Public Information stated in a press release on May 3, 2001 (PI/1342) that "It

\footnotetext{
41 "Implementation of multilingualism in the United Nations System," Geneva 2002, prepared by the United Nations Joint Inspection Unit (JIU/REP/2002/11).
} 
would cost some $\$ 6$ million per year in additional staffing costs alone to produce [press releases] in all six official languages." ${ }^{42}$

31. World Bank. Like the IMF, the World Bank does not have an official language; English is the working language. On a selective basis, the World Bank publishes hard-copy documents and other publications in Arabic, Chinese, French, German, Portuguese, Russian, and Spanish. The World Bank indicated that it regularly posts documents in Chinese, Portuguese, Russian, and Spanish on its website.

32. WTO. The WTO states that it publishes and posts all documents and publications in its three official languages (English, French, and Spanish). It has no web-only publications.

33. The language publication practices of the other international organizations surveyed are shaped by their designation of official and working languages with, at times, limited additions as a result of special needs or exemptions due to budgetary constraints. Most did not provide, and presumably do not have, formal policy statements governing languages or formats for publications. It would seem that the publication decisions of other international organizations, where they have discretion and are not mandated to publish, are made on the basis of judgments by management and staff of perceived utility, demand, and cost factors, much as they are in the Fund (see Box 3 on the Fund's publications program and Box 4 on the Fund's external website). No organization comparable to the Fund appears to have a policy of translation and publication extending much beyond a relatively small set of official/working languages. (The World Bank's practice appears to be the most extensive in this respect.) The Fund's practice of publishing mainly but not exclusively in English, its working language, therefore, appears to be well within the mainstream of current practices of comparable international organizations.

${ }^{42}$ For more information on language publications in the UN system, see Appendix IV. 


\section{Box 3. The Fund's Publications Program}

The IMF currently produces 80-90 nonstatistical print publications and about 10 statistical titles as well as several CD-ROMs, annually. These publications are itemized in each financial year's Publications Budget, which covers publication sales revenue and costs of external printing (and some typesetting and chart making), mailing, and handling, but excludes staff resource costs and internal costs for language and graphics services. The budget is approved each year (subject to subsequent Board approval of the Fund's administrative budget) by a Fund-wide staff committee, the Publications Committee, which is chaired by the Director of EXR. Publications Committee oversight is intended to ensure that proposals for publication are prioritized appropriately. The budget is managed by EXR, which is responsible for ensuring quality and consistency in editorship and production, and that approved publications support the Fund's external communications strategy. Departments submit proposals for published titles in November of each year and EXR prepares a title-by-title budget. The Publications Committee meets in January or February to consider the budget and quarterly thereafter to review and, if needed, adjust publication plans. When approved by the Publications Committee, the budget is sent to OBP, which incorporates it into the Fund's Administrative Budget for Board approval.

Departments' initial publication proposals every year would, if realized, exceed the Publications Budget allocation and EXR's capacity to edit and produce them. The selection of manuscripts (other than Board documents) for publication depends on judgments by EXR (and, if necessary, the Publications Committee) on the relative importance of the publications in supporting Fund objectives, especially the external communications strategy and on the timing of submissions and marketability for priced publications. Usually, all the manuscripts that are actually finalized in departments and sent to EXR for editing and production are published.

Fund publications that are not priced, as well as a proportion of those that are priced, are distributed free of charge to fulfill the Fund's mandate to disseminate information and analysis widely to the public. The publications program is not managed as a strictly commercial operation, although the generation of revenue (about $\$ 5$ million annually) is an important consideration. EXR has taken the initial steps toward using e-commerce to improve the Fund's publication sales capabilities and, thereby, increase revenue. 


\section{Box 4. The Fund's External Website, www.imf.org}

\section{Services}

EXR manages the IMF's external website (except the DSBB and GDDS sections of the site) and posts material originating from throughout the Fund. EXR provides web content consultations ranging from editorial support to content formatting, website usability advice (TGS provides design support and related technical functions), and postings, often at predetermined embargo times.

\section{Policies}

The external website operates under a set of objectives, criteria, and policy guidelines for content. The goals are to further the Fund's transparency and external communication objectives by ensuring the quality and timeliness of the content of the site and its usability - that is, its user friendliness for the general public. In addition, there are written style standards for browser compatibility, coding, design, and other technical aspects of the site. These are updated when warranted by advances in usability research. Since 1996 EXR has commissioned three reviews by external consultants. These have helped to ensure that the site is as user friendly as possible, is of a standard at least comparable to those of other international organizations, and takes advantage of the latest technology, when appropriate.

\section{Cross References Within the Fund's External Website}

The Task Force's Terms of Reference mention the issue of adding more cross-references among documents posted on www.imf.org. The Task Force agrees that additional linking throughout the Fund website would enhance usability. EXR has increased the number of links on the site, especially links to and from country material. Nearly all country material on www.imf.org now has, at a minimum, a link to the relevant country page, and the country page has, in turn, a link to all relevant country material. At the document level, links from PRSPs and I-PRSPs to the relevant JSAs (Joint Staff Assessments) are in place, as are links from PINs to Article IV reports. Links from press releases to PRSPs or I-PRSPs have also been established in most cases. The formats for speeches, transcripts, press releases, news briefs, and PINs have been updated to allow for more links to country pages and other material, such as policy papers.

\section{Budget}

The website budget is divided into (1) an IT budget for hardware, software, and other IT-related activity, including contractual staff; and (2) funds for "content conversion" that are used to format material for posting, to develop designs and images for the site, and to carry out some activities to increase public awareness of the website and its content.

With the increase in IMF transparency and growth in Fund work in recent years, there has been a major expansion in the flow of items posted on the website that does not yet seem to have reached a plateau (see chart). As a result, website resources, which were increased in 2000, have become increasingly stretched. In the course of this growth, the benefits of a centrally managed website have become increasingly clear. By reusing templates, scripts, database routines, etc., in conjunction with written style standards and stated goals and objectives for the site, much of the work related to maintaining and enhancing the site is facilitated. The growth in the flow of material posted on the website may well plateau in the period ahead, but it is difficult to project. A decision to post a significant quantity of material in multiple languages would require additional resources devoted to the website, especially in the early years - the startup phase - as maintenance routines, database content and fields, scripts, searches, etc. were extended to function in other languages. 
Box 4. (concluded). The Fund's External Website, www.imf.org

The IMF's External Website - Items Added to What's New 1/

May 1999 to January 2003

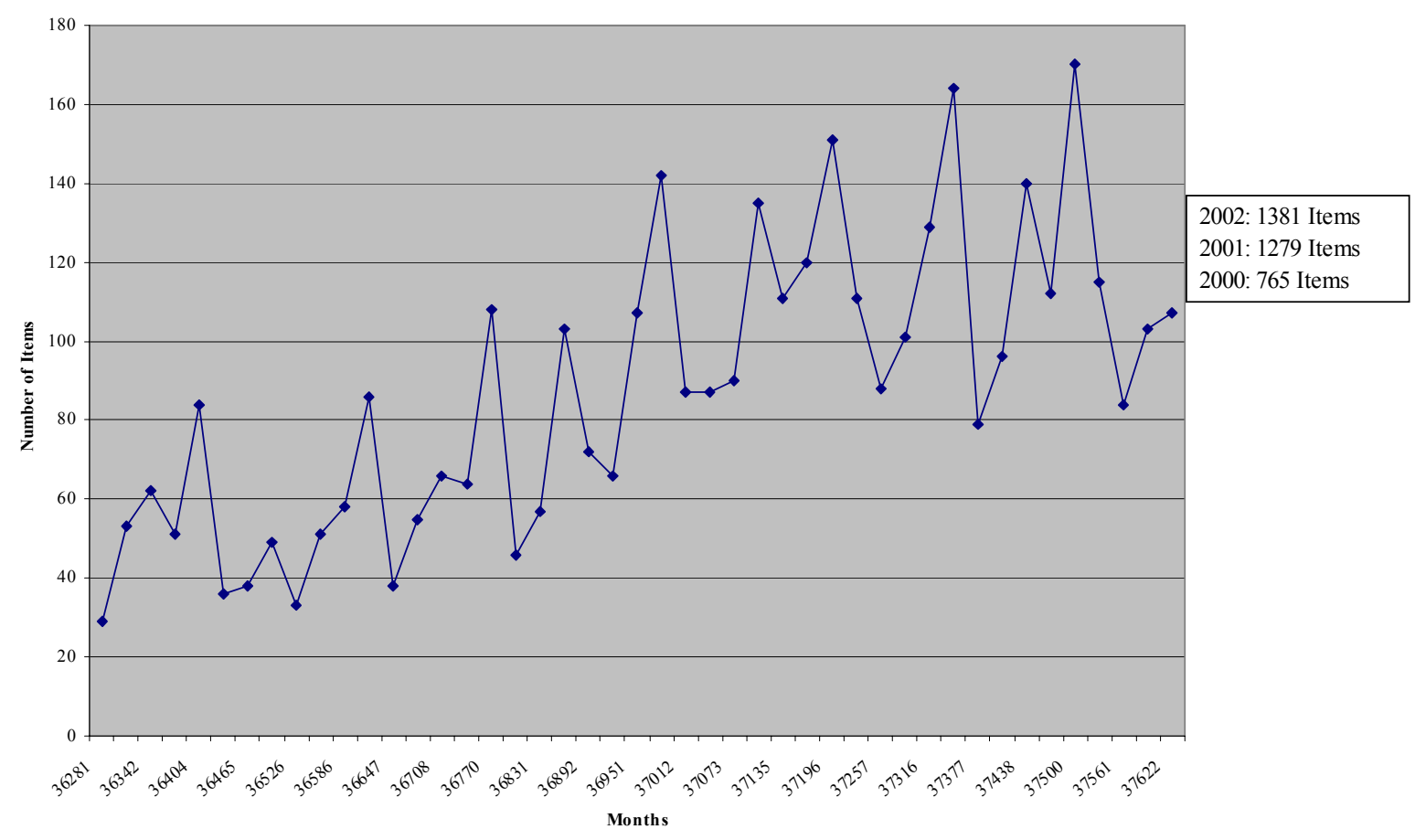

1/ This chart underreports content added to www.imf.org. It excludes, for example, non-English language material, speeches by Governors at the Annual Meetings, and items posted on Resident Representatives' segments of www.imf.org. In addition, the count of entries does not reflect the volume of material posted-for example, one entry in "What's New" for International Reserves signals the addition of more than 150 web pages. Enhanced or updated pages are usually not counted either.

\section{Options And Costs for Languages and Formats of Publications}

34. The Fund's policy of one working language, and its largely pragmatic approach to publication in languages other than English have hitherto allowed its publishing program to include a substantial number and variety of publications in such languages, as indicated in Table 1. Non-English versions are translations from the original English version, and current practice is to have all translations from the English version done, or at least revised, by TGS Language Services prior to publication to ensure accuracy. ${ }^{43}$ In addition

\footnotetext{
${ }^{43}$ Area departments and PDR report that translations (or original versions) of some Board documents, especially program documents, exist in local languages in many countries; however, in many cases it seems that such versions were not prepared or reviewed by TGSLS for accuracy and may not correspond exactly to the content of the Board document.
} 
to the cost of translation, there are costs for printing (for both internal and external distribution), web posting (including conversion of documents and manuscripts into an appropriate format for posting, and costs associated with creating or improving access and search capabilities in non-English languages), and distribution (order and fulfillment). NonEnglish-language printed versions are sometimes produced in lower-cost formats (for example, in black-and-white rather than color, or with a less expensive cover) in order to reduce costs, given the more limited demand. In some cases, licensing or other arrangements are made for publishing houses overseas to produce, market, and distribute non-English editions.

35. As part of the work of the Task Force, the Office of Budget and Planning (OBP) prepared an estimate of $\$ 11.2$ million for the total net cost of the Fund's current publishing program (electronic and hard copy), after subtracting over $\$ 5$ million in annual revenue and adding a factor for Fund overhead for space, utilities, etc., in addition to staff time and direct outlays, but excluding authoring costs. This estimate also excludes the cost of printing, distributing, and web publishing Board documents (whether internally or for the public), which are currently printed for the Board in English only. OBP estimated the cost of printing and distributing Board documents during a recent 12-month period to be about $\$ 2.8$ million, when staff time, administrative costs (maintenance and amortization of equipment, for example), and capital projects were included. Thus, the Fund makes substantial outlays for publications and documents in the annual administrative budget, plus periodic outlays in the capital budget.

36. The Fund's administrative budgets for FY 2004 and the medium term do not assume any significant increase in resources devoted to the publishing program, although efficiency gains, together with some IT investments under consideration in the capital budget, may lead to higher productivity and possibly higher revenue over time. ${ }^{44}$ Accordingly, there is little, if any room within current budget limits to translate, publish, and distribute additional material without undertaking cost reductions in either these or other areas.

37. Given the various possible combinations of languages and formats, and the range of publications to which any language/format combination could apply, whether selectively or on a blanket basis for given categories, the costs of any expansion of language publication would vary greatly depending upon the options chosen. As a base point for discussion, recognizing that printing and handling costs are a significant cost factor for publications, and that Internet access is increasing rapidly in many countries (although it is still quite limited in some low-income countries and although some users, even in industrial countries, must pay per minute for access), EXR, OBP, and TGS prepared a cost estimate for the translation and web-only publication of a range of selected additional material in five languages: French, Spanish, Russian, Chinese, and Arabic (see Table 3). It is estimated that the one-

44 The FY 2003 Publications Budget, which is included in the Fund's administrative budget, showed a net outlay of $\$ 3.83$ million for the publications program ( $\$ 4.77$ million in revenues and $\$ 8.60$ millions in expenses, primarily for external printing and postage and excluding inhouse TGSIM costs and capital outlays, staffing, and overhead in all departments). For FY 2004 an increase in expenses to $\$ 8.81$ million is assumed. 
time "IT start up" costs for developing website access and search capabilities in each language, as well as templates and automated-site-management features, would amount to more than $\$ 0.8$ million. (Although the website currently has homepages for French, German, and Spanish, additional features would need to be added to enable persons not fluent in English to find and navigate the site efficiently. There are currently no homepages for Arabic, Chinese, and Russian.) The annual costs for publishing the additional selected items in the five languages, however, which would need to be covered in the administrative budget, would total about $\mathbf{\$ 7 . 8}$ million - a sum equal to about two-thirds of the total net cost of the Fund's current publications program. As indicated in footnote 3 to the table, about $\$ 3$ million of this amount would be for additional staffing needs in EXR's website section (5 full-time equivalents-FTEs) and in TGSLS (14.3 FTEs). About three-fourths of the total cost of $\$ 8.6$ million (over 90 percent of the annual "series costs" for selected items in Table 3 ) would be attributable to translation, although translation costs for specific items would vary considerably as a proportion of the total, depending upon the type of material translated and the language into which it was translated. Finally, where there are no costs or minimal costs shown in the table, this is because the indicated items are already translated and published (in print only in some cases) in the language indicated. 
Table 3. Estimates for Translating and Posting Selected Material on the Web 1/

(in U.S. dollars)

\begin{tabular}{|c|c|c|c|c|c|c|c|}
\hline \multirow[t]{3}{*}{ Series } & \multirow{3}{*}{$\begin{array}{c}\begin{array}{c}\text { Number } \\
\text { of }\end{array} \\
\text { Items per Year }\end{array}$} & \multicolumn{5}{|c|}{ Languages } & \multirow{3}{*}{ Totals } \\
\hline & & \multicolumn{2}{|c|}{ Phase 1} & \multicolumn{3}{|c|}{ Phase 2} & \\
\hline & & \begin{tabular}{l|l} 
French \\
\end{tabular} & Spanish & \begin{tabular}{l|l} 
Russian \\
\end{tabular} & Chinese & Arabic & \\
\hline WPs & 6 to 20 & 60,718 & 70,462 & 30,924 & 1,694 & 74,769 & 238,566 \\
\hline PINs & 25 to 35 & 24,996 & 30,979 & 31,834 & 3,628 & 33,823 & 125,260 \\
\hline PRs and NBs & 25 to 35 & 22,142 & 22,913 & 24,633 & 16,683 & 24,083 & 110,454 \\
\hline Views and Commentaries & 5 & 1,993 & 1,993 & 2,790 & 2,890 & 2,830 & 12,497 \\
\hline Speeches & 5 & 0 & 0 & 399 & 399 & 439 & 1,236 \\
\hline Issues Briefs & 1 to 3 & 0 & 0 & 1,435 & 1,940 & 3,487 & 6,862 \\
\hline Transcripts & 5 & 10,763 & 10,763 & 10,763 & 10,763 & 10,803 & 53,856 \\
\hline Country Reports & 18 to 20 & 161,497 & 146,657 & 154,077 & 161,497 & 161,656 & 785,384 \\
\hline PDPs & 2 & 5,884 & 5,884 & 5,884 & 148 & 5,884 & 23,683 \\
\hline$F \& D$ & 4 & 0 & 0 & 957 & 177,071 & 177,623 & 355,651 \\
\hline IMF Survey & 25 to 26 & 0 & 0 & 295,499 & 295,499 & 295,706 & 886,704 \\
\hline Factsheets & 48 to 50 & 242 & 605 & 23,750 & 24,746 & 24,391 & 73,734 \\
\hline LOIs/MEFPs & 9 to 20 & 20,937 & 23,225 & 14,836 & 23,225 & 23,385 & 105,609 \\
\hline PRSPs & 1 to 5 & 399 & 399 & 159 & 80 & 88 & 1,124 \\
\hline JSAs & 2 to 6 & 13,002 & 15,437 & 15,437 & 5,146 & 5,394 & 54,416 \\
\hline Economic Issues & 2 to 5 & 2,828 & 2,828 & 120 & 80 & 5,894 & 11,749 \\
\hline Occasional Papers & 2 to 3 & 1,913 & 19,290 & 19,290 & 27,979 & 28,003 & 96,476 \\
\hline Pamphlets & 1 & 0 & 0 & 80 & 655 & 663 & 1,398 \\
\hline Policy Papers & 25 & 136,023 & 136,023 & 136,023 & 136,023 & 136,222 & 680,312 \\
\hline HIPC papers & 2 to 5 & 15,461 & 38,054 & 22,833 & 7,611 & 88 & 84,046 \\
\hline WEO & 1 to 3 & 97,838 & 97,838 & 286,688 & 286,688 & 95,207 & 864,261 \\
\hline Annual Report & 1 & 0 & 0 & 121,417 & 319 & 121,417 & 243,153 \\
\hline GFSR & 2 to 4 & 9,267 & 16,301 & 16,301 & 2,232 & 16,301 & 60,403 \\
\hline Manuals, Guides & 2 & 0 & 0 & 0 & 0 & 0 & 0 \\
\hline 1. Series Costs & & 585,903 & 639,652 & $1,216,129$ & $1,186,995$ & $1,248,155$ & $4,876,834$ \\
\hline \multicolumn{8}{|l|}{ 2. Development Costs } \\
\hline IT Costs 2/ & & \multicolumn{2}{|c|}{572,020} & \multicolumn{3}{|c|}{236,580} & 808,600 \\
\hline Non-IT Costs 3/ & & 368,947 & 489,104 & 706,227 & 624,189 & 762,081 & $2,950,548$ \\
\hline Subtotal ( $1+2$ by Phase) & & \multicolumn{2}{|c|}{$2,655,626$} & \multicolumn{3}{|c|}{$5,980,357$} & $8,635,983$ \\
\hline Grand Total & & & & $8,635,983$ & & & \\
\hline
\end{tabular}

1/ These costs take into account ONLY the expenditures related to posting the listed publications to the web. No expenditures related to printing hard copies of these publications and/or other related costs (such as postage and freight and supplies) are included. No cost estimate is given for series/items that are being posted now in the quantities indicated. The estimates assume that English material will be posted before other languages, i.e. not simultaneous posting. The cost may vary from one language to another depending on the format used to post the material.

2/ These are "one-time" costs. All other costs in the table would be annual costs.

3/ The "Non-IT Costs" category comprises the additional 5 Full-Time Equivalents (FTEs) which would be required by the External Website Section of EXR and another 14.3 FTEs by Language Services of TGS. EXR estimates assume that IT funding and requisite EXR staffing would be in place for each phase. FY 2003 standard costing for FTEs were used in compiling this table. Updated costs for FY 2004, which are not yet available, would need to be used if Phases 1 and 2 were considered for implementation. 
38. Table 3 is illustrative only, and the cost estimate could be reduced or increased significantly under different assumptions. As can be seen from the table, annual costs for translating and web publishing could be reduced by limiting further the categories (first column - Series) and quantities (second column - Number of Items per Year) of material to be published in non-English languages and/or by reducing the number of languages. For example, expanding only in French and Spanish (in which a significant amount of material is already published) for the indicated series and quantities would reduce total cost to about \$2.6 million, including large one-time IT start-up costs to improve the language sections of the external website (\$570,000 for French and Spanish only). ${ }^{45}$ Another variable to be determined would be whether printed copies would be produced in addition to, or instead of, the web versions. Adding production of hard copies would add to the annual outlays: that is, all costs for printing and distributing print copies internally and externally would be additional to the estimates in Table 3. These additional costs (or alternative costs, if print were chosen instead of web) would depend on a number of variables relating to the quality and quantity of production, including, for example, how many colors are used; quality of paper, cover, and binding; print run; where the printing is done; where the copies are stored and how they are distributed (in bulk or single-item parcels and what modes of delivery are used, ranging from courier to ocean freight). For the least expensive printing format, it may be noted that the cost of printing Working Papers, for example, which are photo-reproduced only in black and white and stapled, averages about 2 cents per page per copy. Producing a 40-page WP with a 2,600-copy print run, therefore, costs about $\$ 2,080$ plus distribution costs. This may be used as a basis for a rough calculation of minimum costs of producing printed versions.

39. A much less costly approach to increasing the dissemination of non-English material would be to link to translations, when they are available, on authorities' websites. The web user could be guided to a translated version without the Fund incurring translation costs, assuming that the web user knew enough English to find the link to the non-English version on www.imf.org as a starting point. The Fund has begun a project in this vein-EXR notified Executive Directors on March 19, 2002 that the website would add links to non-English versions of PRSPs posted on the World Bank's external website and that Executive Directors may request links to non-English versions of PRSPs, LOIs, and MEFPs/technical MOUs that have been posted on the official websites of member countries. A disclaimer will be included, noting that "The IMF is not responsible for the content of any linked site and cannot vouch for the accuracy or reliability of information on linked sites." This initiative has received little response - as of January 2003, only one link to a non-English version of a country policyintention document had been requested.

${ }^{45}$ An underlying assumption is that the largest one-time IT development costs would be incurred in developing the features and mechanisms for the first one or two languages; costs for adding more languages would decline as procedures could be carried over and adapted. Thus, the IT development costs for French and Spanish are higher in the table than for Russian, Chinese, and Arabic even though there are already homepages for the former and not for the latter. 
40. While the practice of linking could, in principle, be applied to a much broader range of Board documents and the costs of setting up additional links, which have to be added manually to the Fund site, would be modest by comparison with other options - particularly those requiring translation - there would be a number of drawbacks:

- Access would depend upon the user first finding and then using the link in the English-language version on the Fund's external website (except for languages for which homepages are included), i.e. French, German, and Spanish.

- The Fund would not verify the accuracy of the translation and the completeness of the document. (Discrepancies between the Fund's English-language version and the nonEnglish version posted by authorities could contribute to misunderstandings.)

- Even if TGSLS did check the version initially posted by the authorities (which could prove to be a significant cost factor), it is not clear how disagreements over correct translation would be resolved, nor is there any way for the Fund to verify continuously that the target of the link (the web address of the translated version of the document) had not been modified subsequently. ${ }^{46}$

- The availability of the links would be unevenly distributed by type of report and country, unless all countries' authorities translated and posted local-language versions of country documents published by the Fund.

- Linking to another site could be seen as implicit endorsement of other content on that site. While this should not be a general problem for linking to official sites, the Fund would not have the resources to monitor the content of the sites.

- The Fund's external website could not automatically organize the material on the authorities' websites in a language-specific manner or include it in the site search feature of www.imf.org. Implementing manually the organization and search features would be very costly in staff time.

41. For these reasons, the Task Force considers that the Fund should not generally rely on linking to other websites. Linking to country policy intention documents (LOIs, MEFPs, TMUs, and PRSPs) on official websites is a reasonable exception, but the Task Force believes that the Fund should not rely on translations of its own policy papers and staff reports that have not been done or verified by TGSLS translators. Especially given the Fund's interest in ensuring that the information it provides is accurate and well-organized, and that the files remain available to the public in their original form, the advantages of the Fund's managing its own publications, including via its website, are clear.

\section{FINDINGS AND RECOMMENDATIONS}

42. The Task Force has examined current Fund policy on languages, its practices with regard to languages and its publication program, and the language practices of comparable

\footnotetext{
${ }^{46}$ Procedures exist to check for broken links, but there is no way to monitor content programmatically to ensure that the content of the target link remains as intended.
} 
international organizations, and has constructed illustrative estimates of the costs of additional language publication on its website.

43. The above estimates show that the costs of translating and publishing significant quantities of selected additional material in five non-English languages on the external website and/or in print would be very large, including in relation to the costs of existing Fund translations and publications. Such costs of expanding language publishing - which would comprise mostly recurrent outlays but also a large start-up cost for developing language pages on www.imf.org with search and other features needed for efficient use by non-English speakers - are not included in the proposed administrative budget spending levels for FYs 2004-2006. Therefore, in order to accommodate any significant increase in expenditures for this purpose, either corresponding reductions would have to be made in other planned outlays or the Board would need to consider raising the budget ceilings.

44. The benefits of a major expansion of Fund publications in non-English languages, whether on the external website or in print, could include, in principle, reaching a broader audience, increasing country ownership of Fund-supported programs, and avoiding or reducing possible misinterpretations of the Fund's or authorities' views arising from inaccurate or incomplete translations. In commenting upon a draft of this report, many departments and offices indicated that they find the existing program of selected translation and publication in various languages useful in supporting the Fund's core outputs as well as increasing understanding of the Fund and its activities more generally. Area departments and regional offices believe that extension of this translation and publication program — to include the publication of selected Board documents in non-English languages-would be useful in supporting the Fund's outreach efforts, and the PRSP process, in Sub-saharan African countries where English is not widely spoken.

45. These benefits would be difficult to estimate quantitatively, and actual demand for existing non-English publications provides some evidence that the benefits might not be large, relative to the costs. Sales of the Fund's non-English language publications are insignificant even in Europe, where many of them are available from numerous sources. Surprisingly, demand even for the Fund's complimentary publications in non-English languages also remains low in both industrial and developing countries. (As noted in the Board paper on external communications strategy, Fund staff and Executive Directors could help to distribute, or identify efficient channels for distribution of, Economic Issues, pamphlets, Finance \& Development, Issues Briefs, and other material in non-English languages). Use of non-English material that has been on the website has also been relatively slight to date. In addition, it is notable that other relevant international organizations do not appear to be investing in major expansions of their non-English language publishing programs; nor do they report having experienced much increase in demand for their publications in languages other than English. With regard to web-only publishing, while Internet connectivity is growing rapidly in middle-income developing countries, it remains quite limited in low-income countries and in many cases users must pay per-minute access charges.

46. Nevertheless, to further the Fund's communication objectives in selected countries with broad, non-English-speaking priority "Fund" audiences, the Task Force believes that 
over time it may be possible and advantageous to increase the non-English language publishing program selectively, where significant demand can be shown to exist, where benefits seem likely to exceed costs by a significant margin, and when resource constraints allow. The Task Force did not find sufficient reason to recommend that additional resources, going beyond the established targets for the administrative and capital budgets, be devoted to the publication of translations. The Task Force noted that area departments and regional offices expressed differing views on which documents and languages should be given priority - ranging from limiting translation and publication to PINs and other short documents in the major "international languages," to publishing all program documents in local languages (not necessarily international languages), to publishing any local-language translations of Board documents that may exist (that is, using local translations where they exist, without regard to whether they have been reviewed by TGSLS for accuracy and completeness). The Task Force recommends further exploration of options, and perhaps some experimentation.

47. One possible way to meet specific needs would be for area departments, usually through resident representatives to have short brochures prepared and/or translations of certain crucial documents done locally into the local language of their respective countries and, if feasible, posted on www.imf.org (possibly on the Resident Representative's website) or, perhaps, on the authorities' website. Preparing or translating material locally would depend upon the resources and work priorities of the area department and/or resident representative. Quality assurance for local language translations would also be a concern. With regard to posting on the Fund's website, the setup costs of non-English website posting, referred to above, have to be borne in mind and could not be covered within current budget allocations. Limited local reproduction of hard copies, as needed, should be much less expensive than having material printed and shipped from Washington, D.C. or other central locations. An advantage of this "local option" possibility is that material could be custom made to a larger degree, being made available, for example, in Georgia in Georgian rather than Russian, and in Vietnam in Vietnamese rather than just English and French. But the "local option" has drawbacks. The amount of non-English material provided would be likely to vary from country to country, language to language, area department to area department, and from one overseas office to another, with Resident Representatives and country teams likely to have varying inclinations and resources to take on such a task, and with the possibility of some requesting the publication (including web posting) of material which, from a Fund-wide viewpoint, would be of low priority. The potential costs of such a "local option" could be substantial, and, in any event, what could be done on the website would depend on the resources available in EXR to manage material in a wide variety of languages. (EXR is not requesting any additional resources for this or other purposes at this time). Part of the cost of a "local option" might be covered by reducing or eliminating translation and publication of material for which there has proven to be little demand, especially timesensitive material that is published with a lengthy delay.

48. In spite of these drawbacks, the Task Force recommends experimenting with the local option in a few targeted cases. It would also be worthwhile for EXR to continue its current practice of extending language publication on an ad hoc basis when resources and efficiency gains allow and when the priority of the material is high. 
49. There are also two other ways in which the Fund could promote the dissemination of non-English material, which would not have some of these drawbacks and that would require very little by way of additional resources - including no additional translation by the Fund. The first, noted above, would be greater take-up by authorities of EXR's offer to link to nonEnglish versions of country policy intentions documents on official websites. This, too, would allow for the choice of language to be made locally, but it would also have a number of drawbacks, as explained earlier. The second way in which the dissemination of nonEnglish material could be promoted, which has also been mentioned earlier, would be for Executive Directors, authorities, and Fund staff to collaborate in identifying specific opportunities to disseminate more widely, especially in low-income countries, the substantial quantity of non-English publications already being produced by the Fund. 


\section{Terms of Reference for Publications Policy Task Force May 18, 2001}

\section{Background}

1. The Chairman's Summing Up of the Board discussion of August 20, 2000 on the Review of the Pilot Project for Voluntary Release of Article IV Staff Reports and Other Issues in Fund Transparency (SUR/00/85, September 6, 2000), noted that "The Board asked staff to come back with proposals on the publication of documents in languages other than English in the period ahead, taking into account resource costs and modalities."

2. Attachment II ("Some Modalities for the Publication of Staff Reports and Other Selected Documents") to the Board's decision on Publication Policies (SM/00/190 Supplement 7, of January 11, 2001, page 10, section on "Website Cross-References and Languages") states that "Staff would continue to investigate options to facilitate access to documents on the Fund's website with the objective to establish systematic links between relevant documents. This would involve significant resource implications which, together with the costs of implementing the various transparency initiatives agreed, would be taken up in the context of the next budget review exercise. Options for publication of documents in languages other than English would also be considered by the Executive Board in the period ahead."

3. The Board paper on the FY 2002 Budget (EBAP/01/23, March 30, 2001) reported (in Box 4) that "During the meeting of the Committee on the Budget on March 20, 2001, a number of Executive Directors commented on the need to remain within the agreed budget framework, but also emphasized the desirability in some cases of continuing to provide editions in languages other than English. The Director of EXR mentioned some options in this area, and that a task force will be created to review the modalities for publications, including the range of language editions and web-based alternatives."

\section{Modalities}

4. Membership: Representatives of EXR (Chair), PDR, TGS, SEC, STA, and OBP, with other departments being consulted or involved as needed.

5. Report to be submitted by Director of EXR to management by early September 2001. Draft report to be prepared by Task Force for Director of EXR by late August 2001. Reported budgetary impact subject to review by OBP. Subject to management approval, findings to be reported to Board, with recommendations, prior to discussions of medium-term budget in December 2001, possibly in context of discussion of the Fund's External Communications Strategy. [The Task Force decided subsequently to defer finalizing and submitting the report until it could be considered together with the review of the Fund's External Communications Strategy].

6. Describe and review policies (including Board decisions), guidelines, and practices on (a) format (web, other electronic, hard-copy variants (from desk-top Word to "glossy"), 
combinations of these) and (b) languages of publication of (i) Board documents approved for release, and (ii) other published material, broadly defined.

7. Review of languages publication practices to include review (to be coordinated by TGS, working particularly with PDR) of different sources of translations, distinguishing translations done by TGS, those done by other Fund staff including staff in-country, those done by outside publishers under license, and others done outside the Fund (for instance, PRSPs translated by the national authorities as part of the PRSP consultation process). Clarify question of "official" vs. "unofficial" translations. To include survey of area departments/resident representatives.

8. Describe language publication policies and practices of other international organizations, including World Bank and UN.

9. Estimate resource costs of reasonable options for extending publication of (i) Board documents and (ii) other material into non-English languages, under different assumptions about format (web-only, hard-copy-only, or both). Assess the benefits of non-Englishlanguage publication - including the benefits of reaching a broader audience, increasing country ownership, and avoiding misrepresentations of the Fund's views or the authorities' commitments by the authorities or local media - relative to the resource costs and risks. The latter include the potential risks of mistranslations, misformatting, and confusion both about the release sequence for various language versions and about which version of documents is the official version, despite possible use of disclaimers. Survey area departments (including Resident Representatives) to determine their views on additional translation.

10. Assess options to establish links between country documents on the Fund's external website.

11. Formulate proposed policy_rules and/or guidelines — for format and languages of publications:

- format: web (including Resident Representatives' sections of the Fund's website)/other electronic/hard copy variants;

- non-English-languages - both in hard-copy and electronic formats. Current policy is determined partly by Board decisions (including notably on country documents) but is otherwise ad hoc. Any increase in non-English-language output would incur substantial costs to the Publications Budget, as well as to the broader Administrative Budget, including for BLS and EXR. 


\section{Executive Summary: 1994 OIA Review of Non-English Publications}

1. In response to a request by the Director of the External Relations Department, the Office of Internal Audit and Review has conducted a review of the criteria for assessing the benefits of publishing in languages other than English. The terms of reference of the study were mutually agreed upon by the two parties.

2. The request was prompted by the need to reconcile budget constraints with the ever expanding number of requests being received for publishing in languages other than English and the traditional Spanish and French. This conflict of objectives points to the need for selectivity in the decision process and, therefore, for the establishment and use of objective selection criteria.

3. In assessing the current situation, we determined (1) that there was no guiding policy and, as a result, existing non-English publications were most often the product of historical and circumstantial factors, (2) that costs are not fully reflected in the publications budget, therefore, impeding decision making, (3) that cost/benefit analyses had seldom been conducted and, when they had been, attempts at eliminating questionable language editions had met with little success, and (4) that innovative attempts had been made to try to lower costs of non-English editions. We also ascertained that, in the World Bank, the situation was somewhat similar.

4. We also examined the rationale for the selection of non-English languages. In the past, preference was given to the two predominant international languages: Spanish and French. Today, geolinguists consider that Arabic, Chinese, and Russian have also attained the status of international languages. It, therefore, seems that the decision criteria listed below should be applied consistently for non-English editions in any of these five international languages.

5. Leaving aside accommodation factors - which were beyond the scope of this review - we attempted to provide recommendations on how to formulate and assess objective criteria that could be applied to current non-English editions and to future requests. The approach we followed is that of a traditional cost/benefit analysis, whereby the costs of a nonEnglish edition have to be balanced against the perceived value of the benefits derived by publishing in non-English languages. In private business, benefits would be profit considerations and therefore easily quantifiable. In the Fund, while the profit aspect cannot be neglected (since it helps fund the rest of the publication program), there are educational and public relations values that are part of the consideration. It is therefore not possible to quantify the value, but there are objective indicators that should assist the decision makers in the value assessment.

6. From the cost standpoint, our main discovery, following data compilation, was that the costs of non-English publications are very high, and probably higher than previously anticipated. We also determined that, given the very small volume of distribution of most non-English publications, the costs per copy are also extremely high. Lastly, we noted that translation costs account for a large share of the costs. 
7. In our view, the value of non-English editions should address market and product. The size of the existing and targeted readership of the publication as well as the readership's proficiency with English are the main market factors. The contents and purpose of the publication are the main product considerations.

8. When one balances market and product characteristics against costs, choices become rational. As examples, a highly technical publication, such as a specialized economic document, with a small and specialized readership that is likely to be familiar with English, should be published only in English. On the other hand, a publication of general interest with a large and less sophisticated readership and produced at a low cost should be considered for non-English editions. Also, a few options are available for reducing costs for publications where the benefits of non-English editions are clear: greater outsourcing, requests for country contributions, establishment of co-publishing agreements, and licensing. ${ }^{47}$

${ }^{47}$ Study by Office of Internal Audit conducted in 1994 at the request of the External Relations Department. 


\section{Translation of Board Documents}

1. To gain further insight into current practices regarding translation of Board documents, the Task Force surveyed area and functional departments to determine the extent to which Board country documents are translated into, or prepared in, languages other than English for operational purposes, by whom they are translated, whether the non-English versions are published, and-if so- by whom. In addition, the Task Force analyzed all Board documents referenced in FundWise between June 1998 and June 2001 that are not in English, as well as non-English Board country documents on the Fund's external website.

\section{Survey of Practices of Area and Functional Departments}

2. A survey of functional and area departments in June-July 2001 assessed the extent to which Board country documents are translated into, or prepared in, languages other than English for operational purposes (see Table III-1). The survey identified 131 Board country documents issued between June 2000 and June 2001—out of a total of 1,182 - that exist somewhere in non-English versions. The types of document most often available in nonEnglish versions are LOIs/MEFPs/TMUs, which are prepared by, and are the property of, the respective member countries. It identified 51 LOIs/MEFPs/TMUs available in non-English versions. Some of these were negotiated by the country concerned and the Fund in parallel with the English version; others were translated from English after the fact, for distribution to officials or to the public. 
Table III-1. Board Documents in Languages Other than English

(in number of documents)

\begin{tabular}{|c|c|c|c|c|c|c|c|c|c|c|}
\hline \multirow[b]{2}{*}{ Document Type } & \multirow{2}{*}{$\begin{array}{c}\text { Official } \\
\text { Language } \\
\text { Version } \\
\text { Exists }\end{array}$} & \multicolumn{5}{|c|}{\begin{tabular}{|c} 
Official Language Version Was Translated or Prepared \\
by:
\end{tabular}} & \multicolumn{3}{|c|}{$\begin{array}{l}\text { Official Language Version Published } \\
\text { by: }\end{array}$} & \multirow[b]{2}{*}{ Not Published } \\
\hline & & \begin{tabular}{|c|} 
Language \\
Services \\
TGS \\
\end{tabular} & $\begin{array}{l}\text { Other HQ- } \\
\text { based staff }\end{array}$ & $\begin{array}{c}\text { Local } \\
\text { Fund staff }\end{array}$ & $\begin{array}{l}\text { Member } \\
\text { country }\end{array}$ & Other & IMF & $\begin{array}{l}\text { Member } \\
\text { country }\end{array}$ & $\begin{array}{l}\text { Other } \\
\text { (NGO, } \\
\text { media) }\end{array}$ & \\
\hline \multicolumn{11}{|c|}{ Area Departments } \\
\hline $\begin{array}{l}\text { Article IV Staff } \\
\text { Reports }\end{array}$ & 14 & 11 & 0 & 1 & 1 & 0 & 0 & 2 & 0 & 12 \\
\hline $\begin{array}{l}\text { UFR and Combined } \\
\text { Article IV/UFR } \\
\text { Staff Reports }\end{array}$ & 16 & 12 & 0 & 1 & 3 & 0 & 0 & 3 & 0 & 13 \\
\hline $\begin{array}{l}\text { Other Staff reports } \\
\text { (JSAs, HIPC, PPM, } \\
\text { SMP) }\end{array}$ & 5 & 3 & 0 & 1 & 0 & 1 & 0 & 0 & 0 & 5 \\
\hline $\begin{array}{l}\text { REDs, Selected } \\
\text { Issues, Statistical } \\
\text { Appendices }\end{array}$ & 11 & 7 & 0 & 1 & 3 & 0 & 0 & 0 & 0 & 11 \\
\hline $\begin{array}{l}\text { LOIs, MEFPs, } \\
\text { TMUs }\end{array}$ & 51 & 20 & 11 & 6 & 14 & 1 & 0 & 11 & 1 & 39 \\
\hline $\begin{array}{l}\text { PRSPs, I-PRSPs, } \\
\text { Progress Reports, } \\
\text { PFPs }\end{array}$ & 25 & 6 & 1 & 0 & 18 & 0 & 0 & 7 & 1 & 17 \\
\hline \multicolumn{11}{|c|}{ Functional Departments } \\
\hline ROSCs & 7 & 6 & 0 & 0 & 1 & 0 & 3 & 1 & 0 & 3 \\
\hline FSSAs & 0 & 0 & 0 & 0 & 0 & 0 & 0 & 0 & 0 & 0 \\
\hline Other (indicate) & 2 & 1 & 0 & 1 & 0 & 0 & 0 & 0 & 0 & 2 \\
\hline Total & 131 & 66 & 12 & 11 & 40 & 2 & 3 & 24 & 2 & 102 \\
\hline
\end{tabular}

Notes: For each country, respondents were asked to indicate in how many cases a version exists in a country's primary official language (if other than English) and if that version was published (on a website or in hard copy) after June 1, 2000. Estimates were acceptable. Survey was carried out in June and July 2001. 
3. The type of document second-most often available in a non-English version is PRSPs/I-PRSPs/Progress Reports on PRSPs, which, again, are documents prepared by, and the property of, the respective countries concerned. The survey identified 25 available in nonEnglish versions. Smaller numbers of REDs (11), Article IV Staff Reports (14), UFR and Combined UFR/Article IV Staff Reports (16), and other Staff Reports (5) - all documents originating in, and belonging to, the Fund—are available in non-English versions.

4. The survey found that in some cases functional departments have prepared nonEnglish versions of documents for the authorities in member countries whose officials are not fluent in English. Thus the survey identified 7 ROSC modules available in non-English languages (which may be an underestimate). In addition, although the survey showed that no FSSAs have been translated, FSAP missions have in some cases translated the detailed FSAP Report that serves as the basis for the FSSA submitted to the Board. For example, the FSAP Reports for Cameroon and Senegal were prepared in French (this information is not shown in Table III-1).

5. Of the 131 documents that the survey showed to be available in languages other than English, Language Services translated 66 (50 percent), and country authorities prepared 41 (31 percent). The latter group includes 18 PRSPs/I-PRSPs/Progress Reports, which in at least some cases were prepared in a local language as part of the consultation process and later translated into English for submission to the Board. Eleven LOIs/MEFPs/TMUs were translated by non-Language Services, headquarters-based Fund staff. In some cases these were prepared by bilingual mission chiefs who negotiated in a non-English language. Local Fund staff translated another 6 of these documents.

6. The documents identified by the survey were for 58 countries in 18 languages. Major languages account for most documents: French (55), Russian (26), Spanish (18), and Portuguese (15). Other languages included Albanian (2), Arabic (1), Armenian (4), Azeri (1), Bulgarian (2), Chinese (3), Croatian (2), Estonian (2), German (1), Latvian (2), Macedonian (1), Romanian (7), Ukrainian (1), and Vietnamese (4). For eight member countries, translations were available in Russian, although Russian is not the official language of those members; for example, Armenia's LOI/MEFP is prepared and negotiated in Russian, while the official language of Armenia is Armenian. Some documents were translated into more than one language.

7. Of the 131 non-English versions, 29 (23 percent) were published-24 of these by the member country, 3 by the Fund, and 2 by others. This indicates that a number of non-English versions of documents belonging to country authorities have not been published by them. In particular, only 8 of 25 PRSPs/I-PRSPs/Progress Reports available in non-English versions appear to have been published. The three cases in which the Fund published a country Board document in a language other than English - in each case only on its website - are the ROSCs for Argentina, Cameroon, and Tunisia. The 24 cases in which the authorities published a non-English version consist of 11 LOIs/MEFPs, 7 PRSPs/I-PRSPs, 1ROSC, and 5 staff reports. While the survey identified only two cases where other parties (NGOs, the media) published translations, anecdotal evidence from several former Resident Representatives suggests that this is an underestimate, as newspapers have in a number of cases published LOIs/MEFPs/ATMUs in languages other than English. 
8. Seventeen websites of Resident Representative and overseas Fund offices have been identified. Reflecting current Fund practice, none had Board country documents available in languages other than English. But all had hyperlinks to English versions on www.imf.org (see Appendix Table III-2 ). A number of Resident Representatives have, at various times, expressed interest in having non-English versions of Board documents posted on their websites, but they have been advised to await the outcome of this study and the Board's decision on the resource issues and modalities involved in such an undertaking.

9. The results of the survey show that versions of LOIs/MEFPs, PRSPs and I-PRSPs, and ROSC modules are available in non-English languages in many cases where the authorities request the publication of a non-English version. However, two caveats apply:

(a) Non-English versions produced on missions for operational purposesLOIs/MEFPs and ROSCs - are not necessarily updated to incorporate changes to the English version between the conclusion of the mission and the submission to the Board, or to incorporate corrections and deletions after submission to the Board and before publication by the Fund. Significant work and resources would be required to establish and ensure consistency between the English version to be released and other language versions.

(b) In at least eight countries, the operational language version of documents is in a language (Russian) other than the primary official language of the country. The selection of language in these cases reflects operational needs (availability of technical vocabulary in the language, and of translators capable of technical translations) rather than the need for transparency in the countries concerned (the language spoken most widely or used by most newspapers).

\section{Data from FundWise on Document Translation}

10. The Task Force also analyzed Board documents in FundWise in languages other than English between June 1998 and June 2001. During this period, the Board issued 3,666 documents-EBSs (1,565), SMs $(1,607)$, and SURs (494) —in English; and of the total, 194 (5.3 percent) are available in a language other than English. Of these 194 documents, 139 are country documents - EBSs (51), SMs (50), and SURs (38) - and none of these appear to have been published. The EBS and SM documents are mostly staff reports, with a few REDs included. In most cases, the Fund translated these as a courtesy to the authorities or Executive Directors. In several cases, corrections, when they existed in English, were not available in translation in FundWise, although the main document had been translated. Very few translations of LOIs and PRSPs are in FundWise, even in cases where Language Services translated them for missions. In addition, the seven non-English ROSC modules identified in the survey are not in FundWise (including three that are posted on www.imf.org).

11. It is interesting that there is little overlap between the LOIs/MEFPs/TMUs, PRSPs/IPRSPs/Progress Reports, and ROSC modules prepared in non-English languages for operational reasons, which were covered in the survey of departments, and the translations found in FundWise. The only exceptions may be a few cases in which translations of 
LOIs/MEFPs that Language Services prepared during negotiations were updated to match the Board versions in English of these documents. There is no evidence, based on FundWise data, of an increase in the number of country Board documents translated into non-English languages between June 1998 and June 2001. 
Table III-2. Web Pages of Resident Representatives and Overseas Offices

\begin{tabular}{|c|c|c|}
\hline Office & Hosted at www.imf.org & Hosted Locally \\
\hline Moldova & & www.imf.md \\
\hline Romania & & Www.fmi.ro \\
\hline Uzbekistan & & Www.imf.uz \\
\hline Angola & www.imf.org/external/country/AGO/rr/index.htm & \\
\hline Bulgaria & www.imf.org/external/country/BGR/rr/rrindex.htm & \\
\hline Cambodia & www.imf.org/external/country/KHM/rr/index.htm & \\
\hline China & www.imf.org/external/country/CHN/rr/index.htm & \\
\hline Estonia & www.imf.org/external/country/EST/rr/index.htm & \\
\hline Georgia & www.imf.org/external/country/geo/rr/index.htm & \\
\hline India & www.imf.org/external/country/ind/index.htm & \\
\hline Latvia & www.imf.org/external/country/LVA/rr/index.htm & \\
\hline Pakistan & www.imf.org/external/country/PAK/rr/index.htm & \\
\hline Russia & www.imf.org/external/country/RUS/rr/index.htm & \\
\hline Sri Lanka & www.imf.org/external/country/LKA/rr/index.htm & \\
\hline Ukraine & www.imf.org/external/country/UKR/rr/index.htm & \\
\hline Vietnam & www.imf.org/external/country/VNM/rr/index.htm & \\
\hline $\begin{array}{l}\text { Office of } \\
\text { Asia and } \\
\text { the Pacific }\end{array}$ & www.imf.org/external/oap/index.htm & \\
\hline
\end{tabular}




\section{Languages and Formats of Publications: Practices of Other International Organizations}

1. The following synopsis is based on a draft report by the United Nations Joint Inspection Unit (JIU) "Implementation of Multilingualism in the United Nations Systems" of November 2002 and responses to a Task Force survey ${ }^{48}$ by the BIS, FAO, OECD, UN, World Bank, and WTO regarding their language publication policies and practices.

\section{A. Language terminology used within the United Nations System:}

2. Within the United Nations System, the terminology used to define languages and the practice with respect for especially designated languages varies from one organization to another as well as between separate bodies of the same organization.

\section{“Official" and "working” languages}

3. Referring to the attempt to distinguish between official and working languages within the UN System, the JIU report states that: "The situation depicted [...] demonstrates amply that the delineation between official and working languages is blurred if not confusing."

4. For example, the World Health Organization (WHO) defines "official" languages as those languages for which interpretation of speeches is provided. "Working" languages are defined as those languages for which translation services are provided.

5. But according to the JIU report, in the UN the distinction between official and working languages is not necessarily based on whether those languages are used for interpretation or translation. According to the current rules of procedure of the United Nations General Assembly and the Security Council, there is no difference in status between official and working languages in terms of interpretation and translation. Arabic, Chinese, English, French, Russian, and Spanish are both the official and working languages of the Assembly and the Security Council.

6. The rules of procedure in all regional commissions of the UN refer only to working languages and do not mention official languages. ${ }^{49}$ In principle, speeches made in one of the working languages are interpreted in the other working languages; and all resolutions,

\footnotetext{
48 The survey was originally conducted in June 2001. In August 2002, e-mails containing draft summaries of their respective responses were sent to those institutions that responded to the initial survey. The updates/suggested changes of those institutions responding to the August 2002 e-mails were incorporated.

${ }^{49}$ Except for the Economic Commission for Latin America and the Carribean (ECLAC), which defines English, French, Portuguese, and Spanish as its official languages, and English, French, and Spanish as its working languages.
} 
recommendations, and other formal decisions as well as annual reports, are translated into all working languages.

7. The Executive Board of the United Nations Development Program/United Nations Population Fund (UNDP/UNFPA), while distinguishing between official and working languages, also translates all official board documents into the six official languages, except country programs and conference room papers, which are translated into its working languages (English, French, and Spanish) only.

8. The United Nations Educational, Scientific, and Cultural Organization (UNESCO) prescribes Arabic, Chinese, English, French, Hindi, Italian, Portuguese, Russian, and Spanish as its official languages and Arabic, Chinese, English, French, Russian, and Spanish as the working languages of the General Conference and the Executive Board. Requests for translation and interpretation in and from the official languages into Italian, Hindi, and Portuguese have to be paid for by the concerned delegations. ${ }^{50}$ That said, in UNESCO any language can be recognized as an official conference language at the request of a member state/member states. Important documents may be translated into any other official language provided the concerned delegation bears the costs.

9. The Universal Postal Union (UPU) provides for French as its only official language and English and French as the working languages of its International Bureau. Interpretation services are provided in English, French, Russian, and Spanish; and related costs are paid for by users according to their UPU budget share. Translation of documents into nonofficial languages are borne by the regular budget and/or member states according to a defined costsharing formula.

10. Rather than distinguishing between official and working languages, the International Civil Aviation Organization (ICAO) acknowledges "languages of deliberations" and "languages of documentation," and the United Nations Industrial Development Organization (UNIDO) recognizes "languages of the General Conference" and "languages of the Board."

11. The FAO acknowledged that their previously used terms "official languages," "working languages," and "working languages for limited purposes" did not have a defined meaning and that the distinctions made "were both unnecessary and confusing." It adopted Arabic, Chinese, English, French, and Spanish as the "languages of the organization."

\section{Languages of "authentic texts" and "official texts"}

12. Languages of authentic texts are defined as the language or languages in which "the texts of the Constitutive Acts of treaty-based organizations or the texts of treaties administered by them" are signed. Languages of authentic texts are not necessarily the same as official languages. For example, the languages of the authentic texts of the United Nations

\footnotetext{
${ }^{50}$ Similar to the ECLAC practice according to which translation and interpretation services in the official language Portuguese are borne by the requesting member state or states.
} 
Charter and its initial five "official languages" are Chinese, English, French, Russian, and Spanish. Arabic was added later as an official language of the UN. The same is true for UNESCO, which has only English and French as languages of authentic texts, but has six official languages for its Executive Board and nine official languages for its Conference.

13. The World Intellectual Property Organization (WIPO) further distinguishes between authentic texts and official texts of conventions or treaties. Depending on the convention/treaty concerned — and after consultation with the interested government WIPO's Director General can establish official texts in Arabic, English, German, Italian, Japanese, Portuguese, Russian, Spanish, or in "other languages as may be designated by the governing body of each Convention or Treaty." According to WIPO, "authentic texts" are more authoritative than official texts in strict legal terms, but in practice there seems to be no distinction between the two.

\section{B. Languages used for communication and dissemination of information}

\section{Languages of websites:}

14. Of the 42 websites of the United Nations and its affiliated bodies, Specialized Agencies, and the IAEA, BIS, EBRD, EU, OECD, and the WTO that were surveyed, 33 organizations made three or fewer language sections available via their homepages (see tables below). The JIU report observes that the availability of resources seems to determine the availability of languages on UN organizations' websites. The UN noted that non-Englishlanguage material is posted on the UN's websites when the translations become available. The UN's French website is a mirror of its English site, whereas the Spanish and Russian sites were developed with only the information materials available in those languages. (No information on the UN's Arabic and Chinese sites was obtained.) 
Table IV-1. Languages on Homepages of 42 Websites

(United Nations and its Affiliated Bodies, Specialized Agencies, and the IAEA, BIS, EBRD, EU, OECD, and WTO)

\begin{tabular}{|l|l|l|l|l|l|l|l|l|l|l|l|}
\hline & \multicolumn{8}{|c|}{ Number of languages on homepage } \\
\cline { 2 - 11 } & one & two & three & four & five & six & seven & eight & nine & ten & eleven \\
\hline $\begin{array}{l}\text { Number of } \\
\text { websites }\end{array}$ & 18 & 6 & 9 & 2 & 2 & 3 & & & & & $\begin{array}{l}2 \text { (EU, } \\
\text { UNHCR) }\end{array}$ \\
\hline
\end{tabular}

Sources: IMF staff and "Implementation of Multilingualism in the United Nations System," Geneva 2002, prepared by the United Nations Joint Inspection Unit (JIU/REP/2002/11) 
Table IV-2. Languages on the Main Websites of the United Nations and Its Affiliated Bodies

\begin{tabular}{|c|c|}
\hline Organization / Unit & $\begin{array}{c}\text { Languages on Home Page } \\
\text { (Planned improvements / Observations) }\end{array}$ \\
\hline \multicolumn{2}{|l|}{$\begin{array}{l}\text { United Nations (Headquarters and main OAHQ }{ }^{1} \text { headed by an } \\
\text { official accountable to the Secretary- General) }\end{array}$} \\
\hline UN main website (http://www.un.org) & $\begin{array}{l}\text { A C E F R S } \\
\text { ( } 21 \text { other languages on local websites of UN } \\
\text { Information Centers and Services) }\end{array}$ \\
\hline UNCTAD (http://www.unctad.org) & E F S \\
\hline UNEP (http://www.unep.org) & $\mathrm{E}$ \\
\hline UN-Habitat (http://www.unhabitat.org ) & $\mathrm{E}$ \\
\hline Office on Drugs and Crime (http://www.odccp.org) & $\mathrm{E}$ \\
\hline ECA (http://www.uneca.org) & E F (Arabic planned) \\
\hline ECE (http://www.unece.org) & $\mathrm{E}$ \\
\hline ECLAC (http://www.eclac.cl & E S \\
\hline ESCAP (http://www.unescap.org) & $\mathrm{E}$ \\
\hline ESCWA (http://www.escwa.org.lb) & $\mathrm{A} E$ \\
\hline UNHCHR (http://www.unhchr.ch) & E F S \\
\hline UNHCR (http://www.unhcr.ch & $\begin{array}{l}\text { Main homepage in E C F S and } 7 \text { other languages } \\
\text { but not Arabic and Russian }\end{array}$ \\
\hline UNRWA (http://www.un.org/unrwa) & A E \\
\hline OCHA (http://www.reliefweb.int/ocha ol/) & $\mathrm{E}$ \\
\hline UNOG (http://www.unog.ch) & E F \\
\hline UNON (http://www.unon.org) & $\mathrm{E}$ \\
\hline UNOV (http://www.unov.org) & $\mathrm{E}$ \\
\hline UNDP (http://www.undp.org) & E F S \\
\hline UNICEF (http://www.unicef.org) & $\begin{array}{l}\text { E F S (some } 40 \text { UNICEF country offices websites } \\
\text { developed partially in local languages) }\end{array}$ \\
\hline UNFPA (http://www.unfpa.org) & $\mathrm{E}$ \\
\hline WFP (http://www.wfp.org) & $\mathrm{E}$ \\
\hline
\end{tabular}

1/ OAHQ : Offices away from headquarters

Source: "Implementation of Multilingualism in the United Nations System," Geneva 2002, prepared by the United Nations Joint Inspection Unit (JIU/REP/2002/11). 
Table IV-3. Languages on Websites of the Specialized Agencies, and the IAEA, EU, and OECD

\begin{tabular}{|c|c|}
\hline Organization & $\begin{array}{l}\text { Languages on Home Page } \\
\text { (Planned improvements / Observations) }\end{array}$ \\
\hline ILO (http://www.ilo.org) & $\begin{array}{l}\text { E F S (access to local websites in A, G, I, JP, P R and TK but } \\
\text { no C yet). All documents of Governing Body and Conference } \\
\text { in the } 7 \text { official languages. }\end{array}$ \\
\hline FAO (http://www.fao.org) & $\begin{array}{l}\text { A C E F S (major efforts will be pursued to improve language } \\
\text { coverage deeper into the site, in particular for A and C) }\end{array}$ \\
\hline UNESCO (http://www.unesco.org) & A C E F R S \\
\hline ICAO (http://www.icao.int) & E (except press releases) \\
\hline WHO (http://www.who.int) & E F S \\
\hline UPU (http://www.upu.int) & E F (also A P S for documents) \\
\hline ITU (http://www.itu.int) & E F S \\
\hline WMO (http://www.wmo.ch) & $\begin{array}{l}\text { E F S at level } 1 \text { (Core pages in E F S at level } 2 \text { if funds available; } \\
\text { long-term goal of all core pages in six languages at levels } 1,2 \\
\& 3 \text { ) }\end{array}$ \\
\hline IMO (http://www.imo.org) & E \\
\hline WIPO (http://www.wipo.int & A E C F R S \\
\hline UNIDO (http://www.unido.org) & $\mathrm{E}$ \\
\hline IAEA (http://www.iaea.int) & E \\
\hline World Bank (http://www.worldbank.org/ & E F P R S \\
\hline IMF (http://www.imf.org & E F G S \\
\hline IFAD (http://www.ifad.org) & E (Most official material in the four official languages) \\
\hline EU (http://europe.eu.int) & 11 languages (DK, DT, E, FN, F, G, GR, I, P, S, SW) \\
\hline OECD (http://www.oecd.org) & E F \\
\hline
\end{tabular}

Source: "Implementation of Multilingualism in the United Nations System," Geneva 2002, prepared by the United Nations Joint Inspection Unit (JIU/REP/2002/11). 


\section{Languages of hard copy or electronic publications:}

15. The languages used for publications in hard copy or in electronic format are in general the same as the official or working languages of a UN organization. But the JIU stated that "some publications are in one language only (usually English) while others are in two or three languages." Also, "depending on funding sources and co-publishing arrangements some sales publications may not be available in a particular official or working language" although published in other languages.

16. The publication policy and practice with regard to UN publications differs from that for UN documents. The UN Assembly decided in 1981 (Resolution 36/117 B) that parliamentary documents (official documents submitted to any of the principal organs) "shall be given effective simultaneous distribution in the official and working languages" (Arabic, Chinese, English, French, Russian, and Spanish). UN publications are not considered official documents, and the United Nations does not produce its publications in all six languages. Press releases, for example, are produced only in English and French. The United Nations Department of Public Information (DPI) stated in a press release on May 3, 2001 (PI/1342) that: "It would cost some \$6 million per year in additional staffing costs alone to produce [press releases] in all six official languages."

17. The JIU report stresses that the demand for language and related services surpasses supply by far: all UN Secretariats surveyed identified current workloads and the inadequacy of resources as the main constraints with regard to the provision of "full multilingual services," and the Advisory Committee for Administrative and Budgetary Questions noted in the first report on the "proposed programme budget for the biennium 2002-2003" that the "demand for a variety of services is in excess of present capacity and available resources."

18. The FAO should, in principle, release all of its publications in its five languages (except for those intended for specific regions or groups of countries "with limited language requirements"), but FAO staff report that the organization tries to take into account the "real need or demand" for titles in each language.

19. The BIS publishes (in hard copies and on the web) its Annual Report, Quarterly Review, some Committee Papers, the BIS Profile, and the BIS Statutes in its four official languages (English, French, German, and Italian). Its Annual Report and BIS Profile are also published in Spanish.

20. The OECD listed Reports, Surveys, Proceedings, Working Papers, Outlooks, etc. as the documents it regularly publishes in its two official languages (English and French) on the web and in print. Depending on the "interest of the publication for specific countries/constituencies," the OECD decides on requests for publication in nonofficial languages. The OECD also publishes irregularly in German, Japanese, and Spanish.

21. The World Bank publishes many hard-copy documents and publications in Arabic, Chinese, French, English, German (publications only), Portuguese, Russian, and Spanish, and posts many documents and publications in Chinese, English, Russian, Portuguese, and 
Spanish on its website. Like the Fund, the World Bank does not have an official language, and English is the Bank's working language.

\section{Sequential or simultaneous translation and publication}

22. Even though the UN General Assembly has requested that the text of all new public documents be made available on the UN website daily in all six official languages, staff tries to "achieve a balance between the need for multilingual access to UN Internet services and the reality of budgetary constraints."

23. The FAO states that it normally releases its flagship publications and official documentation related to meetings and conferences simultaneously in all five official languages. Language versions of its other publications are published depending on the perceived market for each title, and language versions of its technical publications are released within two years after the publication of the original (English) version.

24. The OECD and the World Bank usually publish English documents/publications first and translations later. The BIS also releases translations later, with the exception of its Annual Report. BIS press releases - if released in languages other than English — are released simultaneously. The WTO says that it translates all documents and publications in its three official languages and aims to release documents/publications in its three official languages simultaneously; if this is not feasible, it releases them in the "original language" first.

\section{Responsibility for translations and copyright}

25. The UN ensures quality control of outside translations through spot checks made by revisers in the internal translation services and periodic audits of the work done for it by individual contractors. No disclaimer is used for translations made for the UN by outside contractors. Generally, the UN seeks copyright protection for all recurrent publications, studies, or reports issued under the authorization of the Publications Board. Some categories of materials (Official Records, UN documents, public information materials) and their translations by governmental institutions or member states are in the public domain.

26. The BIS, FAO, and the WTO review outsourced translations in house and do not add a disclaimer. The World Bank checks the quality of outsourced translations, typesetting, and printing using industry guidelines that they have adapted to their needs and requirements and adds a disclaimer for licensed publications. (It owns the copyright for licensed translations.) When the OECD licenses translations to another institution or publishing house, it attaches a note to those documents/publications specifying who bears responsibility for the translation. Translations of OECD publications/documents are published under OECD copyright as coeditions (joint copyright) or under the copyright of the publisher to whom the translation rights were granted.

27. The BIS, FAO, and WTO do not make their translated documents/publications available on websites other than their own. (The FAO, however, is reviewing its policy.) 
Some of the OECD's translated documents/publications are made available on government sites and linked to the OECD, but the OECD generally retains the copyright.

\section{E. Increasing demand for language publications}

28. The JIU points to several requests by member states with regard to the "unequal treatment" of their respective languages with regard to English, but an analysis of a report of the Secretary-General (Programme performance of the United Nations for the biennium 2000-2001) did not "seem to reflect the expressed dissatisfaction." With regard to external demand for more non-English-language, material the report indicates that reliable surveys are not available and, therefore, that "user satisfaction at the level of civil society is not always easy to access." The FAO reported that requests from publishers in developing countries for authorization to translate and publish FAO documents is very high. The OECD has experienced an increased demand from its member countries for the publication of documents in languages other than its official languages (English and French). Increased sales and readership of OECD publications in such countries as Germany and Japan demonstrated "additional market demand" for language versions of its publications. The BIS observed an increase in demand in connection with the opening of BIS offices for Asia and the Americas. The WTO has seen no internal or external increase in demand for language versions of its publications. 
Table IV-4. Official and Working Languages of the United Nations and Affiliated Bodies (Governing Bodies of Main Organs, Regional Commissions, and Affiliated Bodies)

\begin{tabular}{|c|c|c|c|c|}
\hline \multicolumn{2}{|l|}{ Organ } & $\begin{array}{c}\text { Official } \\
\text { Languages }\end{array}$ & $\begin{array}{l}\text { Working } \\
\text { Languages }\end{array}$ & $\begin{array}{l}\text { Data source / observations } \\
\text { (R.P.: Rules of Procedure) }\end{array}$ \\
\hline \multicolumn{2}{|c|}{$\begin{array}{l}\text { General Assembly (and Main } \\
\text { Committees) }\end{array}$} & A C E F R S & A C E F R S & R.P, Rule 51(A/520/Rev.15) \\
\hline \multicolumn{2}{|l|}{ Security Council } & A C E F R S & A C E F R S & R.P., Rule 41(S/96/Rev.7) \\
\hline \multicolumn{2}{|c|}{$\begin{array}{l}\text { ECOSOC } \\
\text { (and Functional Commissions) }\end{array}$} & A C E F R S & E F S & $\begin{array}{l}\text { R.P., Rule } 32 \text { (E/5715/Rev.2). } \\
\text { (E/5975/Rev.1 for Functional } \\
\text { Commissions). }\end{array}$ \\
\hline \multicolumn{2}{|l|}{ Trusteeship Council } & C E F R S & E F & R.P., Rule 26 (T/1/Rev.) \\
\hline \multicolumn{2}{|c|}{ International Court of Justice } & E F & E F & ICJ Statute 1945 (Art. 39.1) \\
\hline \multirow{5}{*}{ Regional Commissions } & ECA & & A E F & R.P., Art.31 (E/CN.14/111/Rev.8/Corr.2) \\
\hline & $\mathrm{ECE}$ & & E F R & $\begin{array}{l}\text { R.P., Rule } 40 \\
\text { (See www.unece.org/oes/00uneceterms) }\end{array}$ \\
\hline & ECLAC & E F S P & E F S & R.P., Art.42 (LC/G.1403/Rev.3) \\
\hline & ESCAP & & C E F R & $\begin{array}{l}\text { R.P., Rule } 44 \\
(\text { E/2001/39-E/ESCAP/1231) }\end{array}$ \\
\hline & ESCWA & & A E F & R.P., Rule 25 \\
\hline \multicolumn{2}{|l|}{ UNDP / UNFPA } & A C E F R S & E F S & R.P., Rule 4 (DP /1997/32) \\
\hline \multicolumn{2}{|l|}{ UNICEF } & C E F S R & E F S & R.P., Art.26 (E/ICEF/177/ Rev. 4) \\
\hline \multicolumn{2}{|l|}{ UNHCR } & A C E F R S & E F & R.P., Rule 28 (A/AC.96/187/Rev.5) \\
\hline \multicolumn{2}{|l|}{ UNEP } & A C E F S R & A C E F S R & R.P., Art.63 (UNEP/GC/3/Rev.3 \\
\hline \multicolumn{2}{|l|}{$\begin{array}{l}\text { UNCTAD } \\
\text { (TDB \& Main Committees) }\end{array}$} & A C E F S R & A E F S & $\begin{array}{l}\text { R.P., Rules } 69 \text { (TD/63/Rev.2) } \\
\text { and } 64(\mathrm{TD} / \mathrm{B} / 740)\end{array}$ \\
\hline \multicolumn{2}{|l|}{ UNRWA } & & A E F & \\
\hline \multicolumn{2}{|l|}{ WFP } & A E F S & E F S & $\begin{array}{l}\text { R.P. of the Executive Board (Rule XIV) } \\
\text { (special arrangements for Chinese) }\end{array}$ \\
\hline
\end{tabular}

Source: "Implementation of Multilingualism in the United Nations System," Geneva 2002, prepared by the United Nations Joint Inspection Unit (JIU/REP/2002/11).

\begin{tabular}{|c|l|}
\hline \multicolumn{2}{|c|}{ Languages Key } \\
\hline A & Arabic \\
\hline C & Chinese \\
\hline DK & Danish \\
\hline D & Dutch \\
\hline E & English \\
\hline F & French \\
\hline FN & Finnish \\
\hline G & German \\
\hline GR & Greek \\
\hline H & Hindi \\
\hline I & Italian \\
\hline J & Japanese \\
\hline K & Korean \\
\hline P & Portuguese \\
\hline PO & Polish \\
\hline R & Russian \\
\hline S & Spanish \\
\hline TK & Turkish \\
\hline SW & Swedish \\
\hline
\end{tabular}


Table IV-5. Official and Working Languages of the Governing Bodies of the Specialized Agencies, and the IAEA, BIS, EU, OECD, and WTO

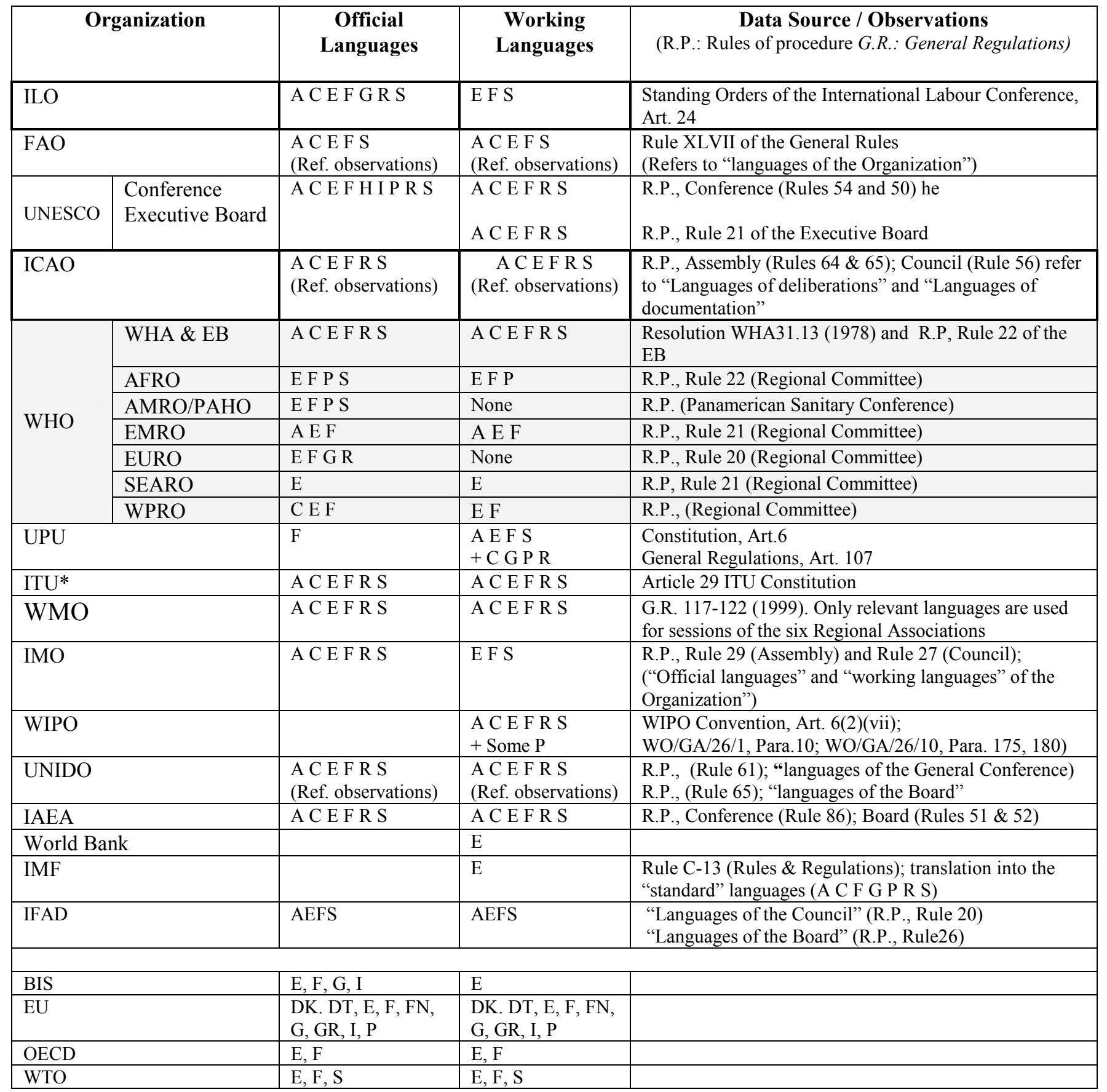

Note: See Table IV-4 for key of abbreviations used for languages.

Sources: "Implementation of Multilingualism in the United Nations System," Geneva 2002, prepared by the United Nations Joint Inspection Unit (JIU/REP/2002/11) and IMF staff. 


\section{Annex II. Survey of Country Outreach by Area Departments Survey design and administration}

In December 2002 EXR undertook a survey of outreach activities in member countries. A questionnaire was sent separately to resident representatives and to the heads of area departments for transmission to headquarters-based country teams. Some 34 resident representatives (40 percent of the total) and 99 country teams (well over half) submitted responses, reporting on 121 member countries.

The responses are indicative of the activity underway in the field. While it is possible - even likely - that respondents are those who have been more active in pursuing contacts with outside groups, evidence from the survey responses points to various factors that would tend to offset this bias: outreach on visits by front office staff are not always counted; desk economists responding to the survey may inadvertently omit some outreach activities by the mission chief; and respondents in their post less than a year are likely to have undercounted outreach by their predecessors (the survey results indicate that outreach is systematically underreported to colleagues).

The survey focused exclusively on country-level outreach to civil society, media, and parliaments by area departments. The extensive outreach by Management, regional offices, functional departments, and EXR are excluded. Into this category falls much of the discussion between Fund staff and civil society in industrial countries, which (apart from the extensive contacts with outside economists) is largely focused on policy issues rather than country matters. Regional efforts such as - to take but two examples - PRSP regional fora and Financial Sector Assessment Paper (FSAP) outreach missions also fall outside the scope of the survey.

This focus will imply that, in many member countries (notably surveillance cases where there is no resident representative), opportunities for outreach will be provided only by Article IV consultation missions, which sometimes find themselves short-staffed. In these cases, and elsewhere where such circumstances as the security situation restrict staff mobility, outreach will be markedly lower than in program countries with frequent missions and a resident representative.

\section{Findings}

In general, the Fund's dialogue with civil society, parliaments, and the media appears well-established in Africa and in the transition countries of Asia and Europe. Many resident representatives (especially in Asia), and even some country teams, reported dozens of contacts with media and civil society. In other areas, however, the picture is quite different. Most Middle Eastern Department (MED) teams reported either no contacts with civil society or else only an annual contact with a Chamber of Commerce or labor union. Contacts in industrial countries were largely limited to research institutions and an annual meeting with a chamber of commerce and/or labor union. Few meetings with NGOs or faith- 
based organization were reported in Latin America, though other kinds of contacts do occur regularly. ${ }^{51}$

The presence of a resident representative is, as might be expected, a major factor in the level of outreach. Responding mission teams reported an average of $71 / 2$ outreach events over the year, as against more than 30 for resident representatives (See Annex Table 1). Curiously, PRSP country teams engaged in $1 / 3$ more outreach than country teams for other developing countries, while PRSP country resident representatives engaged in $1 / 3$ less outreach. (It may be that, in some small, low-income countries, active resident representatives are constrained in their outreach by the number of relevant and interested organizations.)

Still, the survey results show that country teams have been engaging in dialogue with a wide range of civil society groups. On average across the respondents (both mission teams and resident representatives) country staff met about equally with (1) labor unions, NGOs, and faith-based organizations; (2) scholars and research organizations; and (3) business and trade associations. For each of these three sets of organizations, survey respondents reported an average of three meetings a year. Meetings with parliamentarians were somewhat less frequent, averaging slightly more than one a year. (Media contacts, while numerous, are not comparable with other groups because of the clustering of contact in press conferences).

These averages, however, conceal as much as they convey, as variation across countries was extensive. One reason was simply that the Fund's presence varies sharply across countries. Yet there is only a low correlation between the Fund mission team's presence incountry (as measured by the number of staff nights) and the number of contacts with nongovernmental bodies. More important appear to be regional determinants, as teams from some departments are more active than others, no doubt reflecting area departments' understanding of the views of country authorities on such outreach. Anecdotal evidence suggests as well that, at least for media contacts, past experience of departmental management with the media plays an important role as well. And it is likely that the amount of outreach rises as individual staff members gain experience in meeting with nongovernmental groups.

Much of the country outreach takes place without detailed reference to headquarters. Of those engaging in outreach activities, 40 percent of the resident representatives and more than half of the country teams did so without contacting EXR for support, and only 20 percent of resident representatives and about half of the country teams regularly reported to EXR on the activities they had undertaken. Some 20 percent of resident representatives, and roughly one-third of country teams, did not routinely report on their outreach even to their area departments.

\footnotetext{
${ }^{51}$ A low response rate (under 20 percent) for the Asia/Pacific region does not allow any conclusions about the work of mission teams in the region.
} 


\section{Media}

Staff are being extensively quoted in the media. About three-fifths of the survey respondents (a large majority of resident representatives and about half of mission teams) said that they had met with journalists. The vast majority of those who met with the media (90 percent, or over half of the survey respondents) were subsequently quoted in articles or broadcasts. Of those who were quoted, almost all (over 90 percent) were quoted by name at some point during the year, though a majority of those identified by name were also quoted indirectly (e.g., as "an IMF source") on other occasions.

When staff did not meet the press, the most common reason cited-especially in the case of industrial countries--was the preference of country authorities. In the words of one mission chief, "It is up to the authorities to decide if there will be press contacts (in the context of the Article IV mission), and they have indicated no desire." In developing countries, some missions delegated media contacts to the resident representative, while in some cases chiefs newly assigned to a country at the time of the Article IV mission elected not to meet with press. Also, some countries on 24-month consultation cycles had no Fund mission during 2002. Only three respondents cited lack of media training as a primary reason for not meeting the press.

Where staff do engage with the press, however, it is common to be quoted repeatedly. Of those reporting that they were quoted indirectly, half said they were quoted indirectly four or more times. And - perhaps reflecting the importance of press conferences-one-third of those reporting direct quotation were quoted directly eight or more times, with another third reporting direct quotation four to seven times. Some three-fourths of those active with the media reported that they had met with radio or television journalists, which may be another reflection of the press conference format. About 30 percent of the contacts were with foreign media, a share which varied only slightly by type of media outlet.

Staff remain essentially reactive in their relations with the media. While the nature of press reporting is such that a large share of media contacts will be initiated by reporters, only about 10 percent of respondents, almost entirely mission chiefs, said that they generally initiated contacts with the media. More telling - and more important for Fund communications - rarely do respondents place material directly in the press. Only a third of resident representatives, and a very small number of mission teams, placed an article or wrote a letter to the press on their country. ${ }^{52}$

Among mission teams, there was a marked difference in media contacts of all types between countries that make use of Fund resources and those that do not. A majority of mission teams in PRGF countries and in countries with active programs drawing on the General Resources Account (GRA) report media outreach. In contrast, only about a third of mission teams in industrial and in other non-program countries report such contacts. This disparity grows, of course, when the more intensive media contacts by resident

\footnotetext{
${ }^{52}$ As discussed in the body of the paper, however, articles (mainly authored by senior staff on policy issues) are routinely placed in papers around the globe by EXR.
} 
representatives, who tend to be situated in program countries, is combined with that of the mission team.

Most staff in contact with the press have undertaken EXR's media training program. Over the past few years, EXR has worked to provide staff who can expect to come into contact with the press with training on how to express themselves in ways that will be effective in the media context. Among survey respondents, some 80 percent of both resident representatives and mission chiefs reported having completed the training, and some 20 percent of desk economists.

\section{Parliaments}

Respondents reported few requests for meetings from parliamentarians, and staffinitiated meetings occurred most often in the transition countries of Asia and Europe. Just two thirds of resident representatives and less than half of mission teams reported meeting with legislators in 2002. However, over 90 percent of respondents for the transition countries of Europe and Asia report meeting legislators. The rate was about 50 percent for non-transition PRSP countries, with only a quarter of other respondents reporting meetings with legislators. Moreover, 19 of 25 reporting countries where staff met legislators at least three times during the year were transition countries; all but one of the others were in Africa. This geographic concentration may reflect a capacity-building element of the meetings proposed by staff, particularly as the transition countries are either recently independent or have undergone a major transformation in the role of parliament. In about 20 percent of the country cases, an explicit purpose of the meeting was to discuss legislative approval of staffsupported policy measures. The concentration of users of Fund resources in Africa and the transition countries may also explain part of the geographic concentration of meetings.

\section{Staff have generally met with legislators in small groups, encounters with the full} parliament occurring only on rare occasion. The reported meetings have been fairly evenly divided among meetings with parliamentary committees, individuals (often the chairpersons of finance or budget committees), and small groups of legislators with a common interest. Respondents considered that the legislators they encountered were somewhat- to wellinformed about the Fund's policy advice, though there were a number of low-income countries in which staff found legislators less knowledgeable about the role of the Fund. On the other side, instances in which parliamentary interlocutors were perceived not to have been satisfied with the outcome of meetings with staff were also entirely among low-income countries.

\section{Civil society representatives}

Staff met more consistently with business and trade associations than with any other type of group surveyed, with over 80 percent of respondents (including almost all resident representatives) reporting meetings. Country teams met with business and trade associations an average of twice per year, while resident representatives, on average, met with such groups bimonthly. As might be expected, there is a great deal of variation across the membership: some resident representatives speak to such groups almost weekly, while some have little or no such contact. A handful of MED and African Department (AFR) mission teams were almost the only respondents not to meet with at least one such group. These meetings were 
usually initiated by staff, most often to discuss country developments. Perhaps reflecting the largely information-seeking nature of these meetings on the part of staff, quite a number of respondents report that the associations' expectations for the meeting were not always met.

About 60 percent of respondents reported contacts with research institutes ("think tanks") or individual scholars. As with most forms of outreach, a handful of resident representatives have met frequently with researchers, averaging upwards of twice per month in a few cases. Almost all industrial country mission teams have met with researchers, as have most teams in European II Department (EU2), and Western Hemisphere Department (WHD) contacts with researchers are exceeded only by business and trade associations among groups covered by the survey. Despite the extensive network of resident representatives, PRSP countries, particularly in Africa, are underrepresented, possibly reflecting relative lack of research work in poor countries. Most of the meetings were initiated by staff, most often to discuss country economic issues. According to respondents, staff met researchers' expectations for the meeting on almost every occasion.

Generally initiated by staff to discuss issues related to Fund policy advice, meetings between staff and labor unions appear to be common, but not frequent. Some 60 percent of respondents report having held such meetings, with staff meeting with unions in virtually all European industrial countries. Elsewhere, unions appear to have been met by over half of respondents across country groupings. Even the difference between resident representatives and mission teams is substantially less than for other types of civil society interaction. What is striking, however, is that only 20 percent of respondents met more than once with a labor union, and only one mission team held more than two such meetings. Moreover, respondents report that unions were not fully satisfied with their meetings with staff more frequently than other groups.

Meetings between respondents and faith-based organizations were infrequent, with onethird of resident representatives and a small handful of mission teams reporting such contacts, and just one resident representative reporting that such meetings took place frequently. Half of the respondents meeting with faith-based organizations were from AFR, but this still constitutes only a small share of AFR respondents. Such meetings were generally initiated by the staff, and discussions most often centered around the Fund and its role rather than specific country issues.

About half of responding staff had met with other non-governmental organizations (NGOs), but the average conceals widely varying practices across regions. Meetings with NGOs took place in a large majority of the cases in Africa, low-income countries in Asia (where some resident representatives have been especially active with NGOs), and the transition economies. Very few NGO meetings were reported in Latin America or the Middle East, and only one meeting was reported in an industrial country. ${ }^{53}$ Meetings were fairly

${ }^{53}$ As discussed in the main text, the Fund maintains an intensive dialogue with NGOs from industrial countries. This dialogue tends to be focused on policy issues, especially those related to developing countries, rather than on specific home-country issues that would be handled by the area department. 
evenly split between those mainly focused on country issues and those mainly related to the role of the Fund.

Table 1. Average Number of Outreach Events, 2002

\begin{tabular}{llll}
\hline & All & Non-Press & Civil Society \\
Respondent group & Outreach & Outreach & Outreach
\end{tabular}

Resident Representatives (34) PRSP Countries (17) Other (17)

31.0

24.9

37.2

7.8

6.1

7.6

9.4

7.0

7.8
Industrial Countries (15)

Other Countries (84)

PRSP Countries (29)

Non-PRSP Countries (55)

1

6

4

Memo items: Transition economies (33)

Resident Representatives (14)

HQ Country Teams (19)
38.4

12.4
22.7

18.2

27.4

5.8

4.9

6.0

7.2

5.4

27.2

7.5
20.2

16.6

24.0

4.9

4.6

5.0

5.9

4.5

Note: Numbers in parentheses are numbers of relevant survey respondents. "Non-press" includes parliamentarians and civil society groups. "Transition countries" includes responses from staff in EU2 and parts of the European I Department and Asia Pacific Department.

Source: Survey questionnaire and staff estimates. 


\section{Annex III. The Fund and Civil Society Organizations (CSOs)}

\section{Why Engage with CSOs?}

The emphasis in the Fund's outreach to civil society is increasingly shifting from headquarters-based engagement with CSOs on global issues, to country-based interaction on national policy questions. This annex raises some of the issues that IMF staff-and indeed management and Executive Directors - confront in deciding on the appropriate approach to outreach in specific situations.

The IMF's engagement with CSOs recognizes that: ${ }^{54}$

- CSOs are opinion formers and need the best information possible;

- many CSOs have considerable public respect;

- CSOs reflect opinions held by important sectors of society;

- some CSOs bring to the table expertise and experience relevant for understanding economic issues and policies in Fund member countries;

- the Fund can therefore benefit from listening to and take account of CSO views in formulating policies;

- consultation can increase national ownership of Fund-supported policies;

- national participatory processes can be promoted - especially important for the PRSP; and

- consultation with CSOs may supplement governments' dialogue with their own societies.

Two recent developments within the IMF have placed a greater premium on interaction with CSOs at the country level: (1) the PRSP participatory process; and (2) the increased emphasis on national ownership of policies emerging from the conditionality review. Most Fund staff now appreciate that communication with CSOs is not a task just for management or a handful of EXR staff, although both have a leading or specialized role to play in certain aspects of CSO outreach, just as they do with media outreach. The Fund's professional staff should expect to be involved routinely: area department staff in country and regional outreach, and functional department staff in policy-related dialogue.

\footnotetext{
${ }^{54}$ The Fund's outreach to civil society can be seen as a complement to its formal accountability, as an integral part of building credibility and ownership of its own policies and the national policies it supports, and also as a source of information about various aspects of the socio-economic situation in member countries as well as about alternative views and analysis. The Fund is accountable to its member countries, represented in the Board of Governors and the Executive Board but, just as representative governments interact with their own CSOs, the Fund can supplement its formal processes of accountability through engagement with organizations that reflect the views of a variety of people.
} 


\section{Which CSOs?}

How should the Fund decide which organizations to focus attention upon, given the vast array and diversity of CSOs? CSOs serve a wide variety of functions in society: representation (labor unions, nongovernmental organization (NGOs) federations and networks, faith-based organizations); technical expertise; (professional groups, think tanks, and some NGOs; advocacy (labor unions, human rights groups, and most NGOs); capacity building (foundations, NGO support organizations); service delivery (e.g., credit and mutual aid societies); and social functions (e.g., cultural associations). ${ }^{55}$ Some CSOs are tiny and focused on very specific issues. Others - international NGOs in particular - are large multinational organizations with thousands of staff and budgets of $\$ 100$ million or more. Viewpoints are diverse as well - the staff and membership of a single NGO may hold a multiplicity of views. Northern CSOs (based in industrial countries) are more visible than Southern CSOs (based in developing countries) because of their more sophisticated public relations operations, more prominent fund-raising efforts, and sometimes their advocacy of global policy issues. ${ }^{56}$ In contrast, the majority of Southern CSOs concentrate upon the delivery of services or representation of specific societal interests rather than advocacy. Both Northern and Southern CSOs are active in developing countries: (1) international CSOs, typically Northern NGOs or faith-based organizations (FBOs), often have operational programs in developing countries, often in collaboration with international institutions; and (2) national CSOs - domestically based and organized - usually have more limited financial and human resources than international CSOs do, and vary greatly in objectives, operations, and standing from one country to another.

Among the starting points for Fund staff in deciding with which CSOs to engage in support of their operational work are: (1) the relevance of the purposes and activities of the CSO to the work of the Fund (international CSOs command more media attention but national CSOs may have greater legitimacy and relevance for policyrelated outreach, especially in the context of the PRSP process); (2) whether the organization has a declared interest in Fund-related issues; and (3) the CSO's approach to dialogue (at a minimum, whether the organization rejects the use of violence).

${ }^{55}$ This list is based upon a classification used by the World Bank in "Consultations with Civil Society: A Sourcebook."

http://wbln0018.worldbank.org/Networks/ESSD/icdb.nsf/D4856F112E805DF4852566C9007 C27A6/542F52FA26886B8285256AFE0075960D/\$FILE/ConsultationsSourcebook.pdf

${ }^{56}$ Much of the Fund's outreach to CSOs focuses on developing countries - either countrylevel dialogue on national policy issues or global level dialogue on issues that primarily concern developing countries - but the Fund also should interact with CSOs in the industrial countries on global issues, such as trade liberalization, as well as discussing the national economy and the Fund's policy advice (surveillance). 


\section{How to Engage with CSOs?}

Successful engagement with CSOs rests on clearly defined objectives and a good understanding of the expectations and motivations of the interlocutors. In recent years, the Fund's dialogue with CSOs has gradually improved but there remains some dissatisfaction on both sides, possibly even a degree of mutual mistrust. To stereotype the impressions: some CSOs may tend to think that the Fund preaches, does not listen, does not integrate CSO input from the dialogue into its policy-making, and does not see the dialogue as part of greater accountability; some Fund staff may perceive CSOs as generally being interested mainly in pushing their own agenda, often-imprecisely defined, and believe that CSOs often lack broad support, legitimacy, and accountability. Both the Fund and CSOs will need to work deliberately and diligently to establish greater mutual trust.

Fund staff interact with CSOs: (1) at Fund headquarters on global policy issues or country issues; (2) in the context of Article IV consultation missions-staff discussions with labor organizations, for example; (3) in the context of program design and negotiations, including in the context of the PRSP/PRGF; and (4) in more routine discussions, such as those that might be undertaken by resident representatives or country missions. Some specific suggestions for Fund staff (especially country missions and resident representatives) for building trust and establishing a basis for effective interaction with CSOs might include:

- Invite the CSO to set the terms of engagement jointly (designing the agenda, etc.), as this promotes ownership;

- Avoid unrealistic expectations on either side; recognize that each side may have very different perspectives, approaches, even if the objectives sound very similar;

- Establish clearly what interests are (and are not) represented by the groups taking part in the interaction;

- Prepare the ground well: provide documents in advance where they are available, invite CSOs to submit questions;

- Make clear to the CSOs what information is already available, e.g., on the Fund's external website, so that they can prepare;

- Ask for information from the CSO requesting the meeting about its activities in general or concerns in the area of focus for the meeting;

- Hold periodic briefings for groups, e.g., NGOs, press, labor, and business associations, so that they can see and hear transparently what everyone else is being told;

- Consider inviting a representative of the host authorities to attend briefings

- Do not overstate the outcome of meetings: a meeting with a CSO does not necessarily entitle Fund staff to say that civil society was consulted.

- Consider whether it would be useful to piggyback on meetings convened by the World Bank and other international agencies, rather than organizing separate meetings.

- For societies where there are many CSOs, consider what is the most efficient way of interacting - e.g. are there umbrella organizations that group CSOs with similar interests? Is it effective to hold large conference-style consultations? 
Many of the practices are being applied in the already extensive country-level outreach by Fund staff as reflected in the survey reported in Annex II. However, practices clearly differ considerably across countries, area departments, and policy settings. EXR, in collaboration with other departments, will survey existing practices, and seek to identify a set of groundrules and accepted practices to form the basis for operational guidelines for interaction between Fund staff and CSOs. 
Civic and community relations activities are important in the Fund's external communications and contribute modestly but directly to the Fund's goal of helping people improve their lives.

The IMF Civic and Community Relations office was created in 1999 to formally support existing grassroots initiatives of staff who donate their time and money to help others. The office, staffed by one fulltime officer, coordinates the Fund's efforts to be a good neighbor and responsible civic entity by leveraging and integrating three components: (1) the IMF Civic Program for charitable giving, (2) the employee volunteer group INVOLVE, and (3) Community Relations for local outreach and partnering.

1. The IMF Civic Program provides grants and surplus property to organizations worldwide that help the neediest emerge permanently from urgent social problems. It also matches donations to the Annual Giving Campaign and to staff-initiated humanitarian appeals. Its budget (US\$664,950 in FY03) is for humanitarian purposes only and is separate from member financing. The 12-member Civic Program Advisory Committee (CPAC) to Fund management represents staff, spouse/partners, retirees, and INVOLVE volunteers. Request guidelines and names of recipient organizations are posted at www.imf.org.

2. INVOLVE (International Volunteer Venture) is the main volunteerism outlet. Employees, retirees, families and friends join in 33 regularly scheduled projects a year, such as parties for needy children, food for the homeless, rebuilding homes, and mentoring children. Volunteers have received awards recognizing their work with Calvary Women's Shelter, Stevens Elementary School and other partners.

3. Community Relations focuses on integrating the Fund into our host community by partnering with peer organizations and matching local needs with our ability to help. Headquarters facilities are provided for meetings and fundraisers of community groups. Staff participate in public campaigns such as "Race for the Cure" and "Help the Homeless."

Examples of integrated activities. Staff on mission to Moldova purchased medicine for several orphanages, which now also receive Civic Program grants. Staff initiated relief appeals for victims of famine in Ethiopia, floods in Vietnam, the earthquake in the Congo, and other humanitarian emergencies, raising $\$ 285,000$ since FY00, including the Civic Program's 50\% matching donation. The Fund has supported a local after-school educational program, "The Fishing School," for seven years with $\$ 171,000$, computers, and volunteers to upgrade and paint the school buildings. Volunteers continue to mentor the children and offer a one-week summer camp at the Bretton Woods Recreation Center. When U.S. President George W. Bush visited the school, press reported that its founder emphasized how critical Fund help was in the program's early stages.

A January 2002 audit by a consultant found that the Fund's civic, volunteer, and community programs have a history of success. Programs will benefit, however, if outcomes are better tied to the Fund's external relations strategy and overall organizational strategies, and if they receive strong endorsement and involvement at all levels within the institution. Societal and community issues have a direct relationship to Fund work and future success, therefore the Fund's social vision should be integrated with its organizational vision. 


\section{Annex V. IMF Center}

The IMF Center's core mission is to educate and reach out to the public locally and internationally by developing exhibits, programs, events and educational products that directly, and indirectly, educate and inform the public about the work of the Fund.

The IMF Center opened in late 2000 to provide a venue for the public to visit the IMF and to learn more about the institution and its role in the global economy. The Center hosts permanent and special exhibits, welcomes groups visiting Washington, and develops educational materials. The Center also houses a bookstore, theatre, and IMF web access for visitors, and is staffed by one full time Officer and an Assistant, who welcome about 14,000 visitors per year to the Center. The Center reaches out to the international community primarily though its page on the Fund's external website, www.imf.org/center.

\section{Outreach}

Visiting Groups - The IMF Center hosts visiting groups (approximately 250 in 2002) who are briefed by Fund staff. Visitors are from member governments, the private sector, parliaments, think tanks, universities/schools (38 different universities in 2002) and the general public. The Center actively seeks new contacts and has recently briefed groups such as the U.S. Congressional Black Caucus, the Washington Tour Guild Association, and the International Hotel Association.

Special Exhibits and Events - The IMF Center initiates and develops new exhibits for the Center's temporary exhibit galleries. The exhibits directly or indirectly reflect and support some aspect of IMF work such as the recent Artistry of African Currency, E-Commerce, and World Religions, Global Ethic, Universal Peace exhibits. It also arranges for special events such as the Peace Pole, presented by the Goi Peace Foundation and awarded to the IMF for its leadership and achievements for the promotion of international monetary cooperation and the fostering of economic growth, thus contributing to a culture of peace around the world.

Permanent Exhibits - The Center has a number of permanent exhibits on view which help explain the work of the IMF or cover other related themes: Money Matters: The Importance of Global Cooperation; Ancient Coins of the Silk Route Empires; Ancient Coins of the Mediterranean Realm; and Medieval Coins of Rival Worlds.

\section{Educational Publications}

Educational materials, such as interactive modules and lesson plans, are published on the web at www.imf.org/center for high school and middle school students. The high school curriculum is based on the Center's Money Matters: The Importance of Global Cooperation exhibit and promotes student understanding of globalization, international cooperation and the work of the IMF. The curriculum is guided by national standards for social studies teachers published by the National Council for the Social Studies (NCSS) and the Center for Civic Education. The Center is currently working on a book for high school students, the IMF's first major attempt to explain its work to this age group. The Center is also developing IMF participation in a new publication, "Washington: an Illustrated History," also to be released in 2003. 
External Relations Department

Authorized Staffing and Outturns, FY 1993 - FY 2003

(in staff years)

\begin{tabular}{cccccc}
\multicolumn{2}{c}{ Regular Staff } & & \multicolumn{3}{c}{ Other Staffing Resources 1/ } \\
\cline { 5 - 6 } Budget & Outturn & Budget & Outturn & contractuals \\
contrich
\end{tabular}

FY 1993

62.0

58.9

62.0

54.6

6.9

10.8

7.1

14.6

8.4

12.2

12.0

7.5

11.4

8.5

10.6

12.7

10.0

13.9

15.4

10.1

1.0

$\mathrm{n} / \mathrm{a}$

$n / a$

$n / a$

$n / a$

6.5

7.5

65.0

61.0

11.0

6.4

FY 2000

89.5

$69.92 /$

1.0

8.1

FY 2002 2/

89.0

$76.42 /$

1.0

8.6

9.3

90.0

$\mathrm{n} / \mathrm{a}$

4.0

$n / a$

1/ Other staffing resources include overtime, temporary agency help, maternity and sick leave replacement, etc.

2/ For FY 2001 includes contractual positions converted to regular staff under the Categories of Employment (CoE) policy. FY 2001-FY 2002 outturns exclude CoE staff before their conversion to regular staff. 